UCRL-53582

Distribution Category UC-11

UCRL --53582

DE85 008698

\title{
Natural Phenomena Hazards Modeling Project: Seismic Hazard Models for Department of Energy Sites
}

\author{
D. W. Coats \\ R. C. Murray \\ Manuscript date: November 1984
}

\author{
DISCLAIMER
}

This report was prepared as an account of work sponsored by an agency of the United States Government. Neither the United States Government nor any agency thereof, nor any of their employees, makes any warranty, express or implied, or assumes any legal liability or responsibility for the accuracy, completeness, or usefulness of any information, apparatus, product, or process disclosed, or represents that its use would not infringe privately owned rights. Reference herein to any specific commercial product, process, or service by trade name, trademark, manufacturer, or otherwise does not necessarily constitute or imply its endorsement, recommendation, or favoring by the United States Government or any agency thereof. The views and opinions of authors expressed herein do not necessarily state or reflect those of the United States Government or any agency thereof.

\section{LAWRENCE LIVERMORE NATIONAL LABORATORY University of California - Livermore, California - 94550}





\section{DISCLAIMER}

Portions of this document may be illegible in electronic image products. Images are produced from the best available original document. 
PREFACE

The Lawrence Livermore National Laboratory (LLNL) under contract to the Office of Nuclear Safety (ONS), Assistant Secretary for Policy, Safety, and Environment, US Department of Energy (DOE), is developing uniform design criteria for critical facilities at DOE sites throughout the United States. The criteria in question relate to a structure's ability to withstand earthquakes and strong winds from both tornadoes and other storms.

Work began on the project in September 1975, when representatives of LLNL's Structural Mechanics Group met with James Hill of DOE's Division of Operational and Environmental Safety to discuss the project's goals. In other meetings in late 1975 and early 1976, it was decided that a three-phase approach to the project was best. The first phase, completed in 1ate 1978, involved information gathering. Sites were selected, their critical facilities were identified, and information about the facilities was gathered and summarized (Coats and Murray, 1978).

In the second phase, experts in seismic and wind hazards were asked to develop hazard models for each site. TERA Corporation, Berkeley, California, was selected to develop the seismic hazard models. McDonald, Mehta, and Minor, Consulting Engineers, Lubbock, Texas, and T. T. Fujita of the University of Chicago were both contracted to independently develop hazard models for tornadoes and high winds. Once all the hazard models are developed, LLNL will support ONS in developing uniform hazard criteria for the DOE to use in evaluating the existing design criteria at the various sites and upgrading or modifying critical facilities.

The purpose of this report is to present the final seismic hazard models, and recommended response spectra for design and analysis, and the methodology used to develop them. The final hazard models presented in this report are based on the site-specific studies produced by TERA Corporation, as part of the Natural Phenomena Hazards Study. Final seismic hazard reports have been published separately by TERA and were distributed to DOE Headquarters and DOE Field offices for review and comment. The final wind/tornado hazard models were published by LLNL in UCRL 53526 (Coats, 1984).

$$
\text { -iii- IV }
$$



CONTENTS

Preface...............................................iii

Abstract $\ldots \ldots \ldots \ldots \ldots \ldots \ldots \ldots \ldots \ldots \ldots \ldots \ldots \ldots \ldots \ldots \ldots \ldots \ldots \ldots \ldots \ldots \ldots$

Acknowledgments.........................................

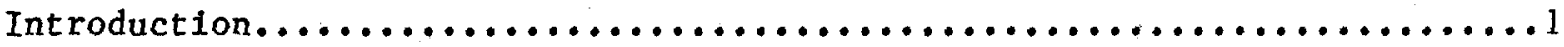

Seismic Hazard Analysis Methodology ...........................

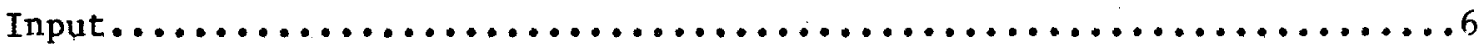

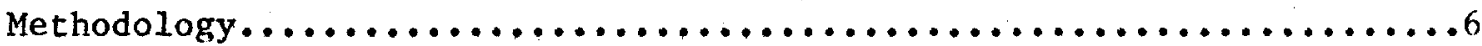

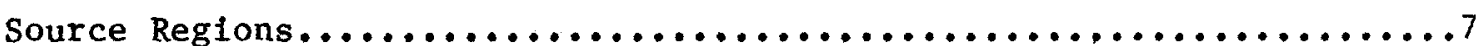

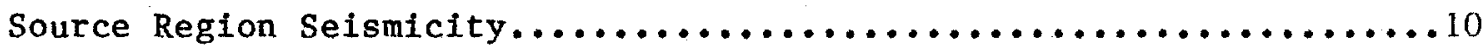

Magnitude and Intensity Relationship.......................

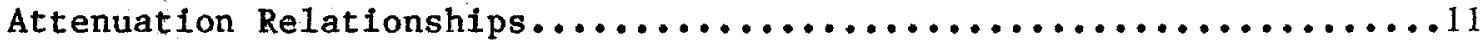

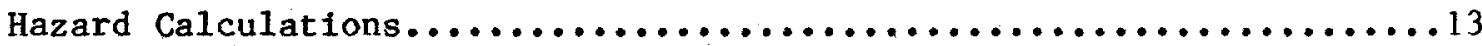

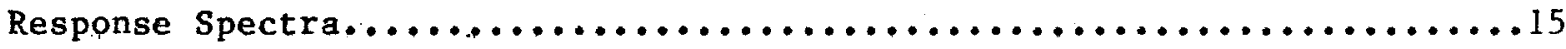

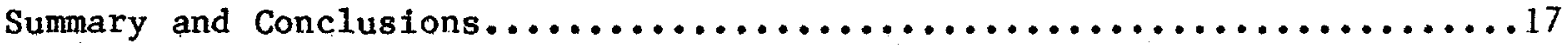

References.............................................19

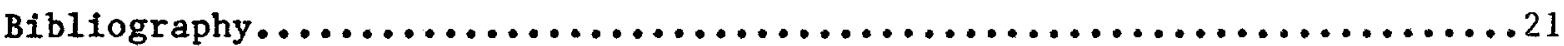

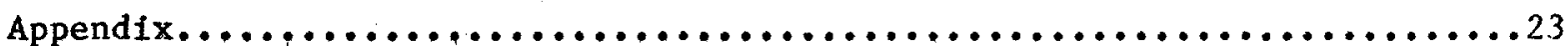

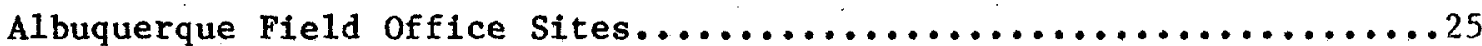

Chicago Field office sites..............................43

Idaho Field office site............................... 53

Oak Ridge Field office Sites........................... 57

Nevada Field office site.............................67

Richland Field office site.............................

San Francisco Field office Sites........................

Savannah River Field office............................... 
Lawrence Livermore National Laboratory (LLNL) has developed seismic and wind hazard models for the Office of Nuclear Safety (ONS), Department of Energy (DOE). The work is part of a three-phase effort aimed at establishing uniform building design criteria for seismic and wind hazards at DOE sites throughout the United States. In Phase 1, LLNL gathered information on the sites and their critical facilities, including nuclear reactors, fue1reprocessing plants, high-level waste storage and treatment facilities, and special nuclear material facilities. In Phase 2, development of seismic and wind hazard models, was initiated. These hazard models express the annual probability that the site will experience an earthquake or wind speed greater than some specified magnitude. This report summarizes the final seismic hazard models and response spectra recommended for each site and the methodology used to develop these models. Wind/tornado hazard models have been published separately by LLNL in UCRL 53526 (Coats, 1984).

In the final phase, it is anticipated that the DOE will use the hazard models to establish uniform criteria for the design and evaluation of critical facilities. 

The authors would like to thank James R. Hill (DOE), the technical monitor for the office of Nuclear Safety for his support and assistance. The support and assistance of the Office of Nuclear Safety, Assistant Secretary for Policy, Safety, and Environment, US Department of Energy, is also gratefully acknowledged. Special thanks go to Mr. Lawrence H. Wight, Vice President, TERA.Corporation, and to Dr. Christian P. Mortgat, Project Manager, TERA Corporation, for their valued technical contributions throughout the course of this project. The seismic hazard studies performed by TERA Corporation, provided the material for this summary report (see Bibliography). Finally, thanks go to members of the DOE community, and DOE contractors for their critical reviews of TERA's work. Thanks also go to Carol Meier (LLNL) for typing the original manuscript and for publications support. 
INTRODUCTION

The Lawrence Livermore National Laboratory (LLNL) has been providing technical assistance to the Department of Energy's Office of Nuclear Safety (ONS), Assistant Secretary for Policy, Safety, and Environment to develop seismic, extreme wind and tornado hazard curves for Department of Energy (DOE) sites throughout the country. (See Table 1 for a list of sites included in this study and Fig. 1 for their geographic distribution.) Experts in seismic and wind hazards were asked to develop the hazard models for each site. TERA Corporation, Berkeley, California, was selected to develop the seismic hazard models. McDonald, Mehta, and Minor, Consulting Engineers, Lubbock, Texas, and T. T. Fujita of the University of Chicago were contracted to independently develop hazard models for tornadoes and high winds. These consultants were selected based upon their nationally recognized expertise and their previous experience in hazard model development.

The hazard models produced have received widespread distribution for review and comment. This distribution included: DOE Field offices; DOE site contractors; DOE headquarters; National Oceanic and Atmospheric Administration (NOAA); the Nuclear Regulatory Commission (NRC); and the United States Geologica1 Survey (USGS).

After review comments were evaluated and acted upon, final hazard model reports were issued. TERA Corporation has issued their final seismic hazard model reports in the form of individual binders for each DOE Field office. These binders contain the final seismic hazard models developed, as well as a brief description of the methodology used to develop the hazard curves.

The draft wind/tornado hazard models produced by McDonald and Fujita were updated to reflect review comments and reissued. A summary of the final wind/tornado hazard models and the methodology used in their development has been published by LLNL in UCRL 53526 (Coats, 1984).

The purpose of this report is to consolidate all of the seismic hazard models and response spectra developed for the sites listed in Table 1 . A brief description of the seismic hazard analysis methodology is also included.

Earthquakes present a unique challenge in the design and evaluation of

$$
-1-
$$


structures. Most people in the US view earthquakes as being a threat only in the western United States, although the historical record would contradict this view, for damaging earthquakes have been widely distributed across the US. In 1811-12 a series of earthquakes in New Madrid, Missouri, was felt from New York to Florida, and was the largest series of earthquakes in recorded US history. If seismic design requixements were based upon historical data alone, then design requirements for the Mid-West and the East would be as severe as those for the West. However, in addition to the maximum earthquake size possible, the frequency of seismic events is also an important consideration in establishing seismic design requirements.

The hazard curves contained in this report characterize the earthquake hazard at a given DOE site by a frequency plot which gives the return period or annual probability of exceedance of different peak ground accelerations of the site. These curves have been derived from a combination of recorded earthquake data, estimated earthquake magnitudes of known events for which recorded data is not available, review of local geological investigations, and use of expert judgment from seismologists and geologists familiar with the region in question. A more detailed description of this procedure is contained in the next section. 
TABLE 1. Project sites, with DOE field offices.

DOE field office Sites

Albuquerque, NM

Bendix Plant

Los Alamos National Scientific Laboratory

Mound Laboratory

Pantex Plant

Rocky Flats Plant

Sandia National Laboratories, Albuquerque

Sandia National Laboratories, Livermore, CA

Pinellas Plant, Florida

Chicago, IL

Argonne National Laboratory--East

Argonne National Laboratory--West

Brookhaven National Laboratory

Princeton Plasma Physics Laboratory

Idaho

Idaho National Engineering Laboratory

Oak Ridge, TN

Feed Materials Production Center

Dak Ridge National Laboratory, $\mathrm{X}-10, \mathrm{~K}-25$, and $\mathrm{Y}-12$

Paducah Gaseous Diffusion Plant

Portsmouth Gaseous Diffusion Plant

Nevada

Nevada Test Site

Richland, WA

Hanford Project Site

San Francisco, CA

Lawrence Berkeley Laboratory

Lawrence Livermore Naticnal Laboratory

Lawrence Livermore National Laboratory, Site 300

Energy Technology and Engineering Center

Stanford Linear Accelerator Center

Savannah, GA

Savannah River Plant 


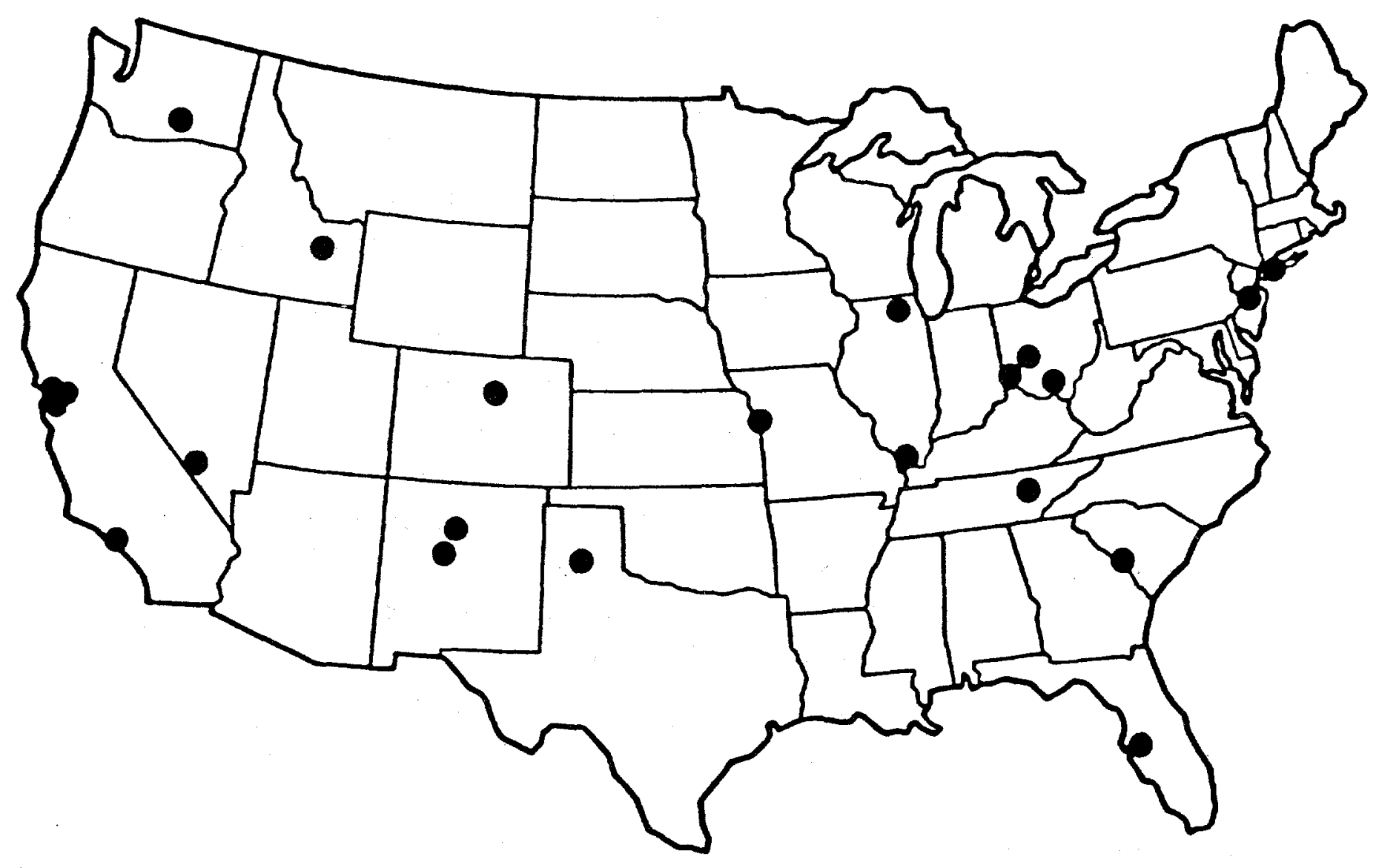

Figure 1. DOE sites for seismic hazard analysis. 
There are two distinctly different approaches to seismic hazard characterization--deterministic and probabilistic. In the deterministic approach, the analyst:

- Estimates that an earthquake of a given magnitude or intensity can occur at a certain location.

- Attenuates the ground motion from the earthquake source to the site.

- Determines the effects of the earthquake at the site. With this approach, it is difficult to define the margin of safety in the resulting design parameters. As a result, the analyst generally uses upperbound estimates of ground motion, which are typically overly conservative.

In a probabilistic approach, on the other hand, the analyst quantifies the uncertainty in the number, size, and location of possible earthquakes and can thus present a trade-off between more cost1y designs or retrofits and the economic or social impact of a failure.

Although the probabilistic approach requires significantly more effort than does the deterministic approach, TERA used it to develop seismic hazard characterizations that would make it possible to:

- Quantify the hazard in terms of Peak Ground Acceleration (PGA) return period, which is defined as the inverse of the annual probability of exceedance of a specific PGA.

- Rigorously incorporate the complete historical seismic record.

- Incorporate the judgment and experience of seismic experts.

- Account for incomplete knowledge about the locations of faults.

- Assess the hazard at the site in terms of spectral acceleration.

In fact, the method is particularly appropriate for eastern facilities where the seismicity is diffuse and cannot be correlated with surface faulting, as it can be in the western United States. The locations of the Safe Shutdown Earthquakes (the maximum credible earthquake at a given site) in the eastern United States are particularly uncertain, and the probabilistic approach can quantify these uncertainties. Its major weakness is the lack of plentiful statistical data from which to characterize the various input parameters in probabilistic terms. Nevertheless, the credibility of the probabilistic 
approach has been established through detailed technical review of its application to several important projects and areas. Applications include assessments of the seismic risk in Boston (Corne11, 1975), the San Francisco Bay Area (Vagliente, 1973), the Puget Sound Area (Stepp, 1974), the country of Nicaragua (Shah, et al., 1975), the continental United States (Algermissen and Perkins, 1976), the country of Costa Rica (Mortgat, et a1., 1977) and the Nuclear Regulatory funded Seismic Evaluation of Commercial Plutonium Fabrication Plants (Bernreuter, et a1., 1979), the Systematic Evaluation Program (SEP) (Bernreuter, 1981), and the Seismic Safety Margins Research Program (Bohn, et al., 1983). Results of these studies have been applied to, among other areas:

- Development of long-range earthquake engineering research goals.

- Planning decisions for urban development.

- Environmental hazards associated with the milling of uranium.

- Design considerations for radioactive waste repositories.

- Licensing decisions for plutonium fabrication facilities and commercial nuclear reactors.

This diversity of application demonstrates the inherent flexibility of the probabilistic approach.

INPUT

TERA used the probabilistic approach to characterize the seismic hazard for each site in this study. The input to a probabilistic hazard assessment comprises specification of local seismic sources, earthquake frequency relations and attenuation functions. Because hazard assessment calculations are very sensitive to the particular composition of the input, experts in local and regional seismology were consulted during the preparation of input for each facility.

METHODOLOGY STEPS

The product of a probabilistic approach is a measure of the seismic 
hazard expressed in terms of return period, or reciprocal annual probability. The methodology used to determine seismic hazard at a site is usually divided into the following steps:

- Specify the geometry of local seismic regions. Based on the geology. and historic seismicity of the region, sources are identified as line sources (faults) $r$ area sources (Fig. 2a). The largest magnitude earthquake associated with each source is established.

- Describe past seismicity in terms of earthquake occurrence. The recurrence of earthquakes of various magnitudes is based primarily on historical seismicity. A straight line or a set of straight lines is fitted onto the data, using regression analysis to develop these relationships (Fig. $2 \mathrm{~b}$ ).

- Develop an earthquake recurrence model. The model assumes that the earthquake occurrence follows a Poisson distribution in time. This is a standard assumption.

- Derive or select a transfer function (attenuation relationship) to mathematically carry information from the epicenter to the site in terms of structurally relevant parameters (Fig. 2c). Most attenuation relationships are empirically derived, at times modified by theory, and express PGA as a function of earthquake magnitude and distances from the epicenter. Different attenuation relationships are used in the western and eastern United States because their ground motion characteristics vary significant1y.

- Combine the potential activity of all sources for all earthquake magnitudes to determine the probability that a certain acceleration will not be exceeded within a given time period (Fig. 2d). This completes the seismic hazard model.

\section{SOURCE REGIONS}

A basic assumption in any seismic hazard analysis is that seismic source zones can be defined within which the future seismicity is homogeneous and stationary.

The seismic zone about each site can significantly influence the site 
hazard; therefore, particular care was taken in the zone definitions for this project. The zones prepared by Algermissen and Perkins were a starting point in the definition of source regions. Their zones were generally considered inadequate for the site-specific results sought by the program because their objective was regional seismic hazard assessment. TERA critically examined the Algermissen and Perkins zones from the perspective of their seismic data base, as well as from various geologic, geophysical, and tectonic data. In the eastern and central United States, TERA relied heavily on the results of the Systematic Evaluation Program (SEP). As part of this project a panel of 10 seismologists was formed to provide expert opinion related to the seismic zonation, earthquake occurrence, upper magnitude cutoff and ground motion in the eastern and central United States (TERA, 1980). The zones were modified as needed to capture the site-specific assessment required.

Where the hazard at a site was sensitive to the zonation, sensitivity studies were performed on that parameter. 


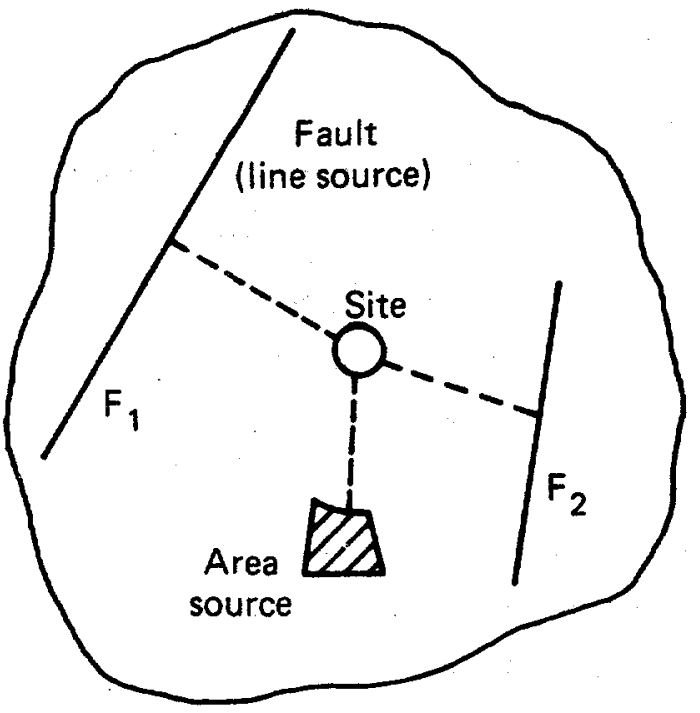

(a)

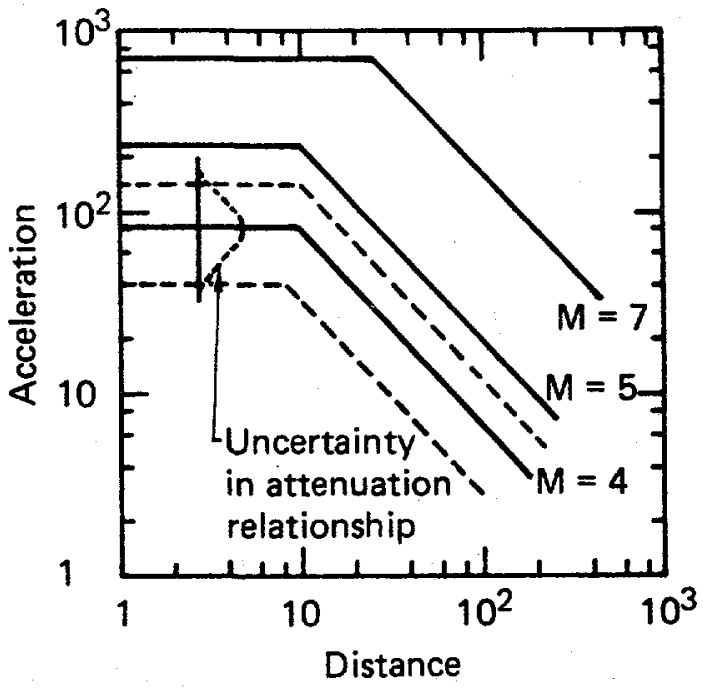

(c)

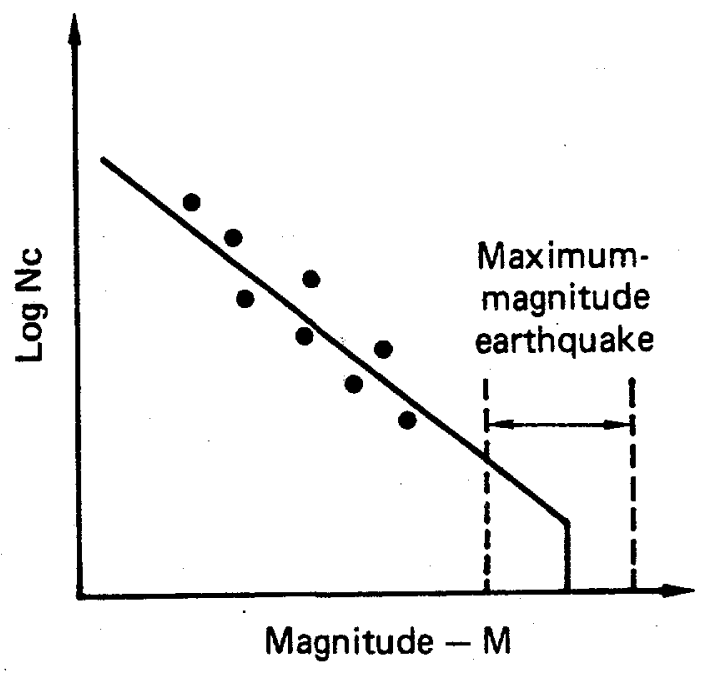

(b)

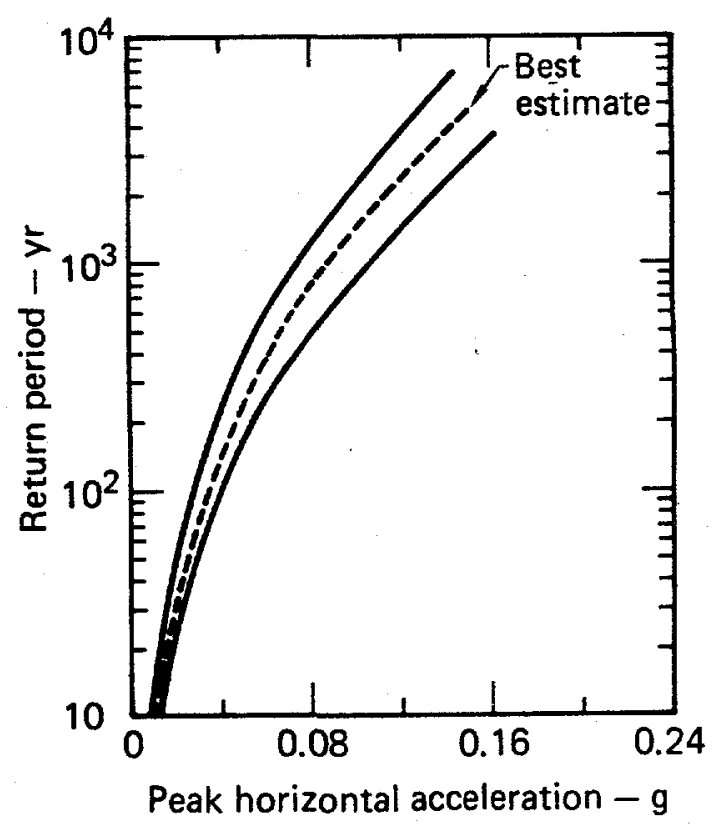

(d)

Figure 2. For a probabilistic hazard assessment, an analyst generally: (a) specifies the geometry of important seismic regions; (b) characterizes the relative frequency of earthquakes of various sizes; develops an earthquake recurrence model (usually a Poisson distribution in time, not shown); and (c) selects a transfer function that transforms information about the earthquake at the epicenter into information at the site, such as ground acceleration, that a structural engineer can use. The result of such an assessment is a plot of return period vs peak horizontal ground acceleration (d). 
TERA updated the earthquake data base to 1977 and found that, for many source regions, there was little change in the earthquake statistics from the 1974 data used by Algermissen and Perkins to calculate the rates at which earthquakes occur in each source region. TERA carefully compared the seismicity model calculated with their data against the model prepared by Algermissen and Perkins and reconciled any differences. Where applicable, the results of the SEP survey were also heavily relied upon. TERA often researched data points that were crucial to the statistics, and always compared their model with all appropriate previous models.

Consistent with conventional practice, the resulting seismicity model for all cases was characterized by

$$
\log N_{c}=a+b m_{b}
$$

where

$$
\begin{aligned}
& \mathrm{N}_{c}=\text { the cumulative number of earthquakes greater than } \mathrm{m}_{\mathrm{b}}, \\
& \mathrm{a}, \mathrm{b}=\text { parameters of a straight line, and } \\
& \mathrm{m}_{\mathrm{b}}=\text { the measure of the earthquake severity (magnitude or intensity). }
\end{aligned}
$$

The upper magnitude cutoff $\left(M_{u}\right)$ is a rather uncertain parameter, particularly in the less seismic areas which were considered. For each source, $M_{u}$ was obtained from reviews of expert opinion conducted by TERA. The values used were intended to maximize the agreement among experts. Both the recurrence relationship and the upper magnitude cutoff were considered uncertain and sensitivity studies were performed on them. 
MAGNITUDE AND INTENSITY RELATIONSHIP

Although most data are already available in terms of magnitude, an important part of the data is described in terms of intensity. In general, the subjective nature and the wide range of uncertainty of the Modified Mercalli intensity scale are such that they cannot be easily compared to the Richter magnitude. This has led to the use of empirical relationships between magnitude and intensity. TERA used a widely accepted linear relationship in the form:

$$
\mathrm{m}_{\mathrm{b}}=\mathrm{a}+\mathrm{b} \mathrm{I}_{\mathrm{o}}
$$

where

$$
\begin{aligned}
& m_{b}=\text { Body Wave Magnitude } \\
& I_{0}=\text { Epicentral MM intensity }
\end{aligned}
$$

with the values

$$
\begin{aligned}
& a=1.75 \\
& b=.50 .
\end{aligned}
$$

This relation has been derived separately for the central United States by Nuttli (1974) and is used by TERA to estimate magnitudes when only intensity is given.

\section{ATTENUATION RELATIONSHIPS}

Once the seismic activity has been determined within a source region, attention focuses on the effect of such activity at the site. Attenuation relationships are transfer functions that carry the information from the source to the site in terms of parameters structural engineers can use (i.e., acceleration, velocity, spectral acceleration). These attenuation relationships are inexact because of the lack of understanding of earthquake- 
generation phenomena, variations in travel paths, variable site conditions, and the limited descriptive capability of the parameters used. Probabilistic models consider the whole spectrum of uncertainties associated with these relationships for any event at any location. Thus, all possible outcomes at the site are covered, from the most favorable to the most adverse, each expressed in terms of how likely it is to occur.

The attenuation relationships were derived empirically. Because data are widely available in the West, but practically nonexistent in the eastern, central, and southern United States, two approaches were used.

The attenuation relations used for the eastern, central, and southern states were developed in two steps. Given the paucity of strong motion data and availability of intensity data, a model for the attenuation of site intensity was first developed. The site intensity was then converted into ground motion parameter, namely, peak ground acceleration, by using existing eastern United States strong motion data in conjunction with data from the western states. The epicentral intensity as a parameter in the attenuation model is changed to body wave magnitude by using Eq. (2). The local magnitude can be transformed to body wave magnitude by the relation:

$$
\mathrm{m}_{\mathrm{b}}=0.98 \mathrm{M}_{\mathrm{L}}-0.29
$$

Attenuation relationships for the western United States were obtained directly from the abundant strong motion data, by regression analysis of the PGA versus magnitude and distance.

It is very important to consider the data dispersion around the mean recurrence relationship. The statistical properties of peak acceleration are usually characterized by the natural logarithm of acceleration, thus, dispersions are expressed in terms of the standard deviation of In PGA where PGA = Peak Ground Acceleration $\left(\mathrm{cm} / \mathrm{sec}^{2}\right)$. TERA has computed values for this parameter on a case-by-case basis. Furthermore, data dispersion is truncated at three sigmas to eliminate nonplausible accelerations. 
HAZARD CALCULATIONS

TERA used the total probability theorem to calculate the probability that peak ground acceleration, $A$, will be exceeded in a given period of time. This is calculated by multiplying the conditional probability of A, given earthquake magnitude, $m$, and epicentral distance, $r$, times the probabilities of $m$ and $r$, and integrating over all possible values of $m$ and $r$ :

$$
P[A]=\& \& P[A / m \text { and } r] f_{M}(m) f_{R}(r) d m d r
$$

where $P$ indicates probability, $A$ is the parameter whose probability is sought, and $M$ and $R$ are continuous, independent random variables which influence $A$.

In TERA's assessments, $A$ is taken as maximum acceleration and is related by the attenuation relationship to epicentral distance and earthquake magnitude. The distribution on earthquake magnitude, $f_{M}(m)$, is readily derived from frequency relationships of the form of Eq. (1). The distribution on distance, $f_{R}(r)$, depends on the geometry of the source region. For simple geometries, the distributions can often be integrated analytically. Realistic geometries, however, require numerical evaluation of the integral.

TERA used versatile computer programs that incorporated the theory presented above with a numerical integration scheme to evaluate complex source-site geometries. For small areas within each source region, the computer code calculated the annual expected number of earthquakes causing accelerations greater than a specified acceleration. The expected number for each source region was obtained by integrating over the whole source. This process was repeated for each source region, and the total expected number was obtained by summation. The resulting annual hazard was calculated as:

annual hazard $=1.0-\exp (-$ total annual expected number $)$.

This expression results from the conventional assumption that earthquake occurrences follow a Poisson process in time.

The return period associated with the specified acceleration can then be approximated by the reciprocal of the annual hazard. It follows from the 
definition of return period that accelerations with a particular return period have a $63 \%$ probability of being exceeded within a period of time equal to the return period.

TERA's estimate of the seismic hazard represents the weighted results from individual calculations for a base case (best estimate) and perturbations on input parameters about this base. The parameters that were considered uncertain and included in sensitivity analysis are:

- The boundaries of the source regions.

- The intercept and slope of the recurrence relationships.

- The maximum earthquake in each source region.

- The attenuation relationship and the uncertainty associated with it.

The sensitivity analyses resulted in a family of hazard curves at the site. Each curve was weighted by subjective estimates of its probability of occurrence.

Results of the probabilistic seismic characterization are presented as three plots of return period vs. peak acceleration: the best estimate together with the estimate of the lower and upper limits. These limits can be taken in a loose sense as the one standard deviation with respect to the best estimate.

These plots are presented in the Appendix of this report. 
TERA also determined appropriate response spectra for the sites because some structures and equipment have fundamental frequencies in the range of spectral amplification of the ground motion. The response spectrum for a site clearly cannot be developed in association with a specified earthquake, since the return period accelerations represent a wide variety of earthquakes having an integrated effect at the site, and the response spectrum must reflect this.

The hazard at most sites is generated by one of two types of events: near-field earthquakes of small to moderate magnitudes in the host region, and large earthquake motion from distant sources. The energy of near-field events is released at the site mainly in the high frequency range, and their response spectra are governed by body waves. On the other hand, large earthquake motions from distant sources are transmitted by surface waves and contribute to the low frequency side of the spectrum.

These considerations, as well as the site soil conditions, are used to develop response spectra for each site. The resulting spectra are, in general, a conservative envelope of the broad frequency range that may be expected to occur at a given site, and are also presented in the Appendix of this report. 


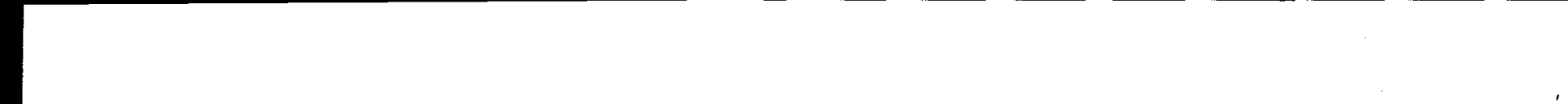




\section{SUMMARY AND CONCLUSIONS}

This report has presented a summary of the methodology used by TERA Corporation to develop seismic hazard models and response spectra as part of a DOE, Office of Nuclear Safety project to evaluate natural phenomena hazards at DOE sites throughout the country.

The seismic hazard curves and response spectra shapes presented in the Appendix are the curves recommended for use in the design of new facilities and in the analysis of existing facilities. We believe these curves represent the most realistic evaluation of seismic hazards at DOE sites currently available, and we strongly recommend their use in analysis and design applications. 


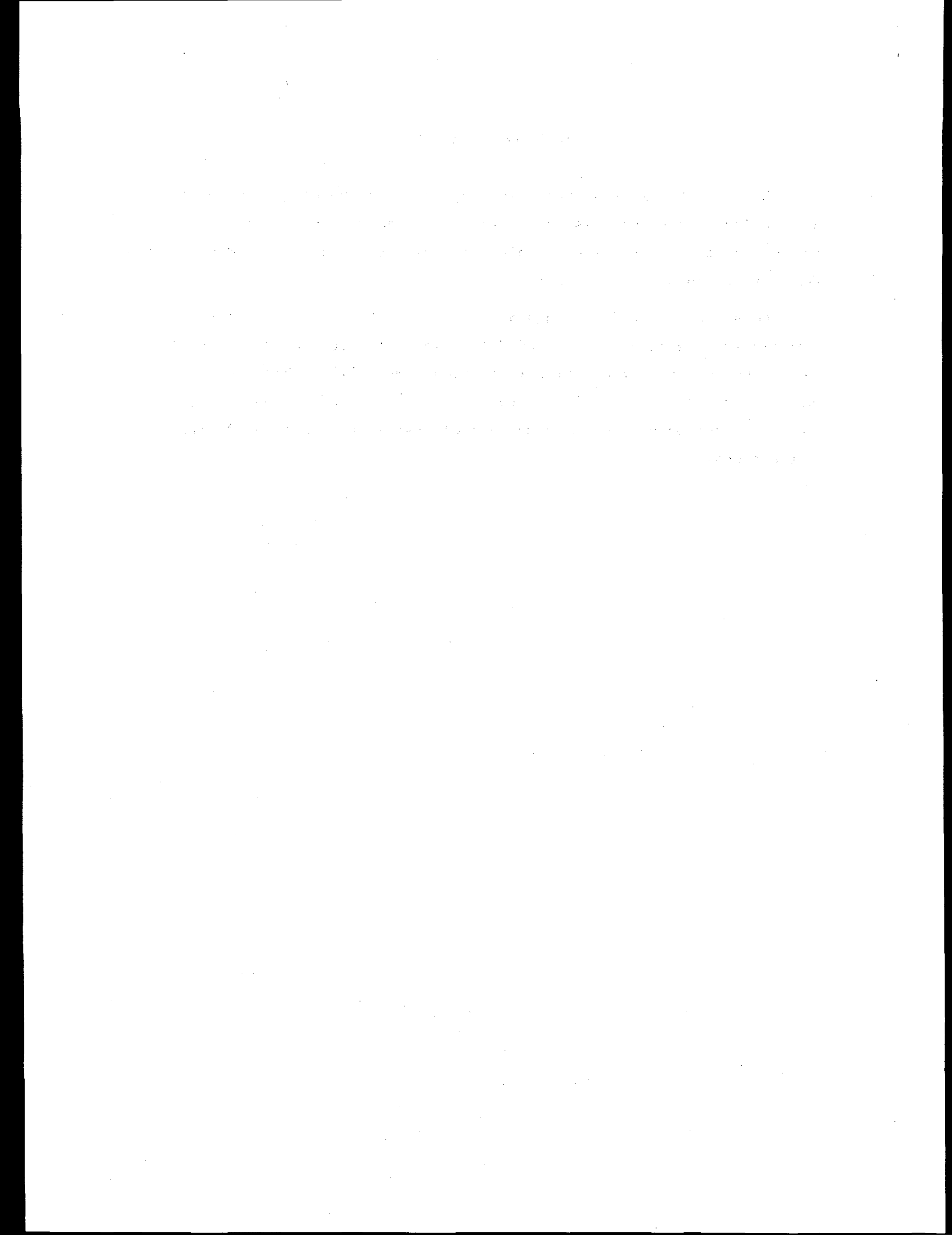




\section{REFERENCES}

Algermissen, S. T. and Perkins, D. M., A Probabilistic Estimate of Maximum Acceleration in Rock in the Contiguous United States, U.S. Geological Survey, Open File Report 76-5416 (1976).

Bernreuter, D. L., et al., Seismic Evaluation of Commercial Plutonium Fabrication Plants in the United States, Lawrence Livermore National Laboratory, Livermore, CA, UCRL-52705 (October, 1979).

Bernreuter, D. L., Seismic Hazard Analysis--Application of Methodology, Results, and Sensitivity Studies, U.S. Nuclear Regulatory Commission report, NUREG/CR-1582, Vo1. 4 (1981).

Bohn, M. P., et al., Application of the SSMRP Methodology to the Seismic Risk at the Zion Nuclear Power Plant, U.S. Nuclear Regulatory Commission report, NUREG/CR-3428 (1983).

Coats, D. W. and Murray, R. C., Natural Phenomena Hazards for Department of Energy Critical Facilities: Phase 1 - Site and Facility Information, Lawrence Livermore National Laboratory, Livermore, CA, UCRL-52599-Draft (1978).

Coats, D. W., Natura1 Phenomena Hazards Modeling Project: Extreme Wind/Tornado Hazard Models for Department of Energy Sites, Lawrence Livermore National Laboratory, Livermore, CA, UCRL-53526 (February, 1984).

Corne11, C. A. and Merz, H. A., "A Seismic Risk Analysis of Boston," Journal of the Structural Division, ASCE, Vol. 101, No. ST10, Proc. Paper $116 \overline{17}$, pp. 2027-2043(1975).

Mortgat, C. P., et a1., A Study of Seismic Risk for Costa Rica, Report 25, John A. Blume Earthquake Engineering Center, Stanford University, Stanford, California (1977).

Nuttli, 0. W. and Zollweg, J. E., "The Relation between Felt Area and Magnitude for Central United States Earthquakes," Bu11. Seismol. Soc. America, Vo1. 64, p. 73-85 (1974).

Shah, H. C., et al., A Study of Seismic Risk for Nicaragua, Report II, Part I, John A. Blume Earthquake Engineering Center, Stanford University (1975).

Stepp, J. C., "Analysis of Completeness of the Earthquake Sample in the Puget Sound Area and Its Effect on Statistical Estimates of Earthquake Hazard," Proceedings, Conference on Microzonation, Seattle (1974).

TERA Corporation, Seismic Hazard Analysis: Solicitation of Expert Opinion, prepared for the Lawrence Livermore National Laboratory (1980).

U.S. Nuclear Regulatory Commission, The Correlation of Peak Ground 
Acceleration Amplitude with Seismic Intensity and Other Physical Parameters, NUREG-0143 (1977).

Vagliente, V., "Forecasting the Risk Inherent in Earthquake Resistant Design," Ph.D. Dissertation, Department of Civil Engineering, Stanford University, Stanford, California (1973). 


\section{BIBLIOGRAPHY}

TERA Corporation, "Influence of Seismicity Modeling on Seismic Hazard Analysis," report prepared for the Lawrence Livermore National Laboratory, Livermore, CA (June 1978).

TERA Corporation, "Draft Report--Seismic Hazard Analysis for the Bendix Kansas City Plant," report prepared for the Lawrence Livermore National Laboratory, Livermore, CA (October 1981).

TERA Corporation, "Draft Report--Seismic Hazard Analysis for Los Alamos Scientific Laboratory and Sandia Laboratories, New Mexico," report prepared for the Lawrence Livermore National Laboratory, Livermore, CA (May 1981).

TERA Corporation, "Draft Report--Seismic Hazard Analysis for the Paducah, Portsmouth, Mound and FMPC DOE Sites," report prepared for the Lawrence Livermore National Laboratory, Livermore, CA (June 1980).

TERA Corporation, "Draft Report--Seismic Hazard Analysis Pantex Ordnance Plant Amarillo, Texas," report prepared for the Lawrence Livermore National Laboratory, Livermore, CA (Apri1 1978).

TERA Corporation, "Seismic Hazard Analysis for Lawrence Livermore National Laboratory and Site 300," report prepared for the Lawrence Livermore National Laboratory, Livermore, CA (May 1983).

TERA Corporation, "Draft--Seismic Hazard Analysis for the Pinellas P1ant, Florida," report prepared for the Lawrence Livermore National Laboratory, Livermore, CA (October 1982).

TERA Corporation, "Seismic Risk Analysis for Argonne National Laboratory East Area," report prepared for the Lawrence Livermore National Laboratory, Livermore, CA (May 1978).

TERA Corporation, "Draft--Seismic Risk Analysis for Argonne National Laboratory, Idaho National Engineering Laboratory," report prepared for the Lawrence Livermore National Laboratory, Livermore, CA (June 1978).

TERA Corporation, "Draft Report--Seismic Hazard Analysis for Brookhaven National Laboratory and Princeton Plasma Physics Laboratory," report prepared for the Lawrence Livermore National Laboratory, Livermore, CA (July 1981).

TERA Corporation, "Draft--Seismic Hazard Analysis for Oak Ridge Nationa1 Laboratory," report prepared for the Lawrence Livermore National Laboratory, Livermore, CA (September 1978).

TERA Corporation, "Draft Report--Seismic Hazard Analysis for Area 410, Nevada Test Site," report prepared for the Lawrence Livermore National Laboratory, Livermore, CA (October 1981). 
TERA Corporation, "Seismic Risk Analysis for the Hanford Reservation Richland, Washington," report prepared for the Lawrence Livermore National Laboratory, Livermore, CA (September 1978).

TERA Corporation, "Draft--Seismic Hazard Analysis for the Lawrence Berkeley Laboratory and Stanford Linear Accelerator Center," report prepared for the Lawrence Livermore National Laboratory, Livermore, CA (October 1981).

TERA Corporation, "Draft--Seismic Hazard Analysis for the Liquid Metal Engineering Center Santa Susana, California," report prepared for the Lawrence Livermore National Laboratory, Livermore, CA (March 1982).

TERA Corporation, "Draft Report--Seismic Hazard Analysis for the Savannah River Plant, South Carolina," report prepared for the Lawrence Livermore National Laboratory, Livermore, CA (August 1980).

TERA Corporation, "Seismic Hazard Analysis of Department of Energy Sites, DOE Field office-Albuquerque," report prepared for the Lawrence Livermore National Laboratory, Livermore, CA (September 1982).

TERA Corporation, "Seismic Hazard Analysis of Department of Energy Sites, DOE Field office-Chicago," report prepared for the Lawrence Livermore National Laboratory, Livermore, CA (January 1983).

TERA Corporation, "Seismic Hazard Analysis of Department of Energy Sites, DOE Field office--Idaho," report prepared for the Lawrence Livermore National Laboratory, Livermore, CA (October 1984).

TERA Corporation, "Seismic Hazard Analysis of Department of Energy Sites, DOE Field Office-Oak Ridge," report prepared for the Lawrence Livermore National Laboratory, Livermore, CA (February 1981).

TERA Corporation, "Seismic Hazard Analysis of Department of Energy Sites, DOE Field Office--Nevada," report prepared for the Lawrence Livermore National Laboratory, Livermore, CA (February 1984).

TERA Corporation, "Seismic Hazard Analysis of Department of Energy Sites, DOE Field office--Richland," report prepared for the Lawrence Livermore National Laboratory, Livermore, CA (September 1982).

TERA Corporation, "Seismic Hazard Analysis of Department of Energy Sites, DOE Field Office--San Francisco," report prepared for the Lawrence Livermore National Laboratory, Livermore, CA (March 1984).

TERA Corporation, "Seismic Hazard Analysis of Department of Energy Sites, DOE Field Office--Savannah," report prepared for the Lawrence Livermore National Laboratory, Livermore, CA (September 1982). 


\section{APPENDIX}

Earthquake Hazard Curves and Response Spectra

for DOE Sites

This appendix contains hazard model curves and design response spectra for all DOE sites considered in this study.

The hazard curves on either side of the best estimates represent lower and upper bound confidence limits; they can roughly be considered the one standard deviation with respect to the best estimates. These curves provide a basis for selecting seismic design criteria for these sites in terms of freefield peak ground acceleration.

For those structures and equipment that could experience structural amplification, we have included the design response spectral shapes which we believe to be most appropriate for the sites. These spectral shapes are scaled to $1.0 \mathrm{~g}$. 


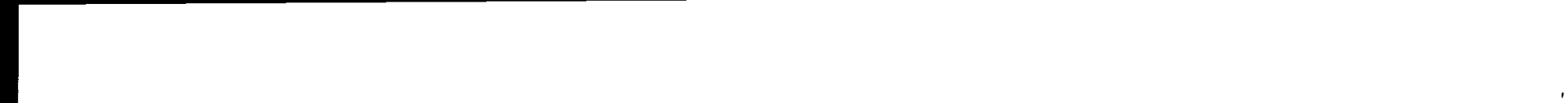




\section{Albuquerque Field Office Sites}

Earthquake Hazard Curves and Response Spectra 


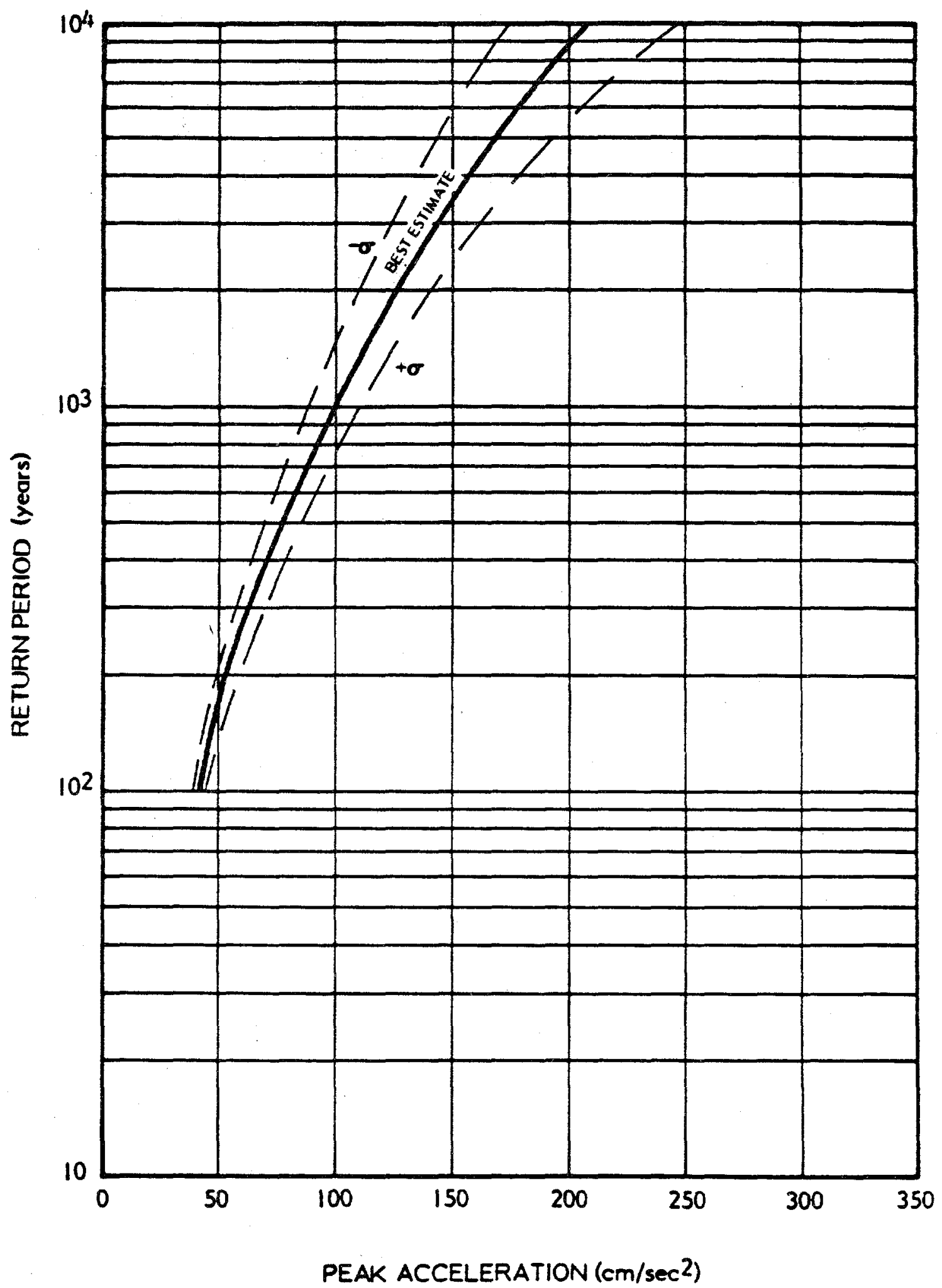

Earthquake Hazard at the Bendix, Kansas City Plant, Missouri 


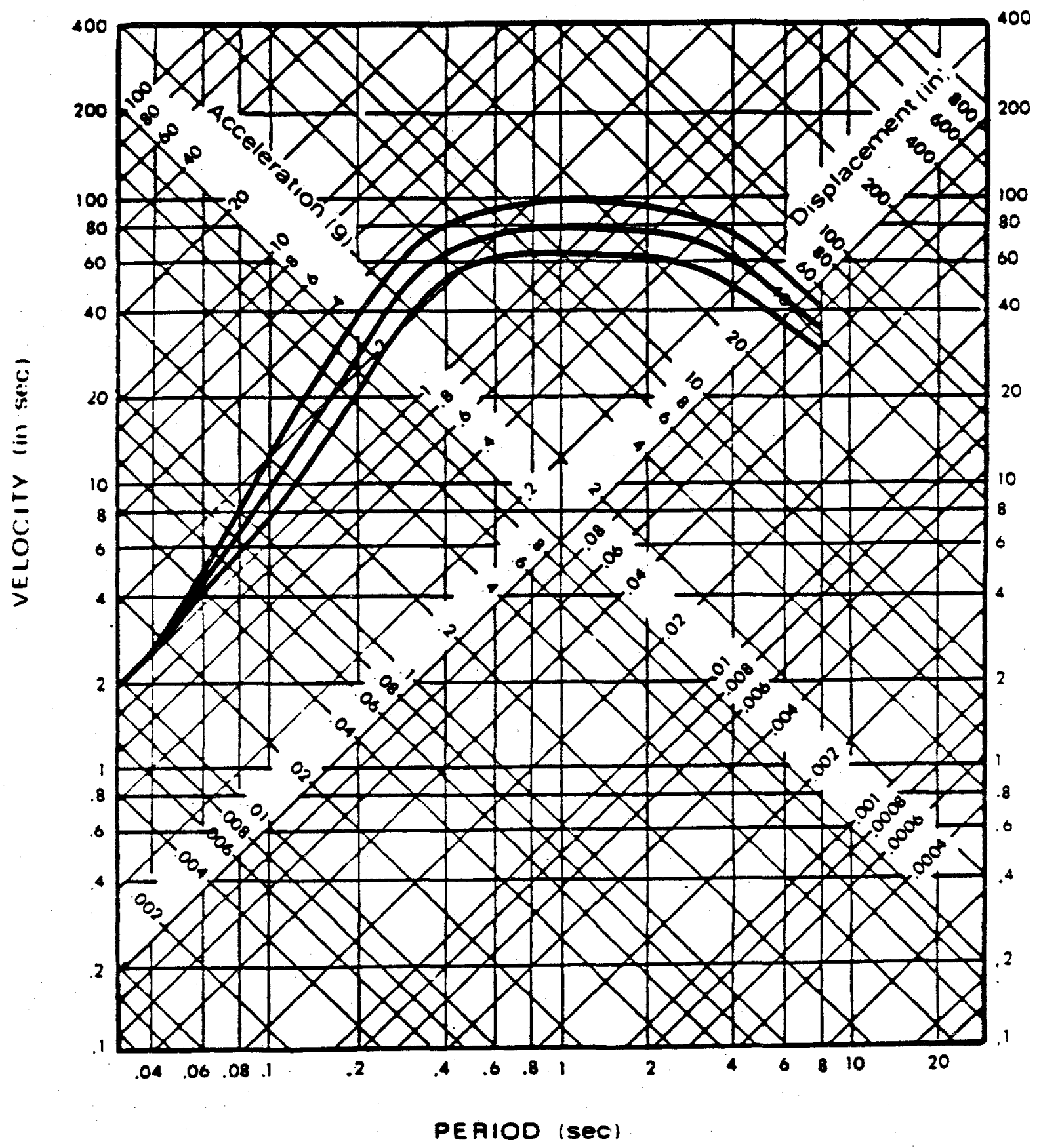

Design Response Spectrum Scaled to $1.0 \mathrm{~g}$

( $2 \%, 5 \%$, and $10 \%$ of Critical Damping)

Bendix, Kansas City Plant, Missouri 


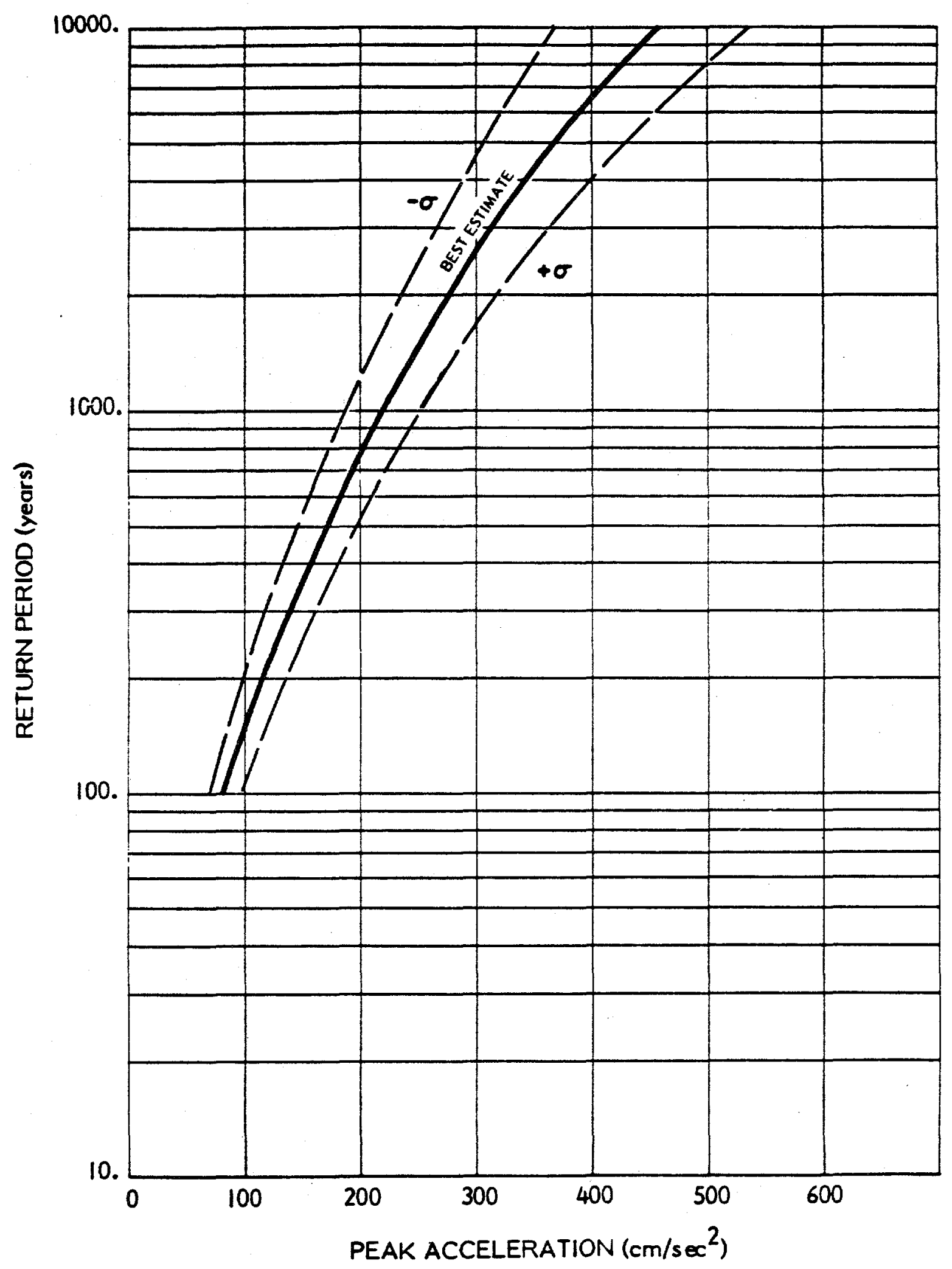

Earthquake Hazard at the Los Alamos National Laboratory, New Mexico 


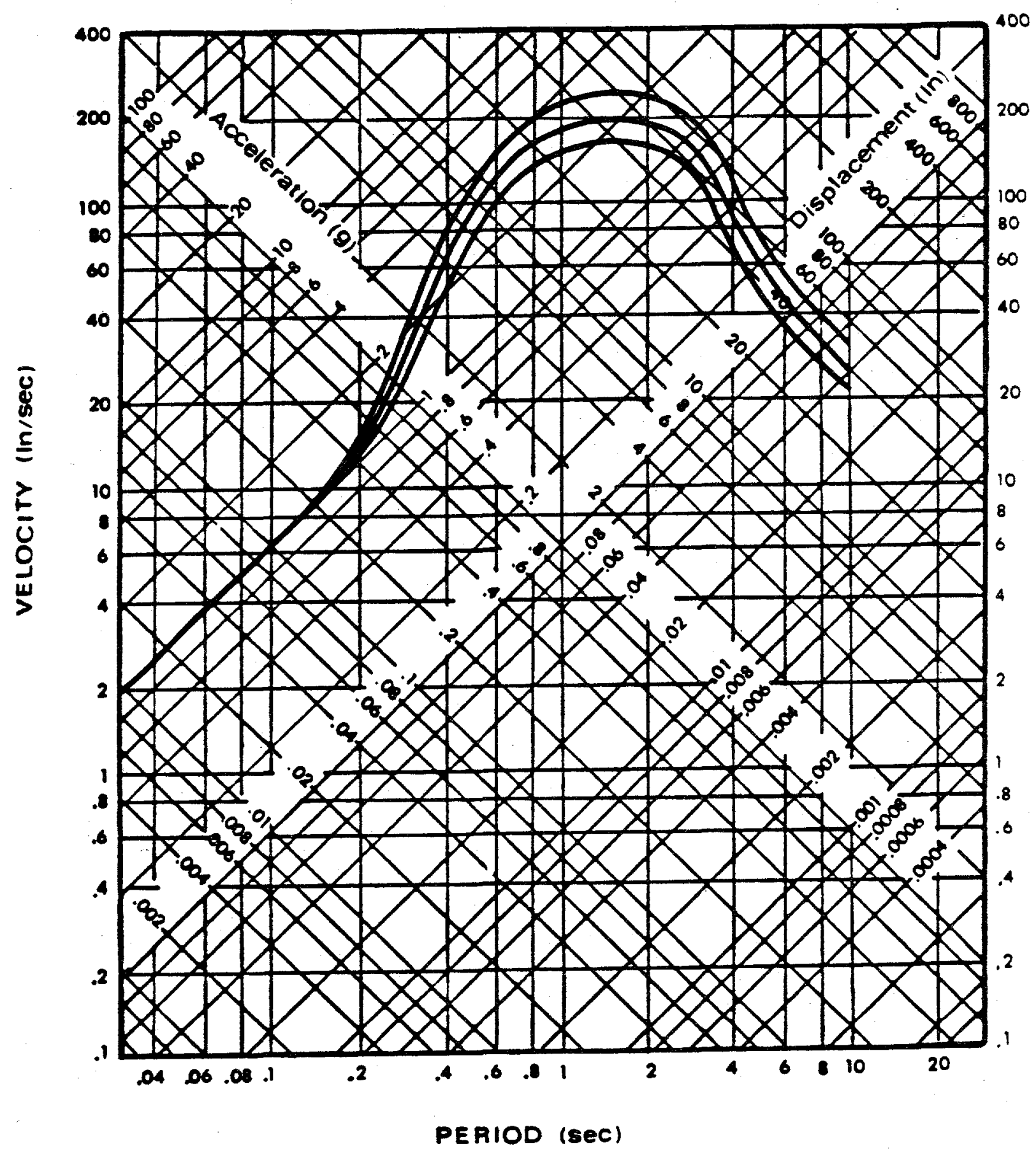

Design Response Spectrum Scaled to $1.0 \mathrm{~g}$

( $2 \%, 5 \%$, and $10 \%$ of Critical Damping)

Los Alamos National Laboratory, New Mexico 


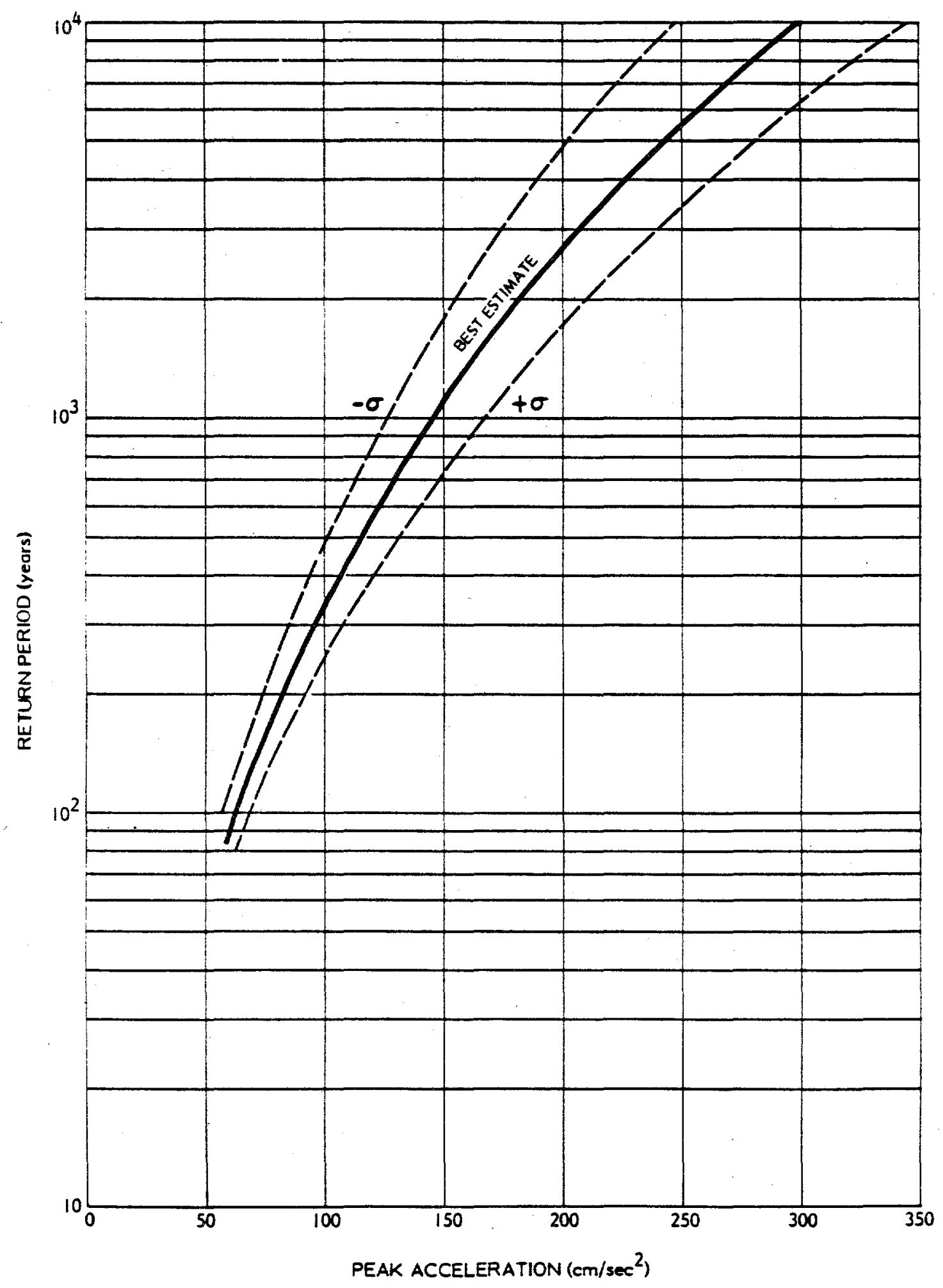

Earthquake Hazard at the Mound Laboratory, Ohio 


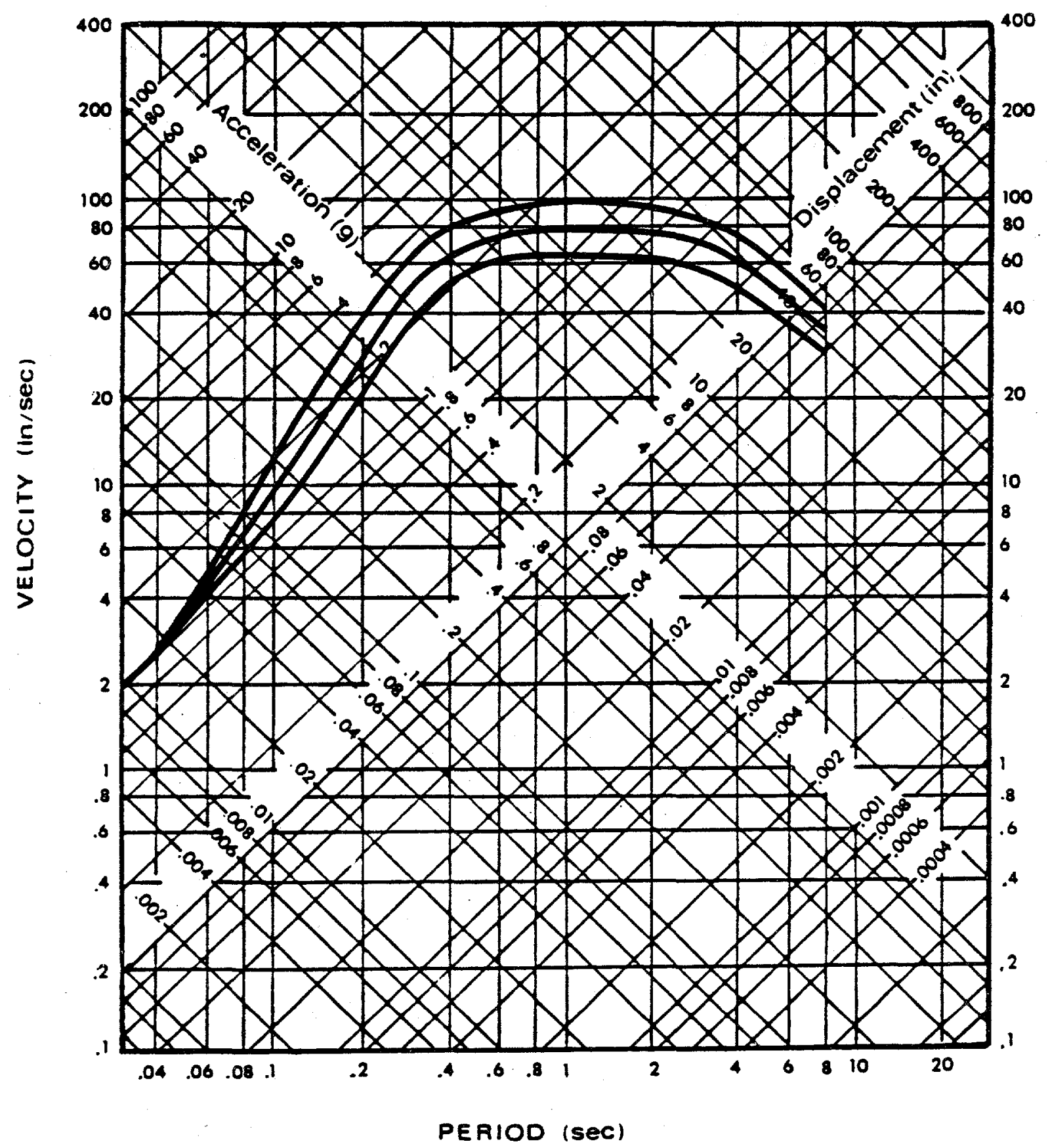

Design Response Spectrum Scaled to $1.0 \mathrm{~g}$

( $2 \%, 5 \%$, and $10 \%$ of Critical Damping) Mound Laboratory, Ohio 


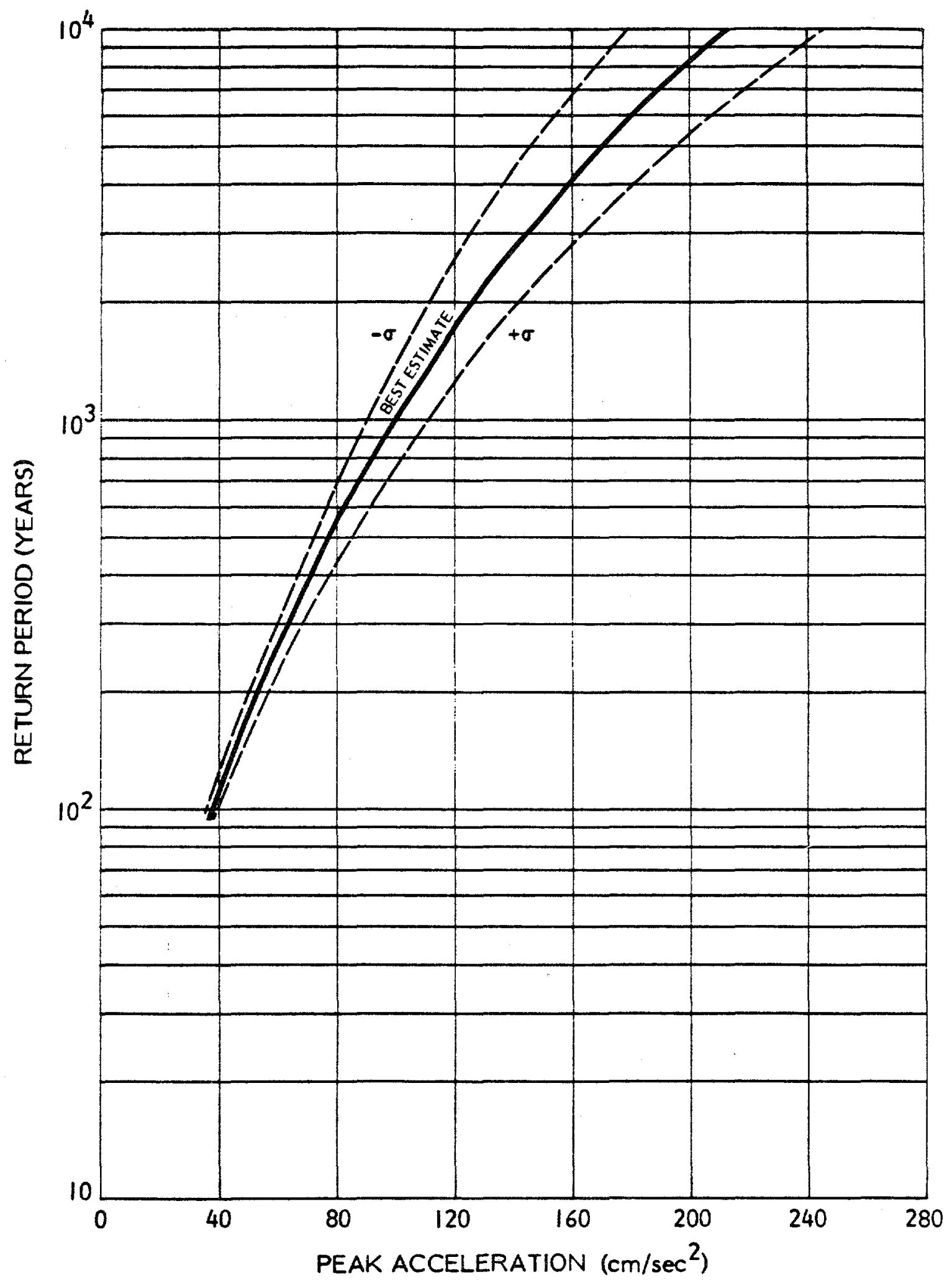

Earthquake Hazard at the Pantex Plant, Texas 


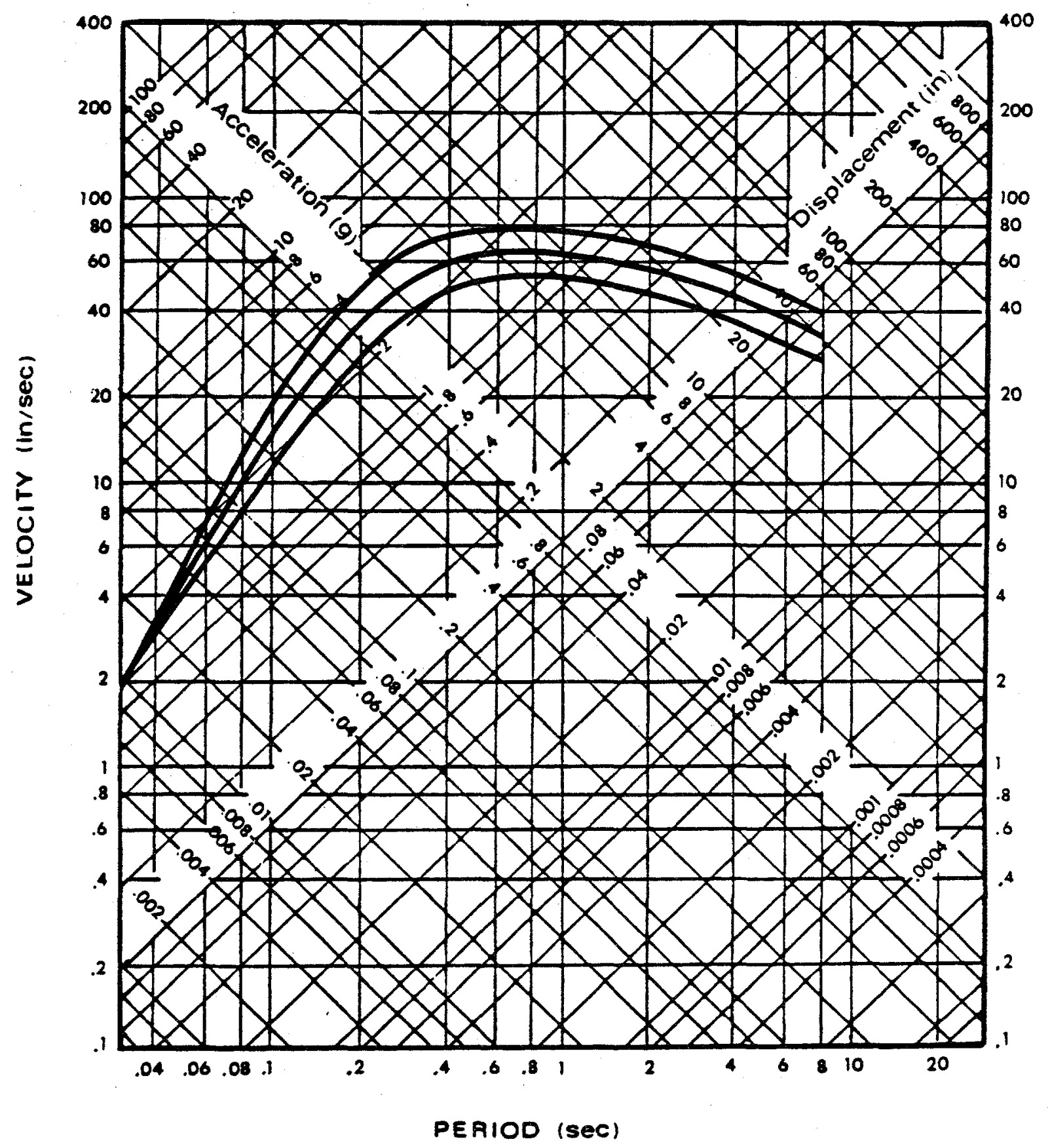

Design Response Spectrum Scaled to $1.0 \mathrm{~g}$

( $2 \%, 5 \%$, and $10 \%$ of Critical Damping)

Pantex Plant, Texas 


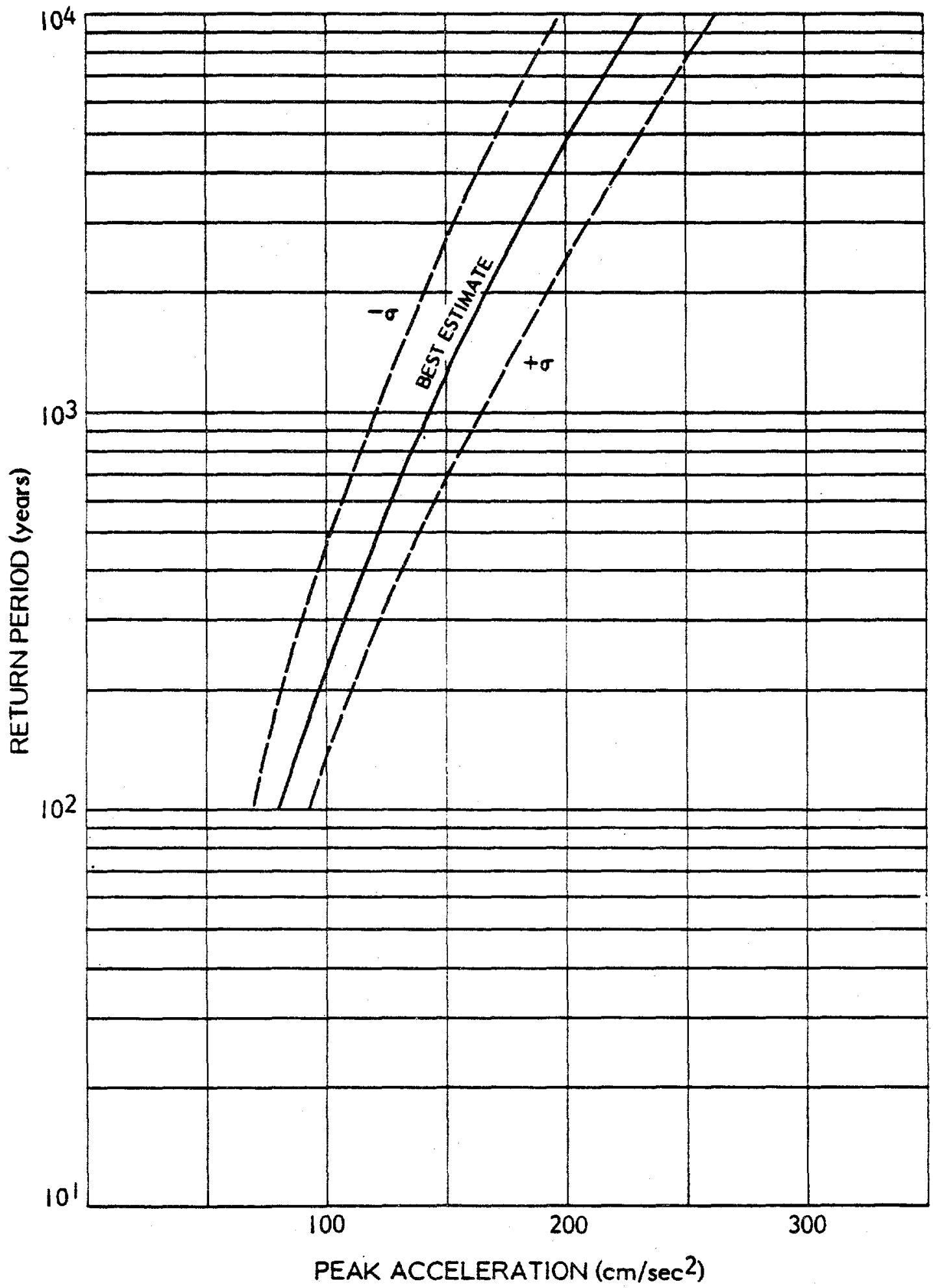

Earthquake Hazard at the Rocky Flats Plant, Colorado 


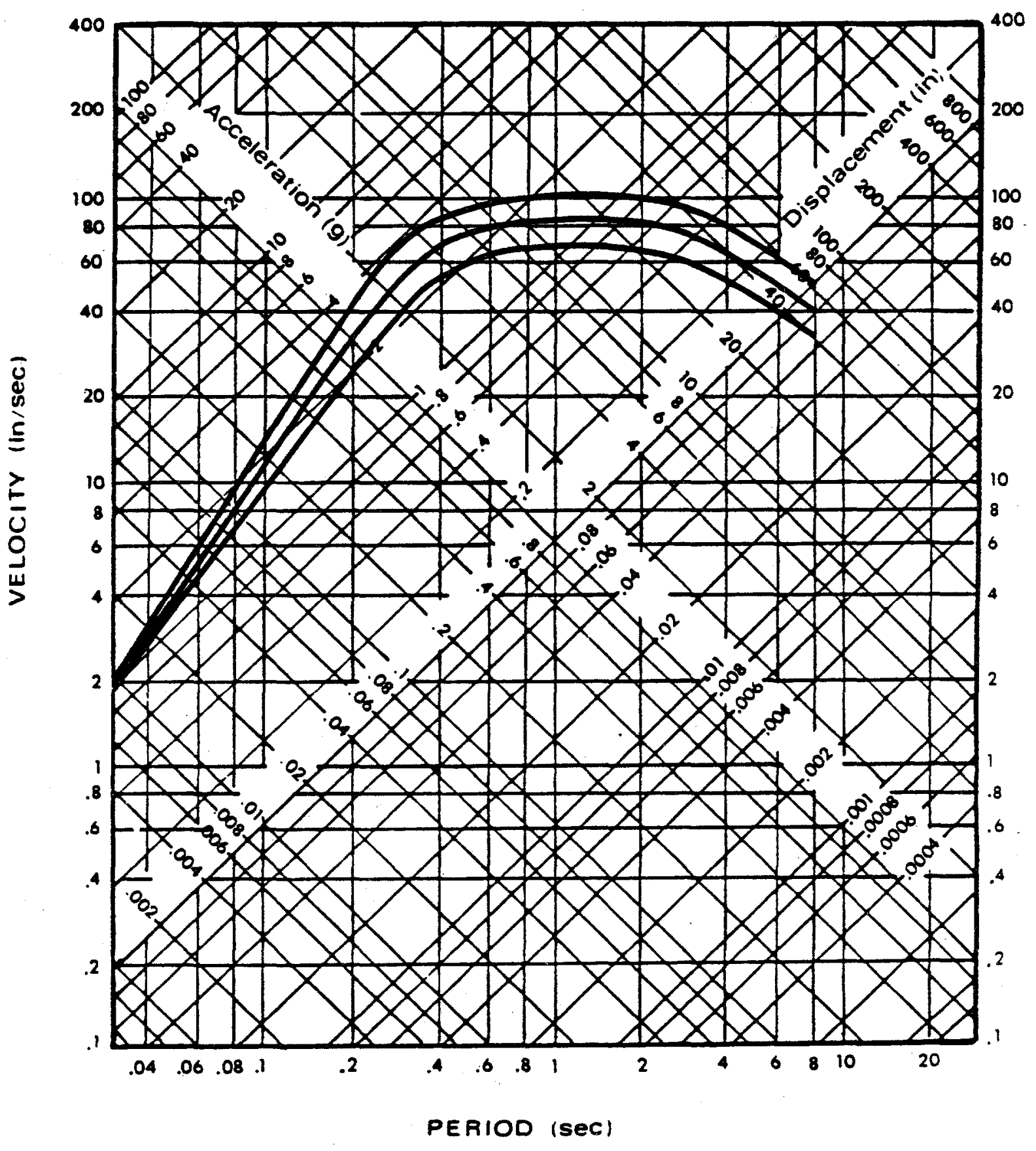

Design Response Spectrum Scaled to $1.0 \mathrm{~g}$

( $2 \%, 5 \%$, and $10 \%$ of Critical Damping)

Rocky Flats Plant, Colorado 


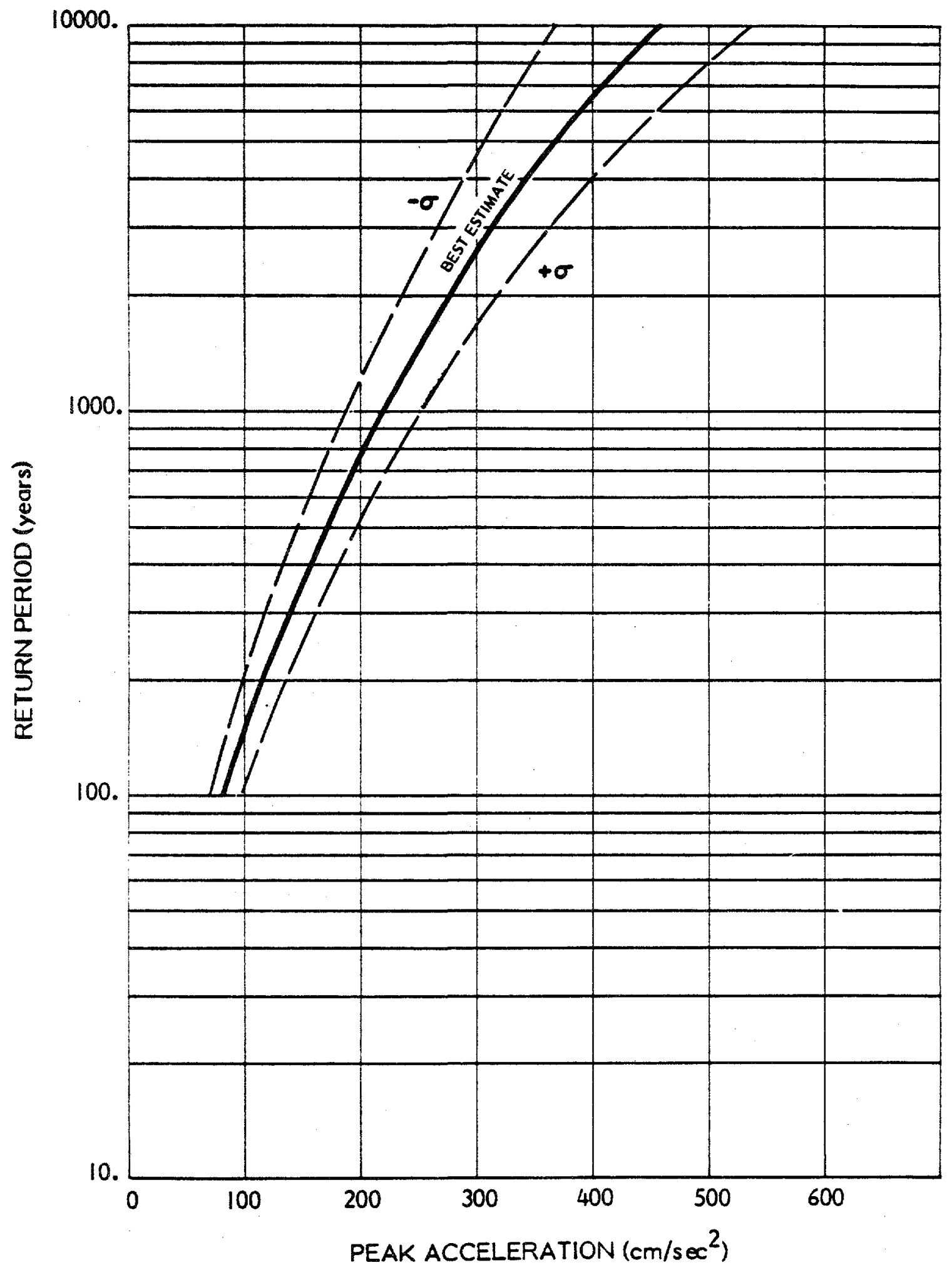

Earthquake Hazard at the Sandia National Laboratory, New Mexico 


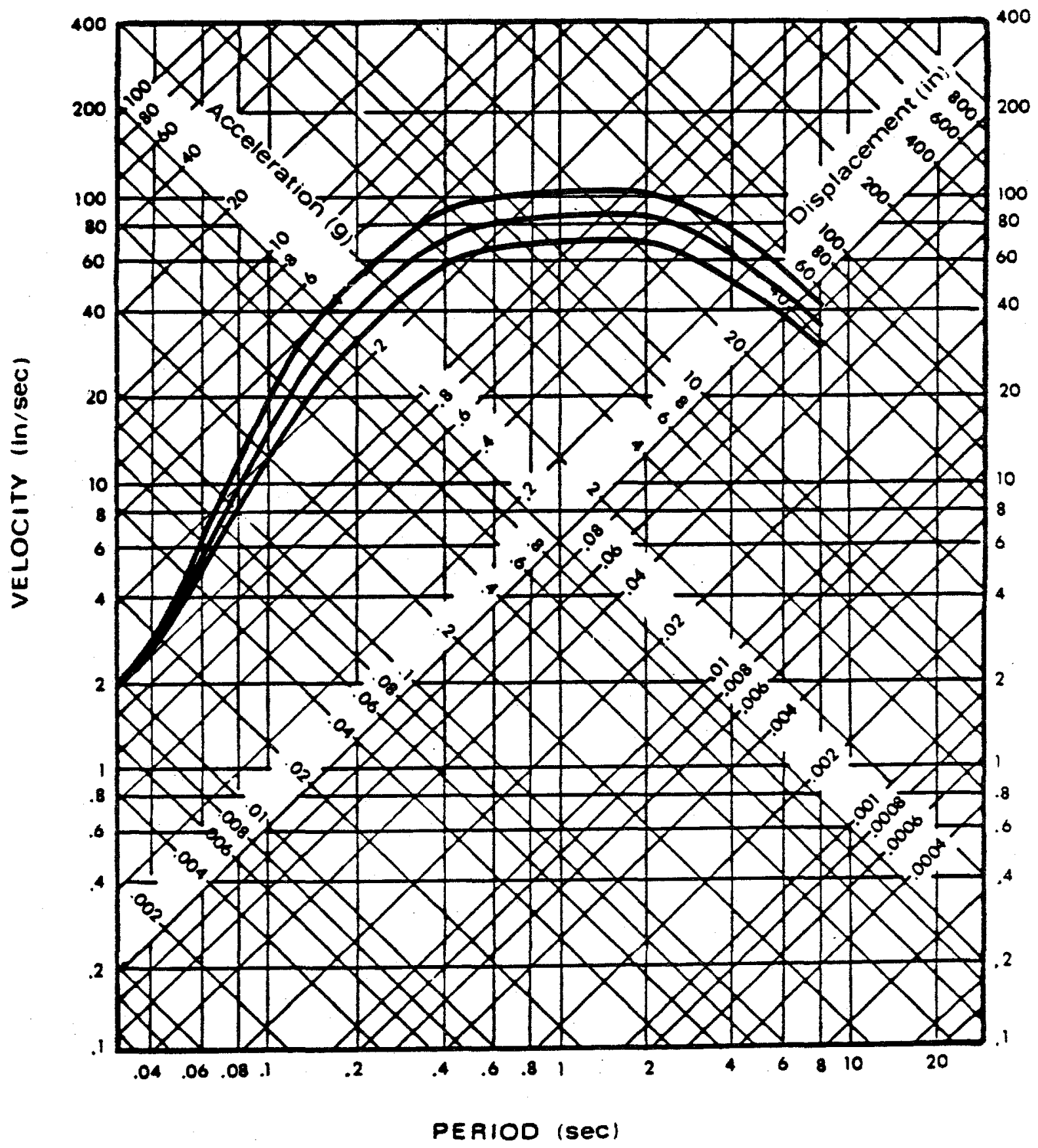

Design Response Spectrum Scaled to $1.0 \mathrm{~g}$

( $2 \%, 5 \%$, and $10 \%$ of Critical Damping)

Sandia Nationa1 Laboratory, New Mexico 


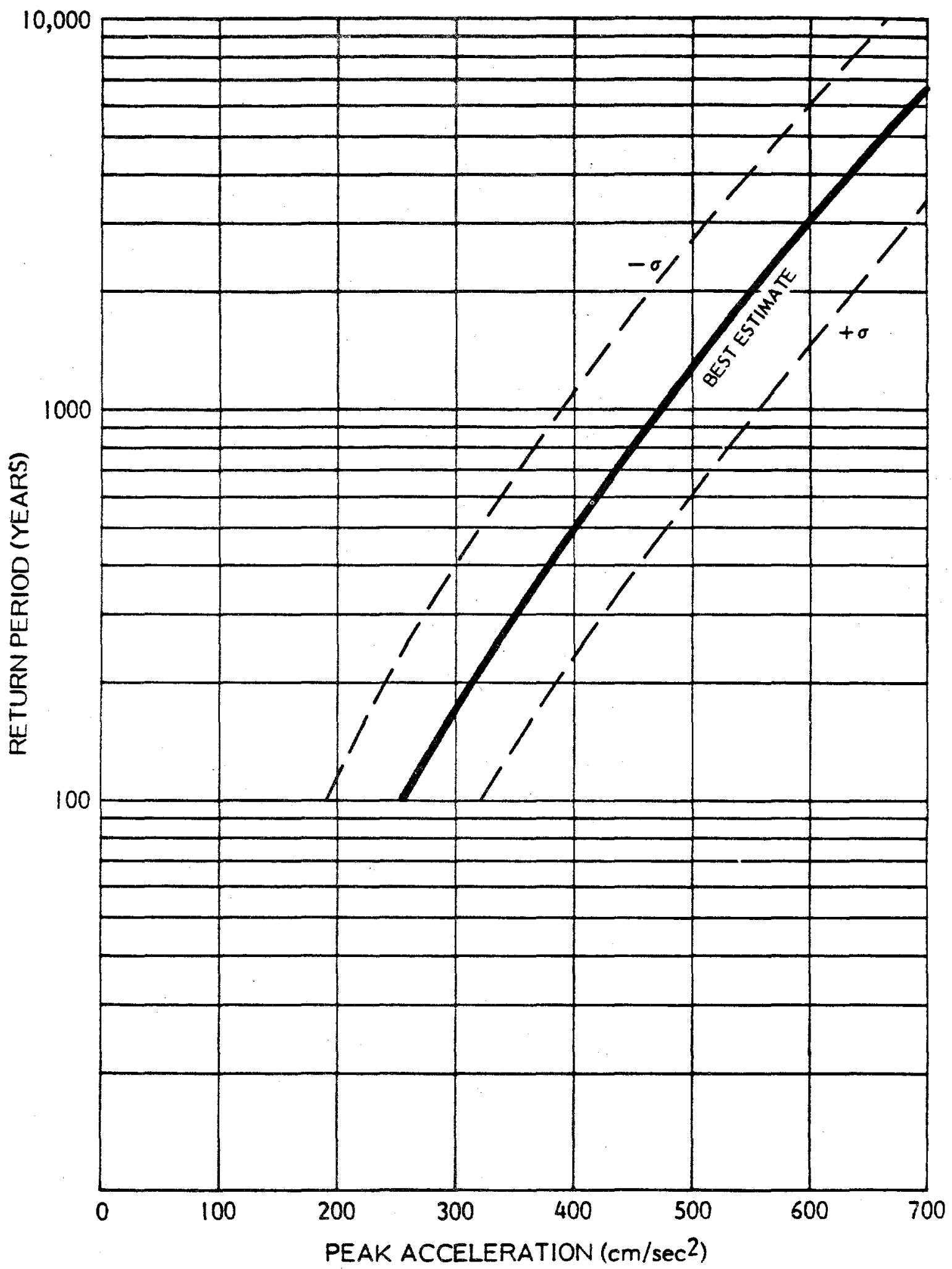

Earthquake Hazard at the Sandia National Laboratory, California 


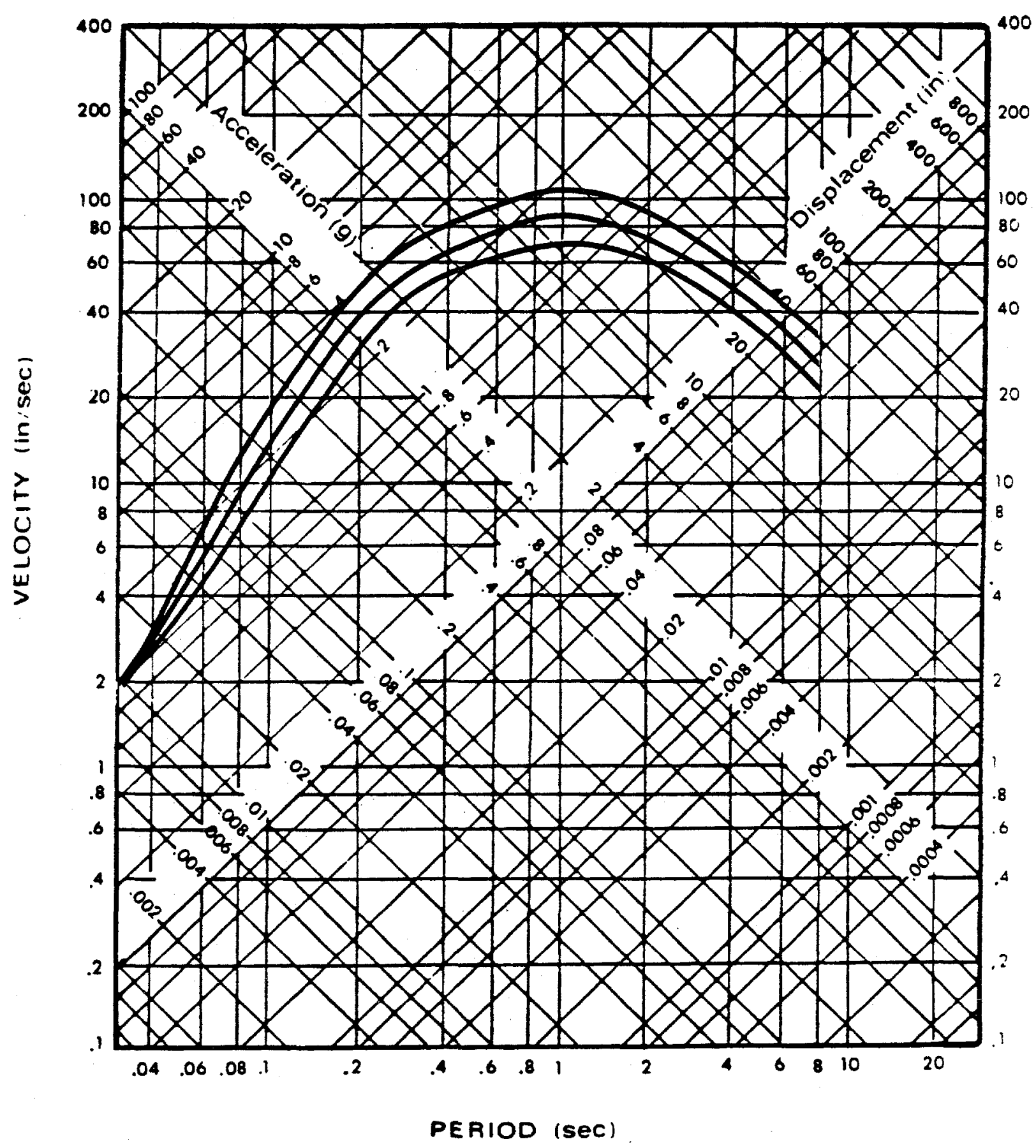

Design Response Spectrum Scaled to $1.0 \mathrm{~g}$

( $2 \%, 5 \%$, and $10 \%$ of Critical Damping)

Sandia National Laboratory, California 


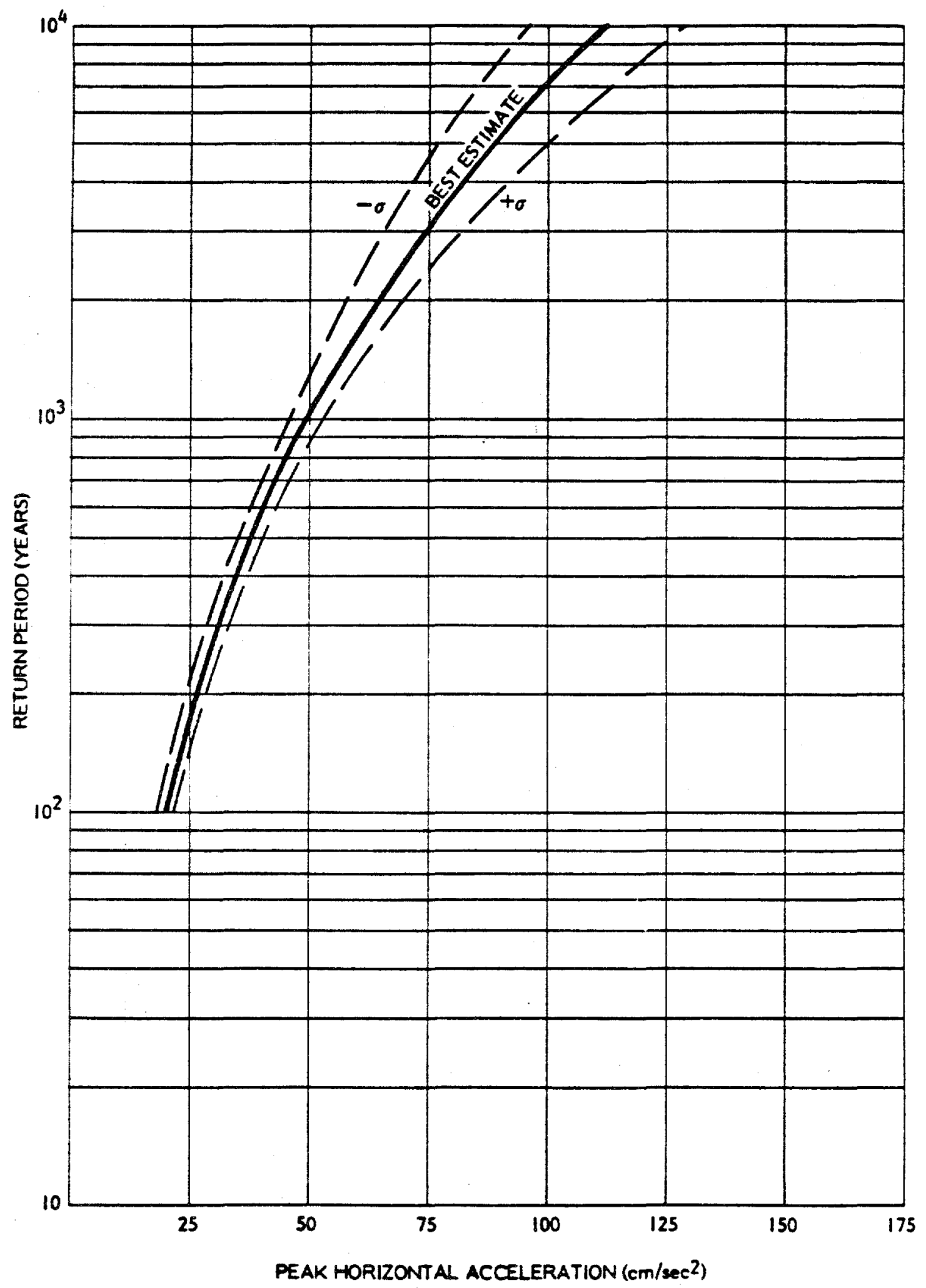

Earthquake Hazard at the Pinellas Plant, Florida 


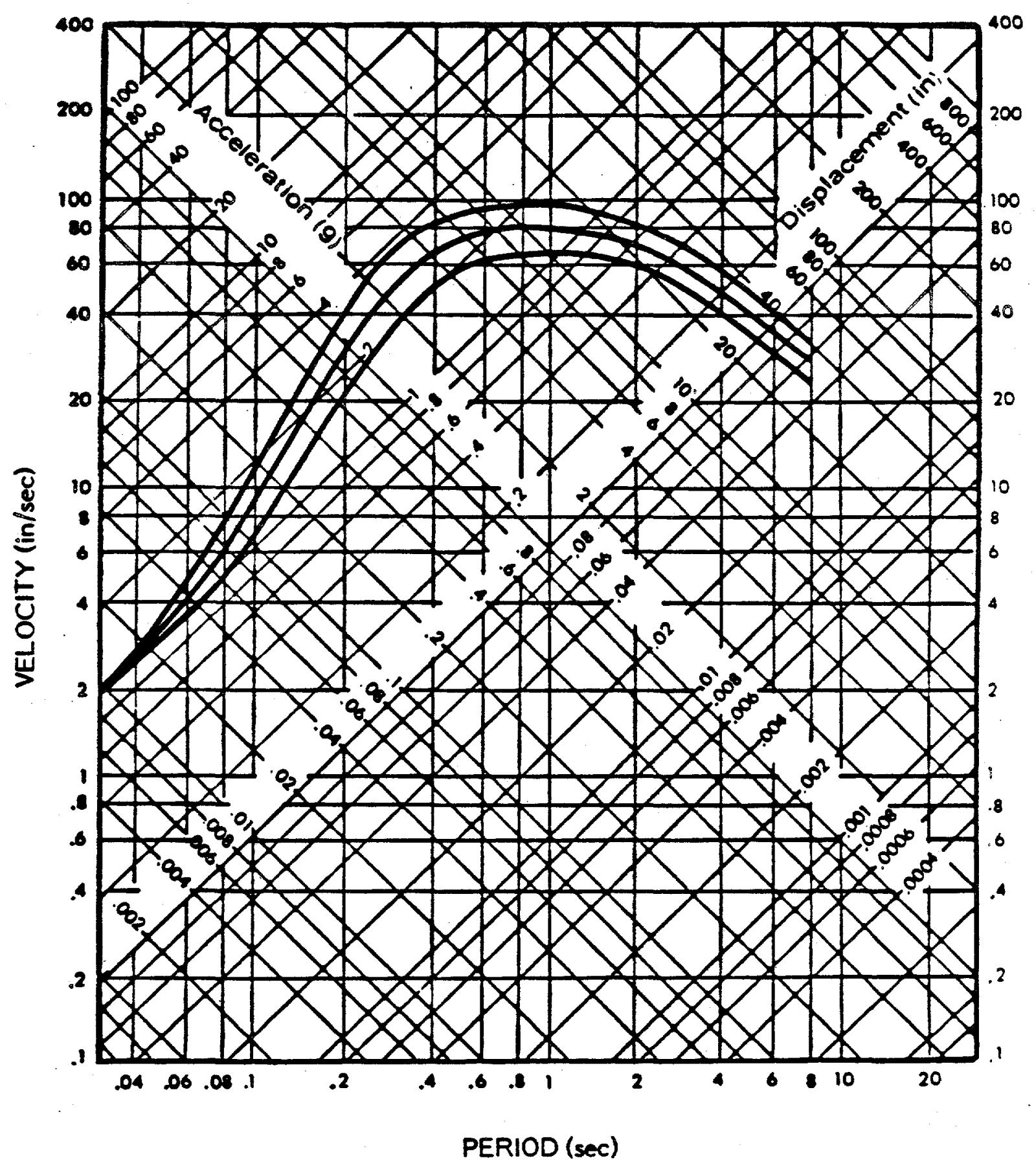

Design Response Spectrum Scaled to $1.0 \mathrm{~g}$

( $2 \%, 5 \%$, and $10 \%$ of Critical Damping)

Pinellas Plant, Florida 



\section{Chicago Field office Sites}

Earthquake Hazard Curves and Response Spectra

$-43-$ 


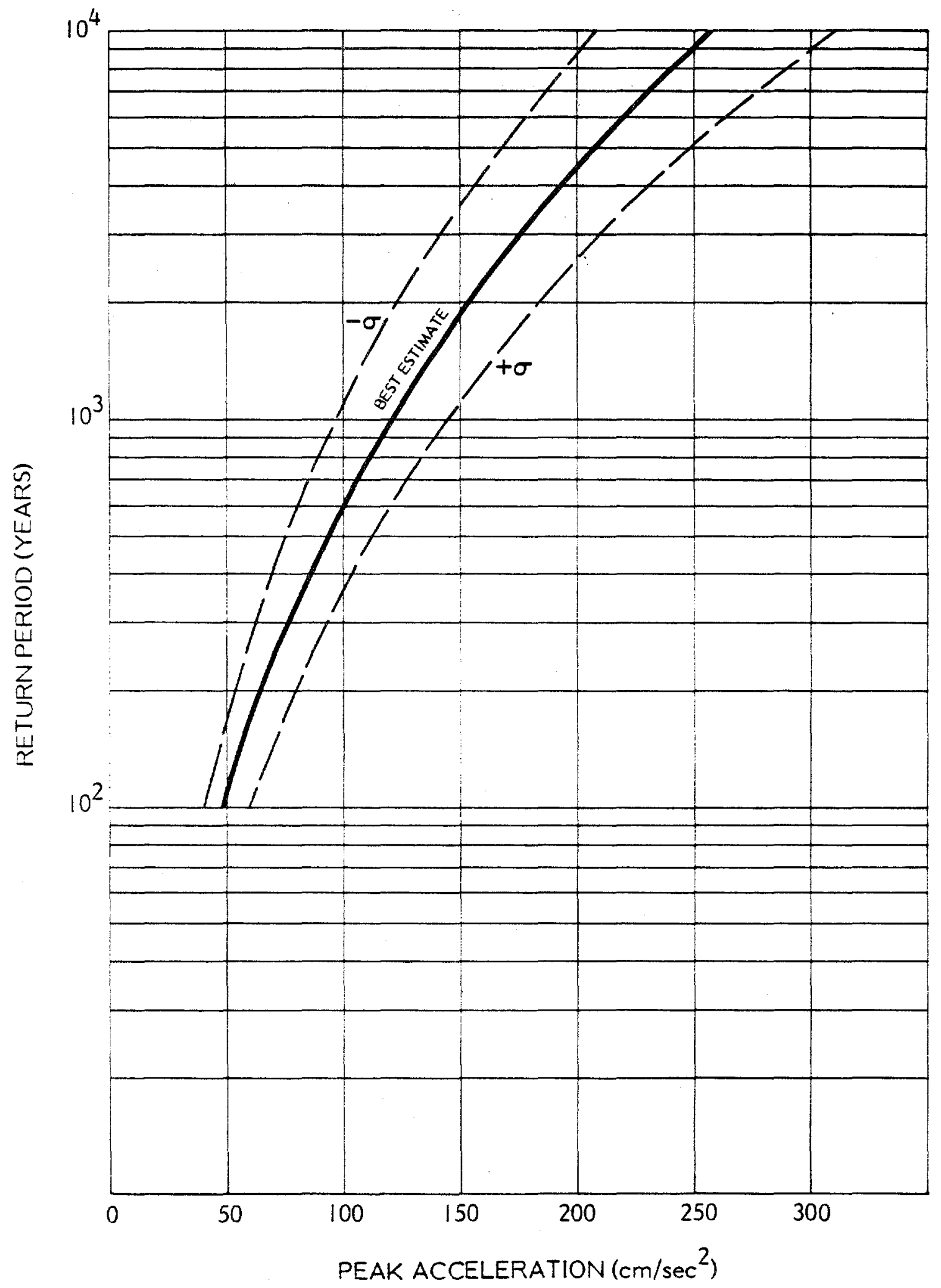

Earthquake Hazard at the Argonne National Laboratory, Illinois 


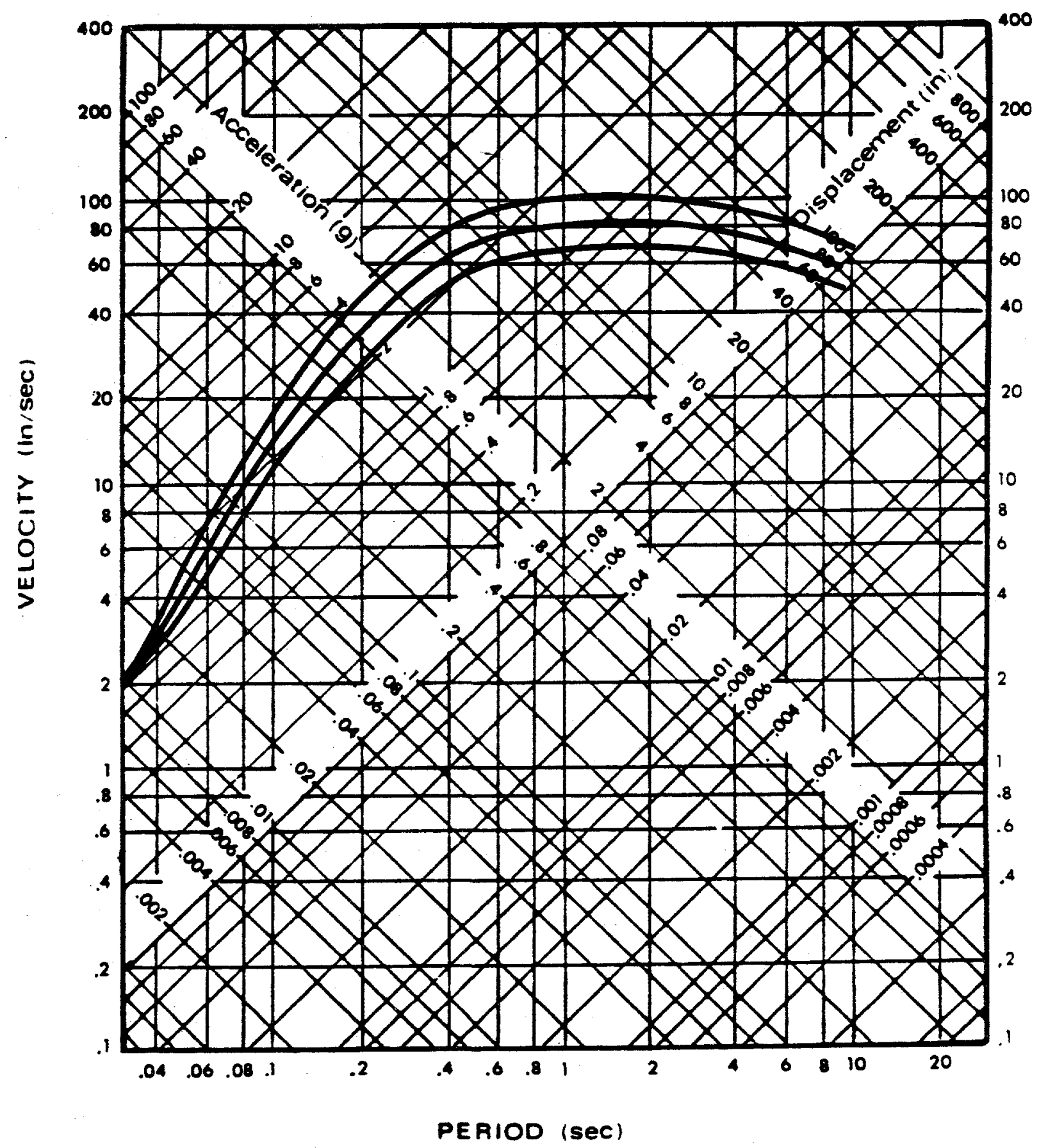

Design Response Spectrum Scaled to $1.0 \mathrm{~g}$ ( $2 \%, 5 \%$, and $10 \%$ of Critical Damping) Argonne National Laboratory, Illinois 


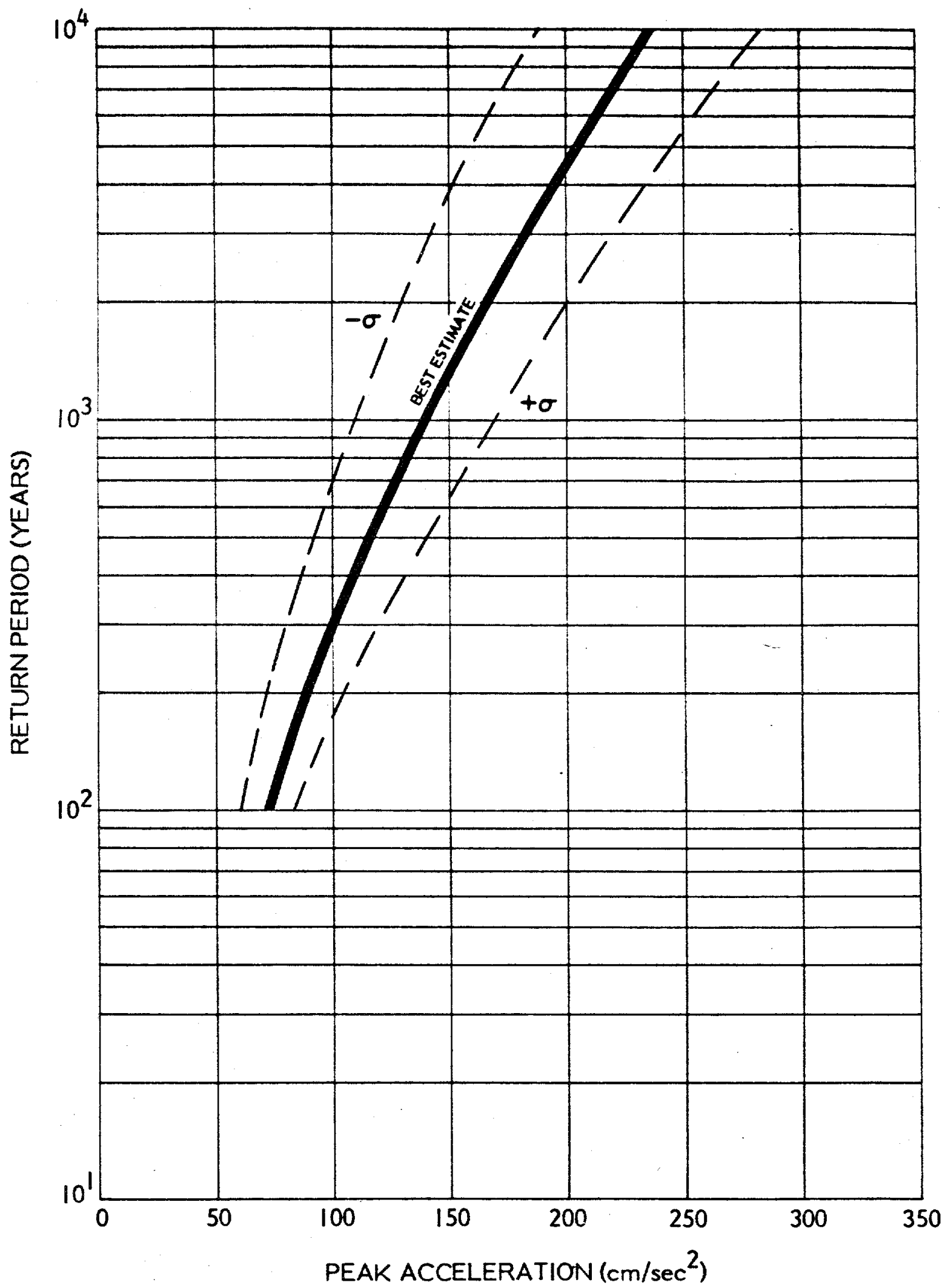

Earthquake Hazard at the Argonne National Laboratory, Idaho 


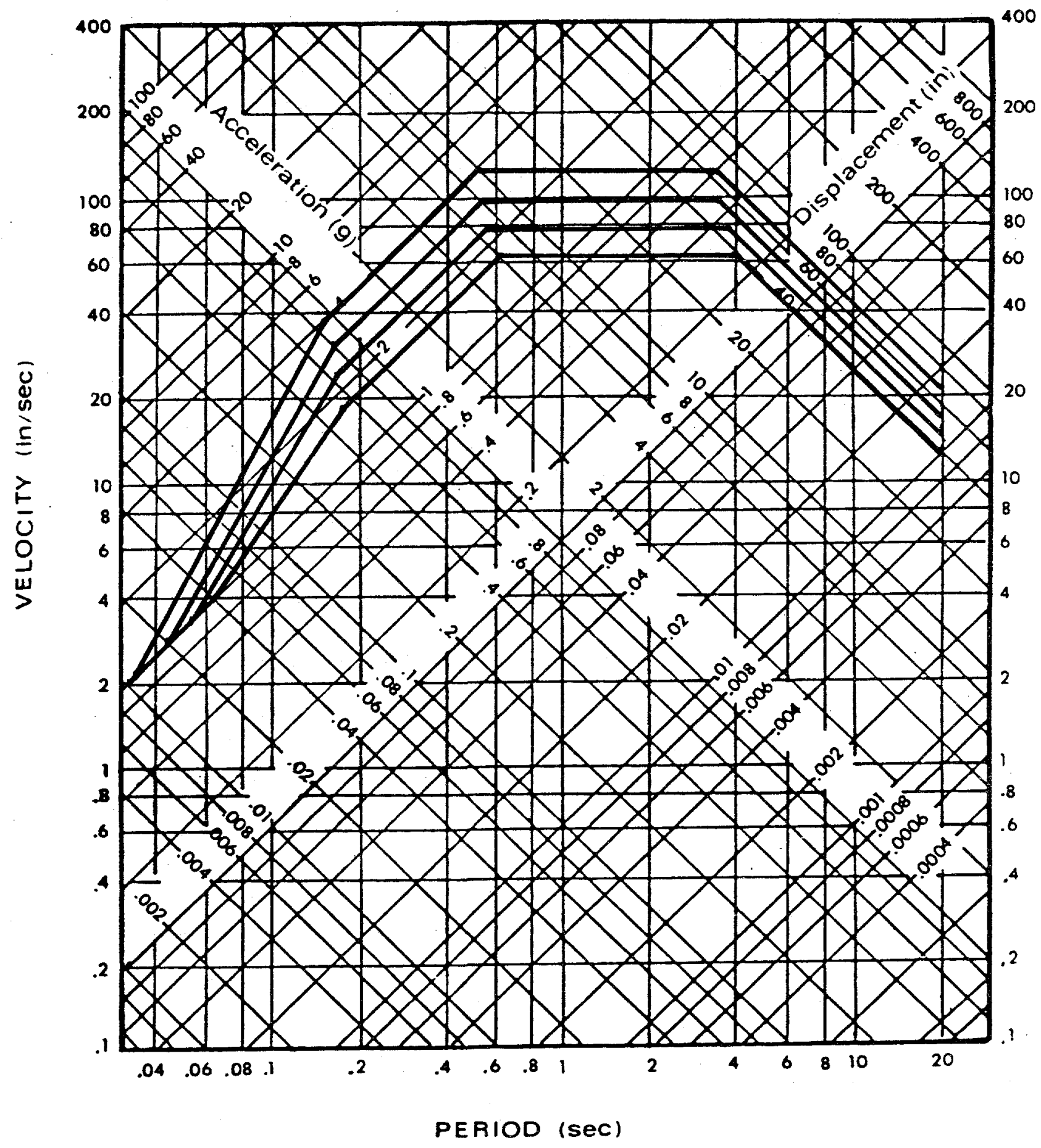

Design Response Spectrum Scaled to $1.0 \mathrm{~g}$ ( $0.5 \%, 2 \%, 5 \%$, and $10 \%$ of Critical Damping) Argonne Nationa1 Laboratory, Idaho 


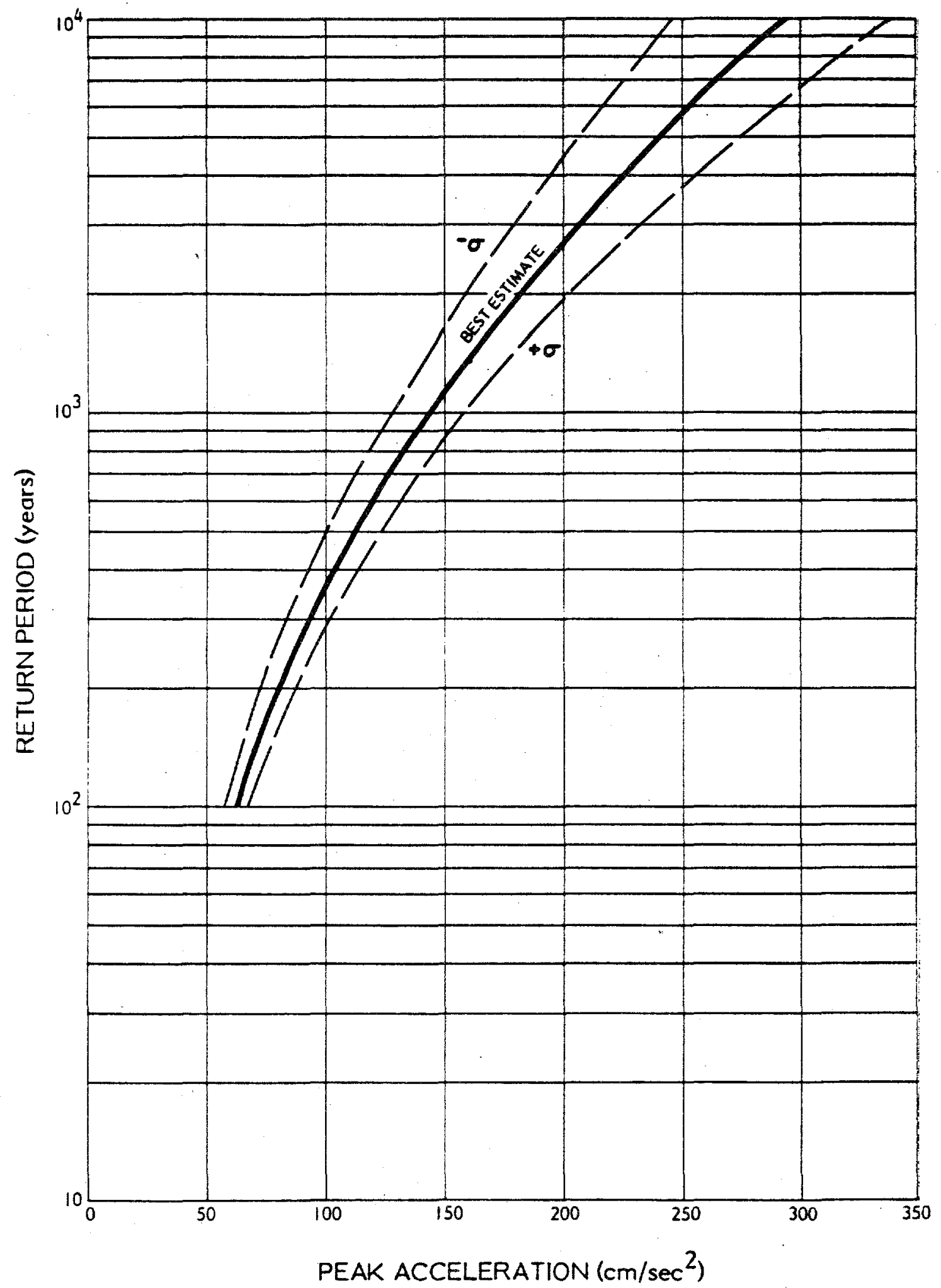

Earthquake Hazard at the Brookhaven National Laboratory, New York 


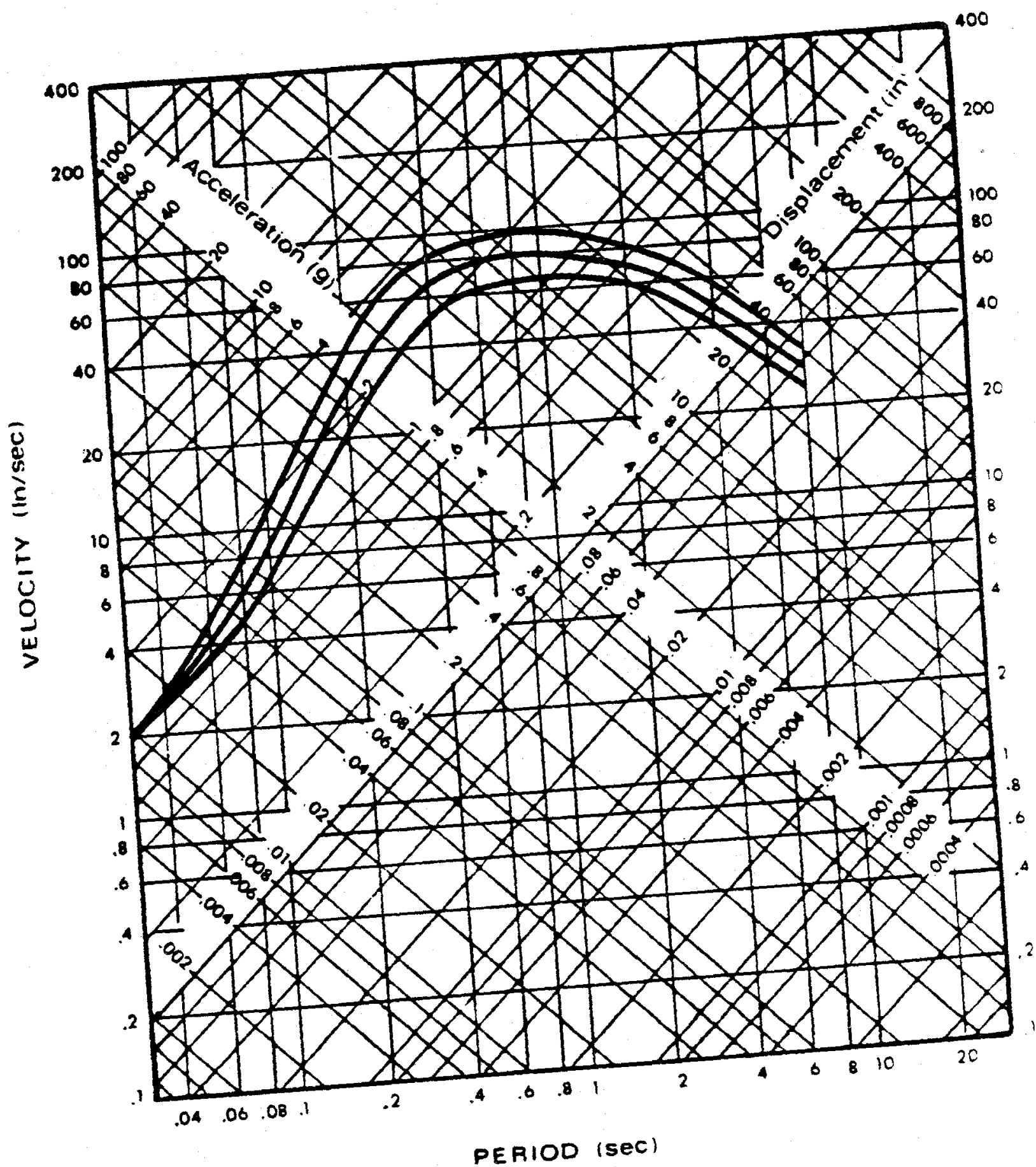

Design Response Spectrum Scaled to $1.0 \mathrm{~g}$

( $2 \%, 5 \%$, and $10 \%$ of Critical Damping)

Brookhaven Nationa1 Laboratory, New York 


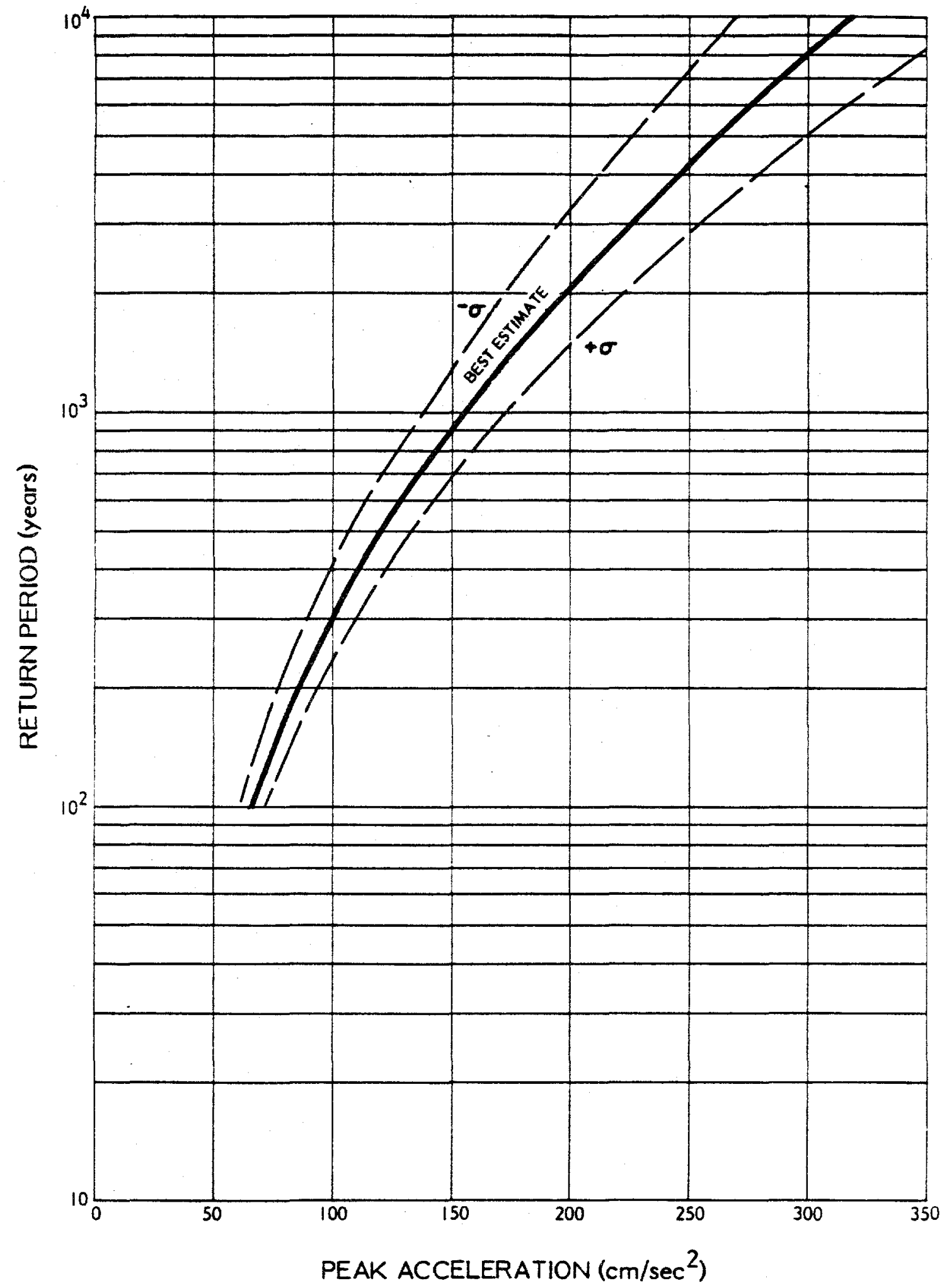

Earthquake Hazard at the Princeton Plasma Physics Laboratory, New Jersey 


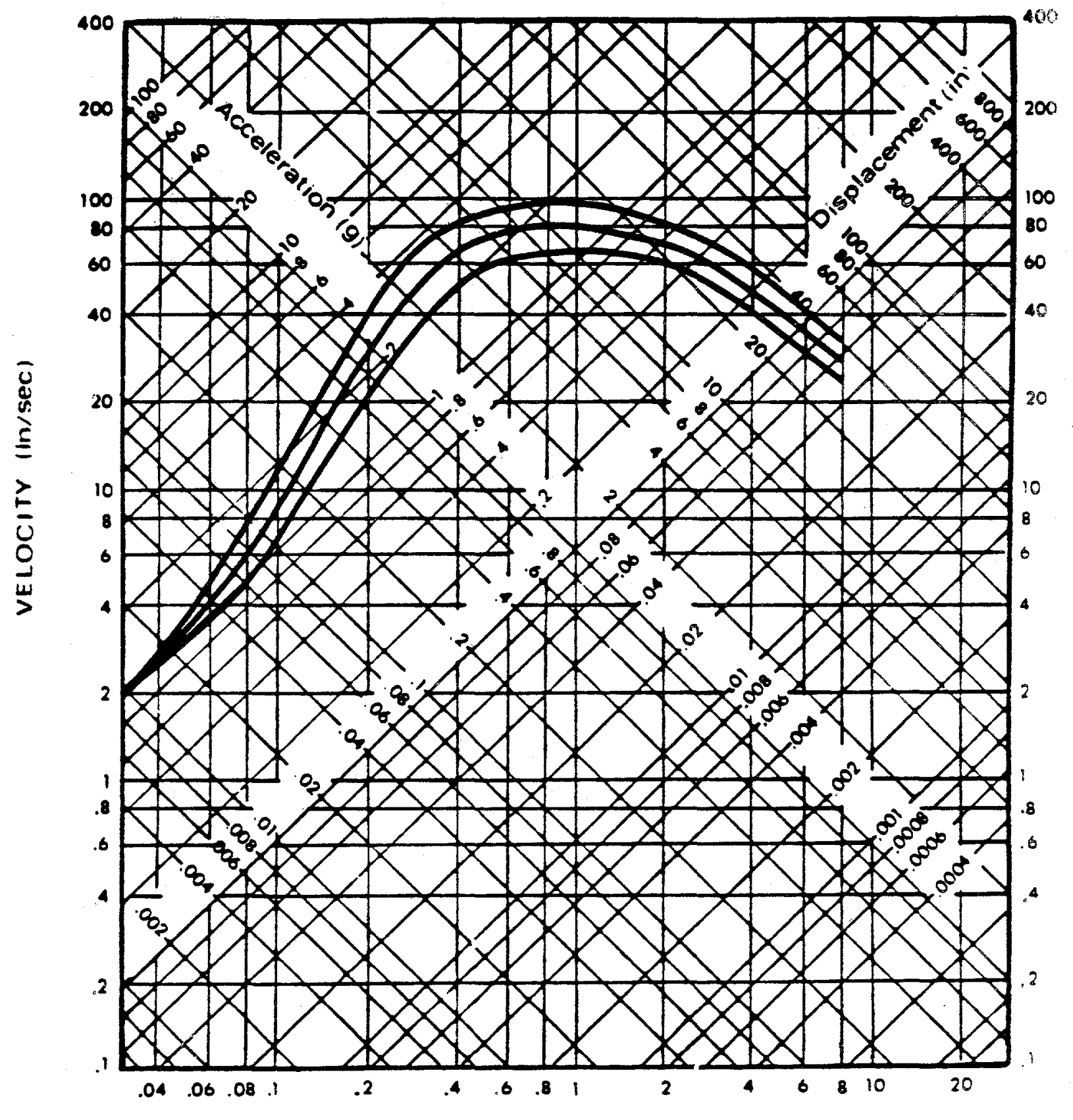

PERIOD (sec)

Design Response Spectrum Scaled to $1.0 \mathrm{~g}$

( $2 \%, 5 \%$, and $10 \%$ of Critical Damping)

Princeton Plasma Physics Laboratory, New Jersey 
Idaho Field office Site

Earthquake Hazard Curve and Response Spectrum 


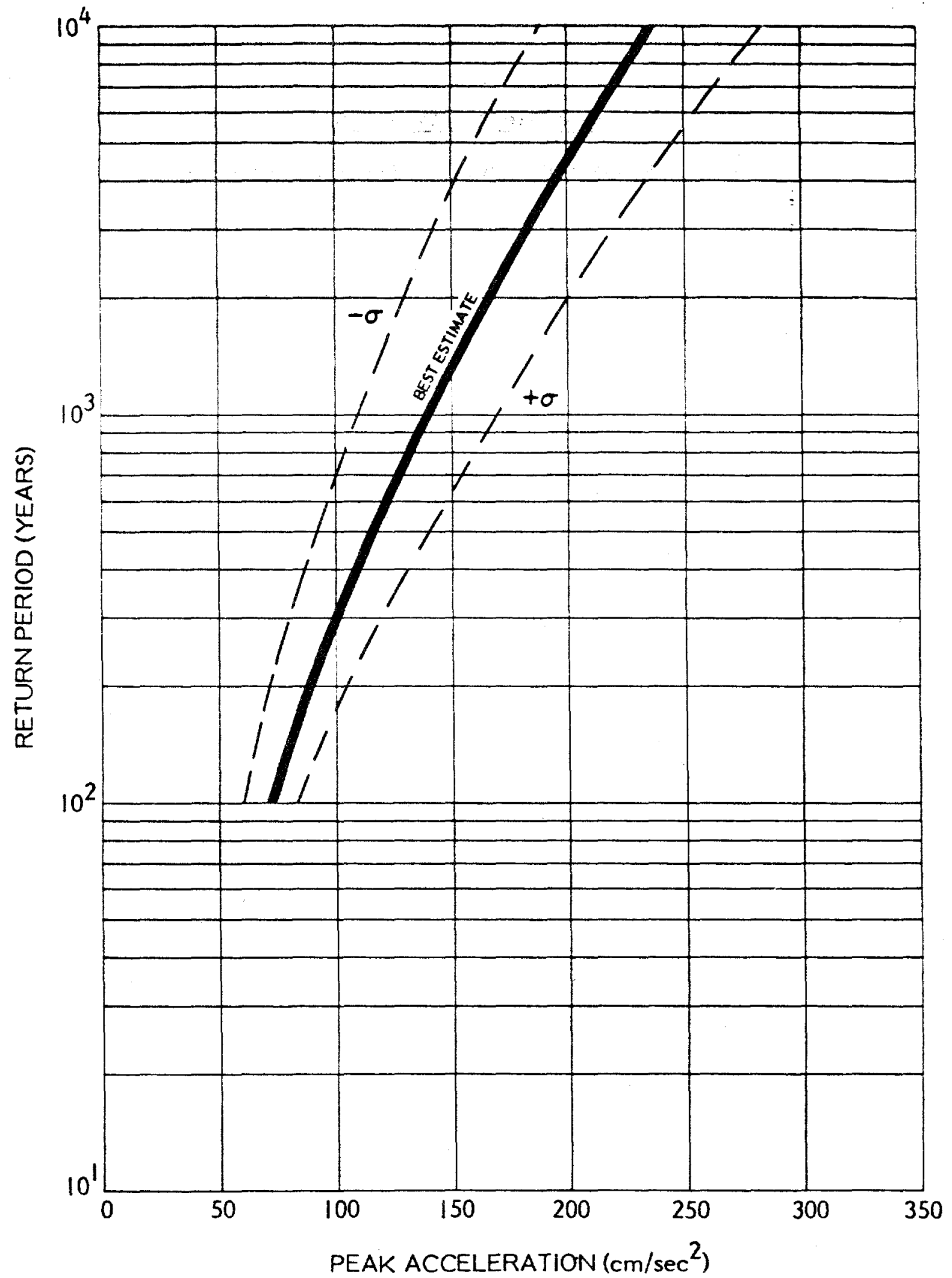

Earthquake Hazard at the Idaho National Engineering Laboratory, Idaho 


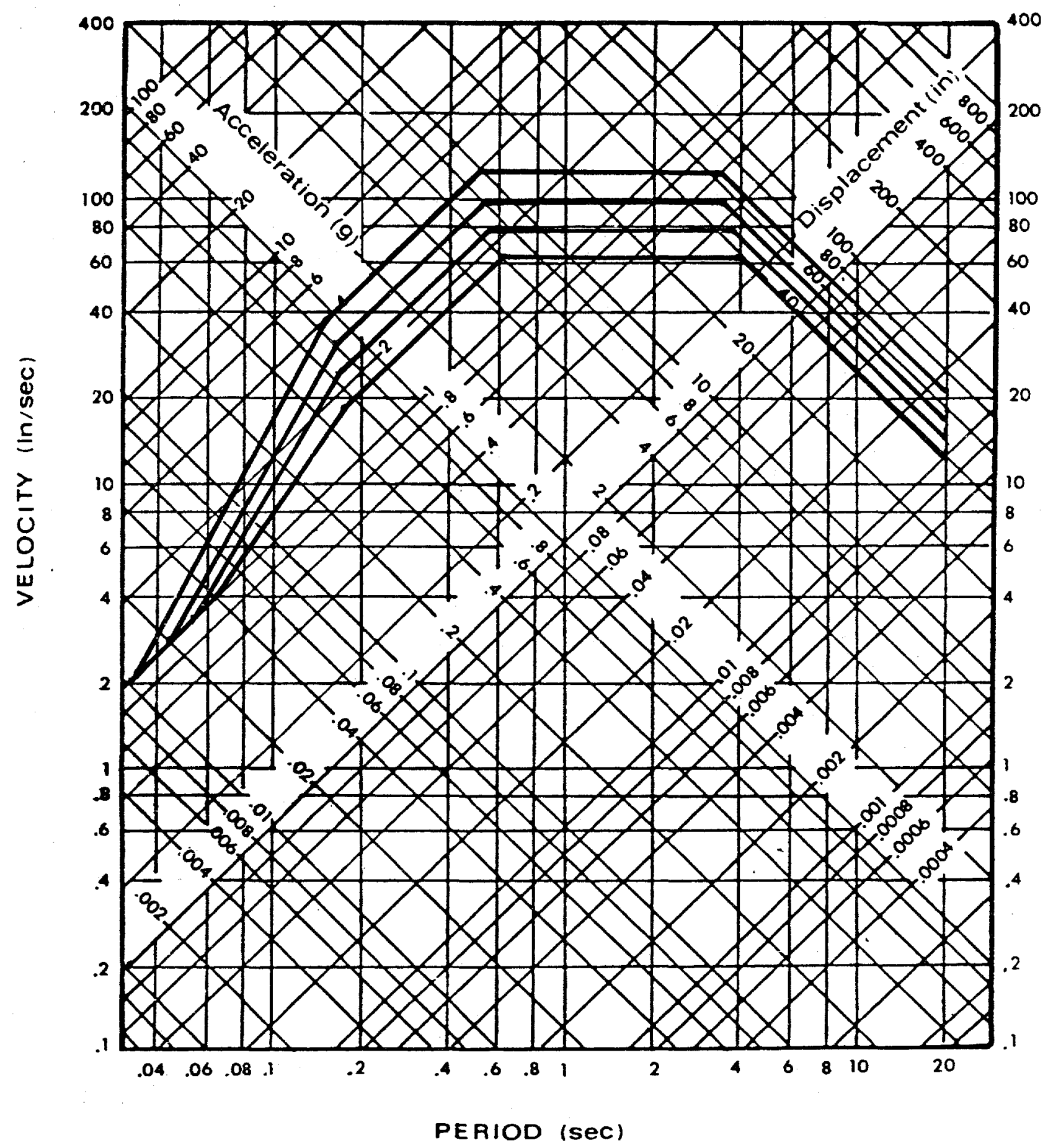

Design Response Spectrum Scaled to $1.0 \mathrm{~g}$

$(0.5 \%, 2 \%, 5 \%$, and $10 \%$ of Critica1 Damping)

Idaho National Engineering Laboratory, Idaho 


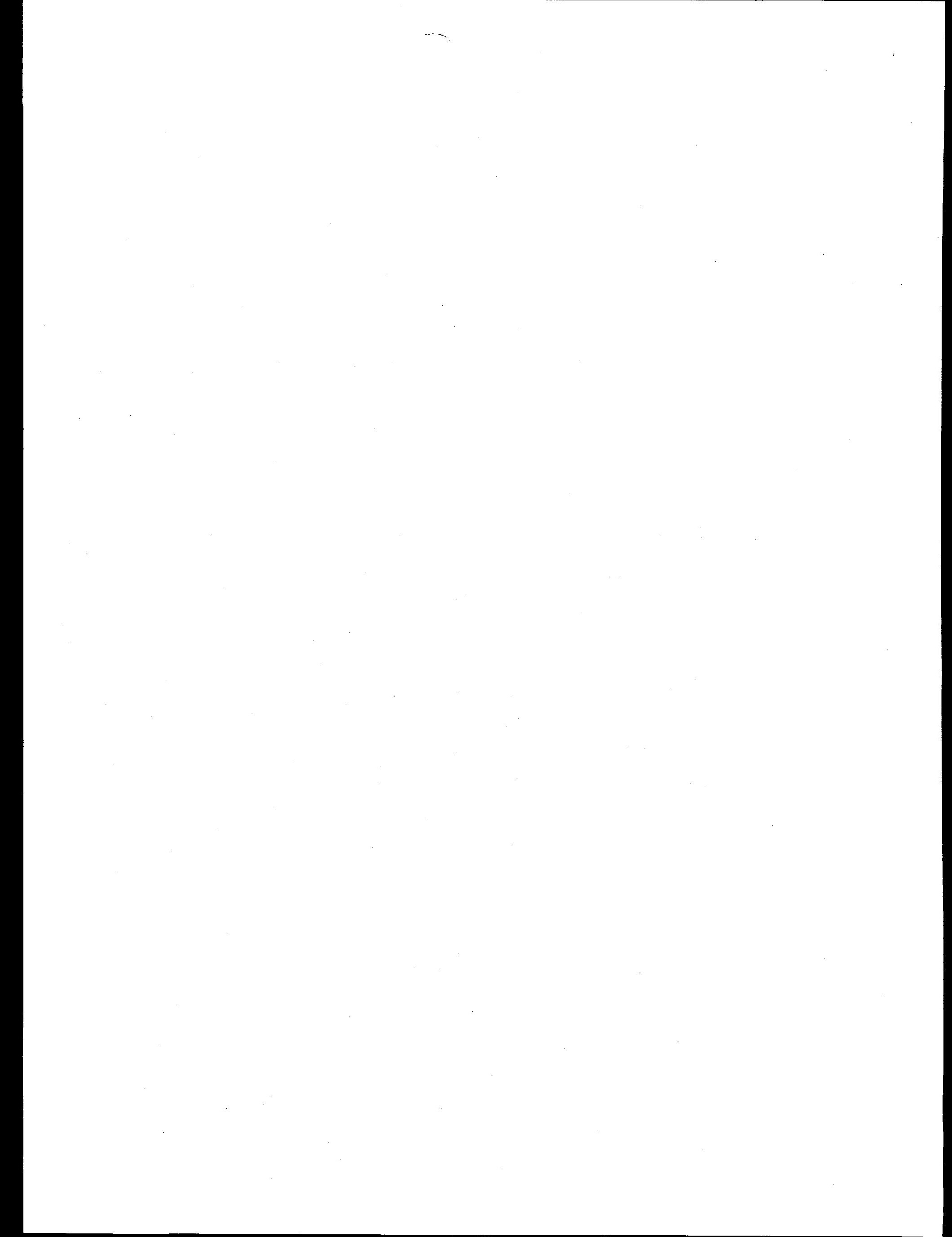


Oak Ridge Field Office Sites

Earthquake Hazard Curves and Response Spectra 


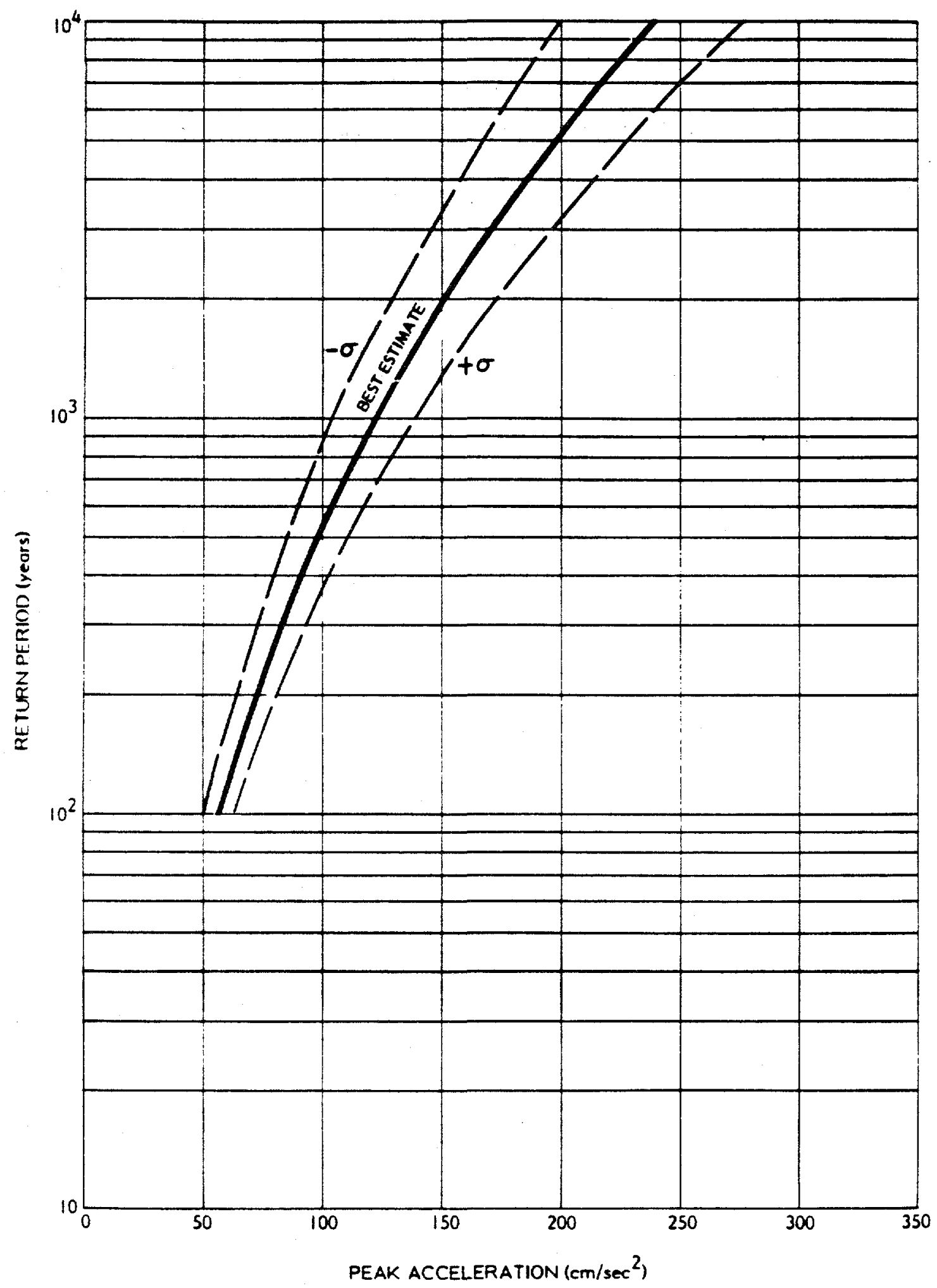

Earthquake Hazard at the Feed Materials Production Center, Ohio 


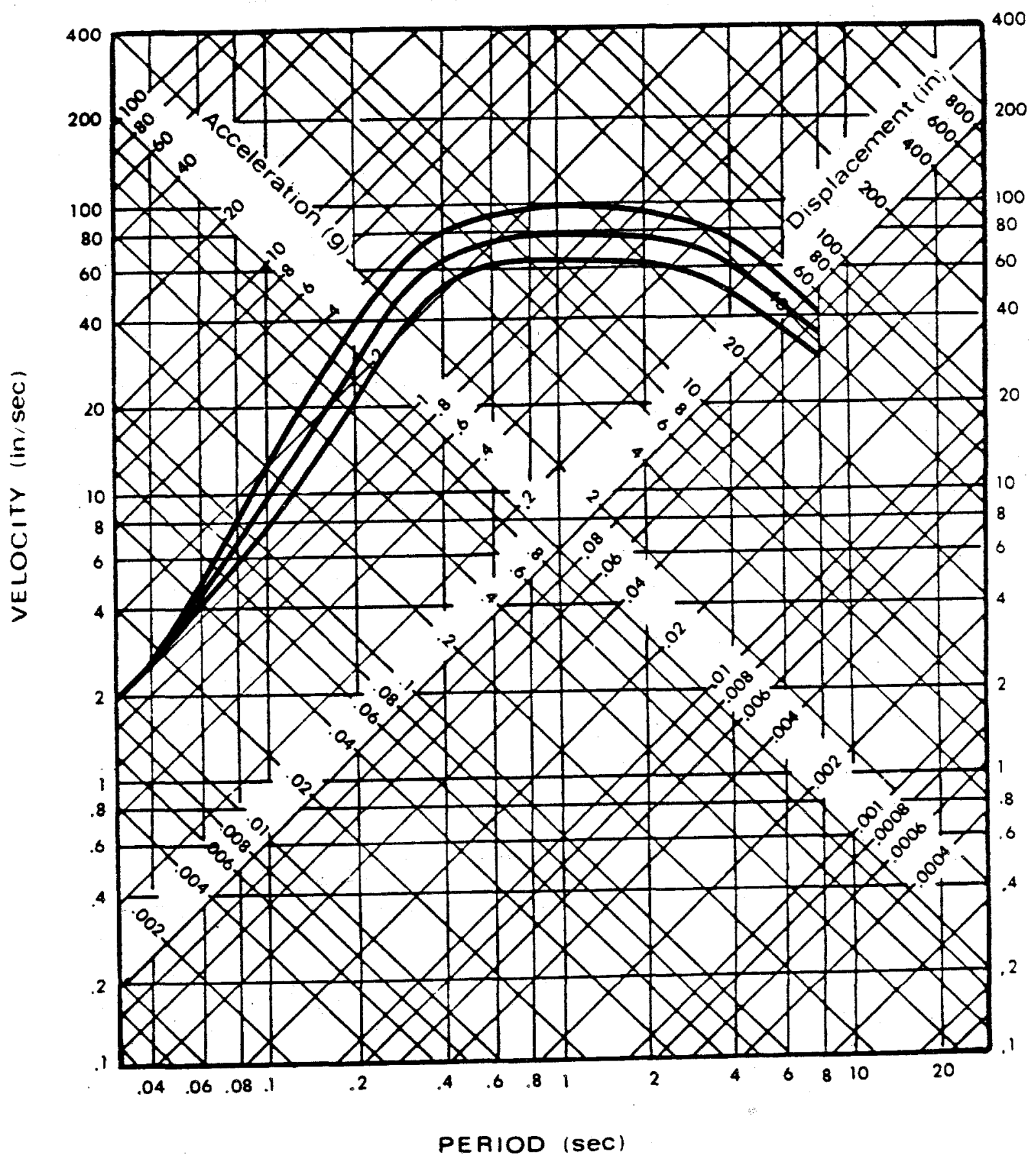

Design Response Spectrum Scaled to $1.0 \mathrm{~g}$

( $2 \%, 5 \%$, and $10 \%$ of Critical Damping)

Feed Materials Production Center, Ohio 


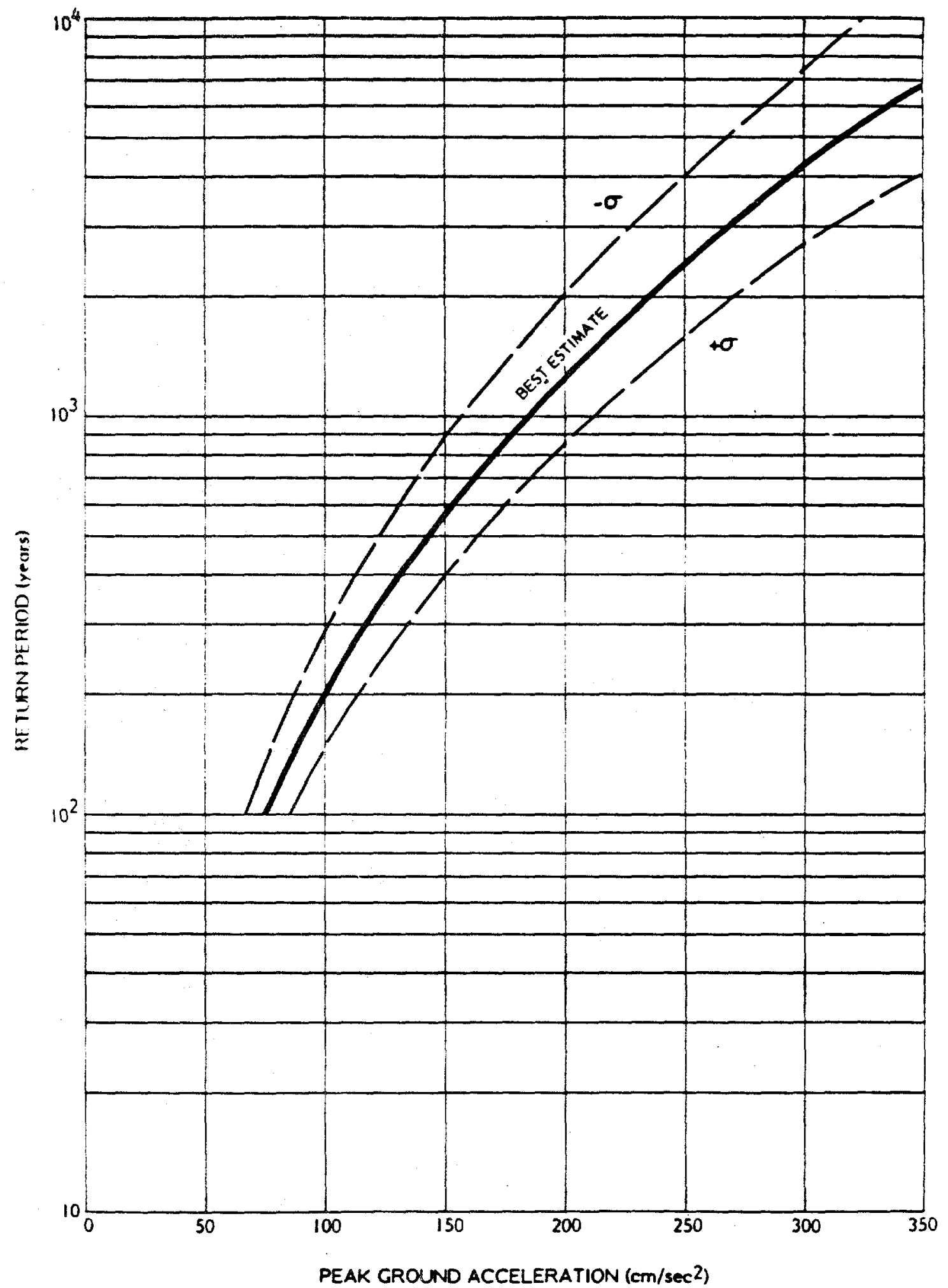

Earthquake Hazard at the Oak Ridge National Laboratory, $\mathrm{X}-10, \mathrm{~K}-25$, and $\mathrm{Y}-12$ Sites, Tennessee 


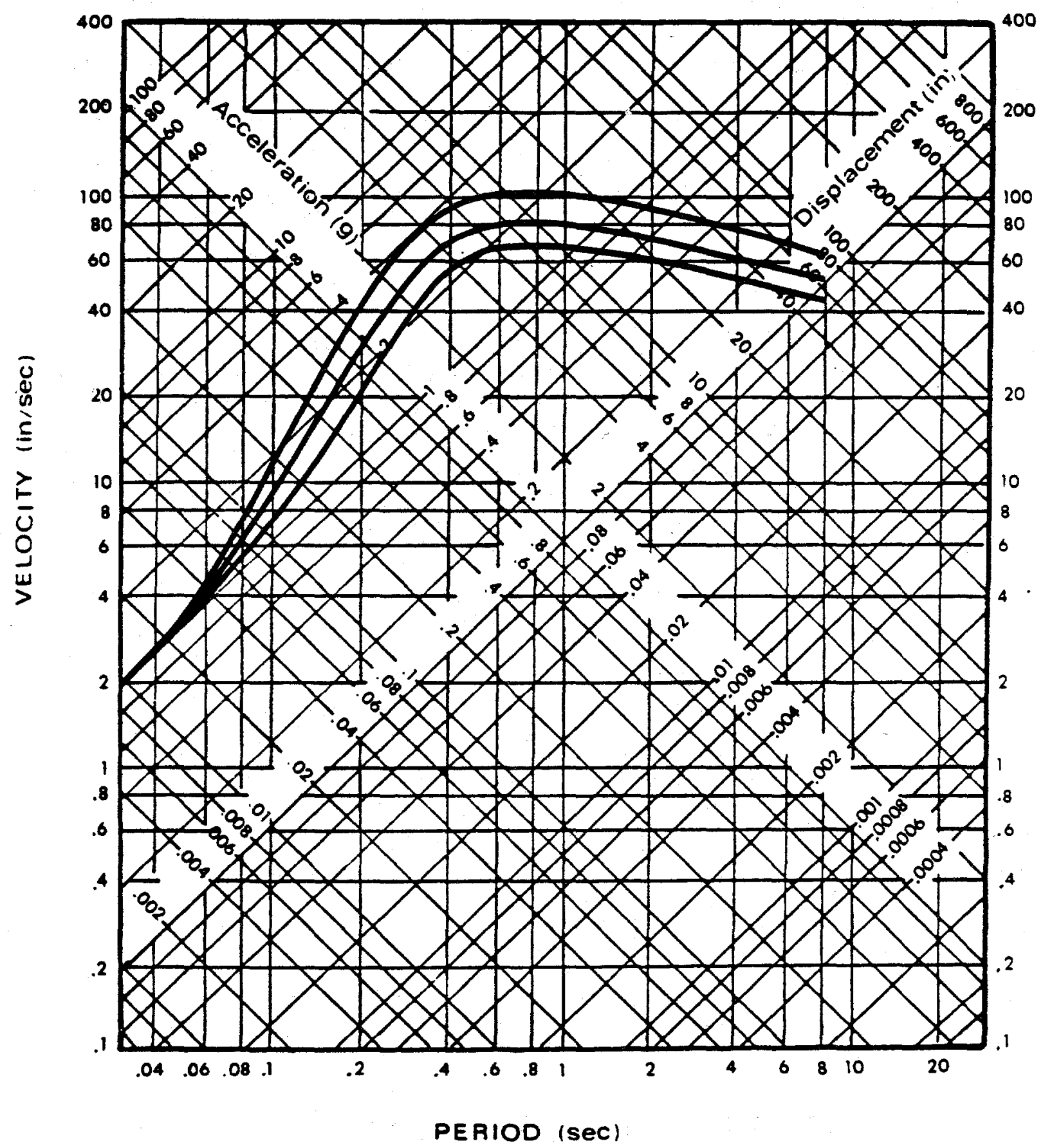

Design Response Spectrum Scaled to $1.0 \mathrm{~g}$

( $2 \%, 5 \%$, and $10 \%$ of Critical Damping)

Oak Ridge Nationa1 Laboratory, $\mathrm{X}-10, \mathrm{~K}-25$, and $\mathrm{Y}-12$ Sites, Tennessee 


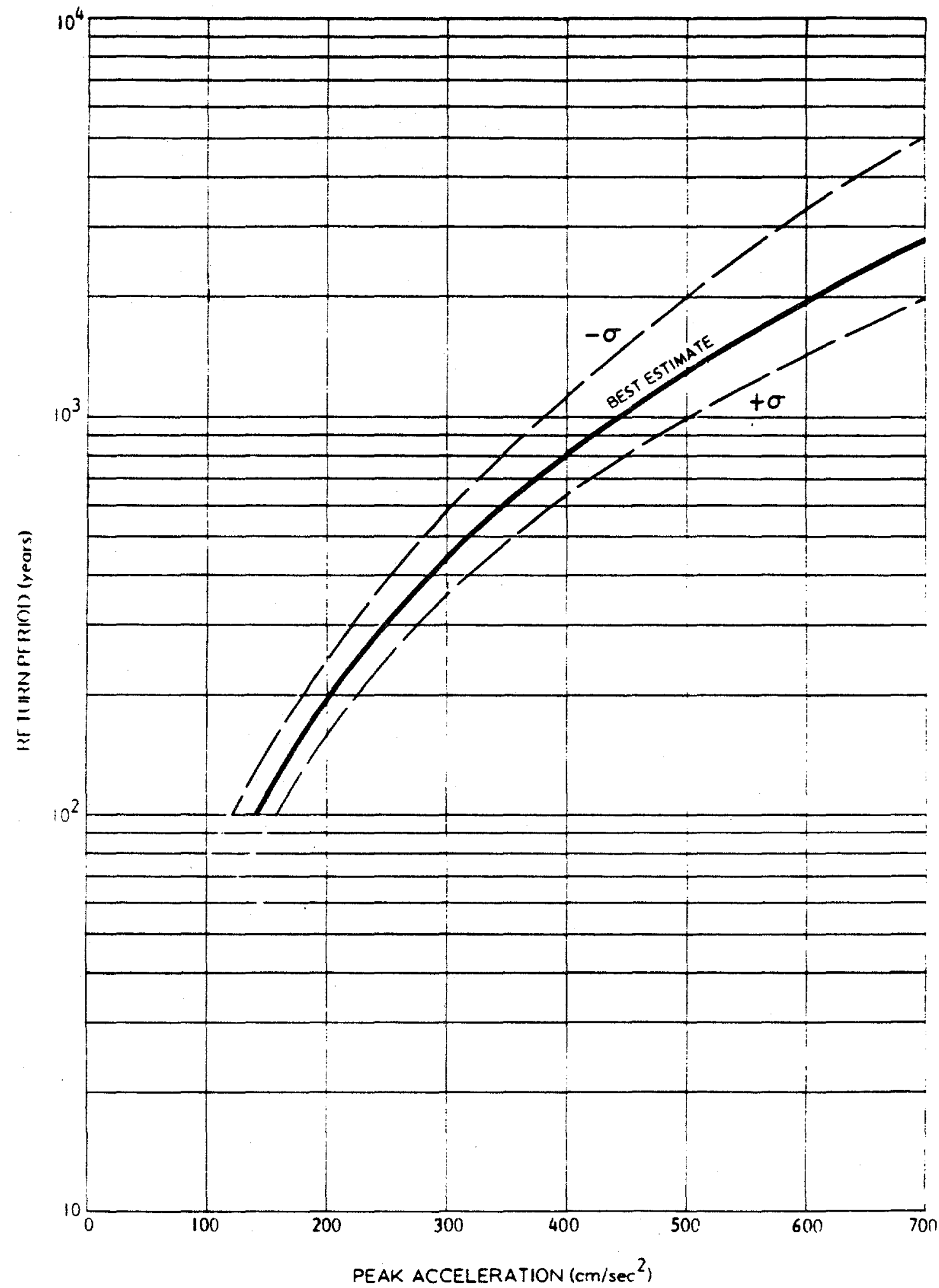

Earthquake Hazard at the Paducah Gaseous Diffusion Plant, Kentucky 


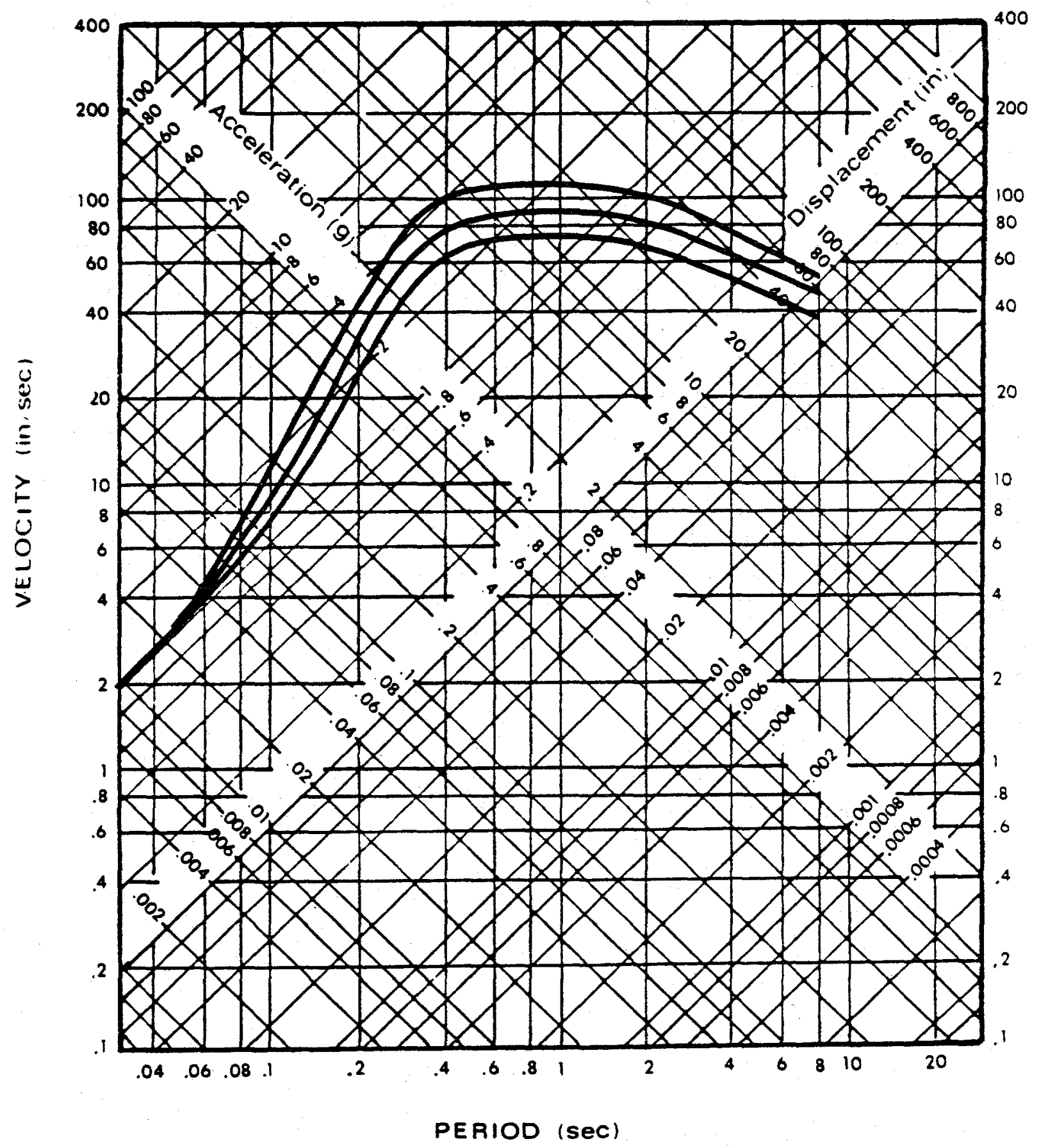

Design Response Spectrum Scaled to $1.0 \mathrm{~g}$ ( $2 \%, 5 \%$, and $10 \%$ of Critical Damping)

Paducah Gaseous Diffusion Plant, Kentucky 


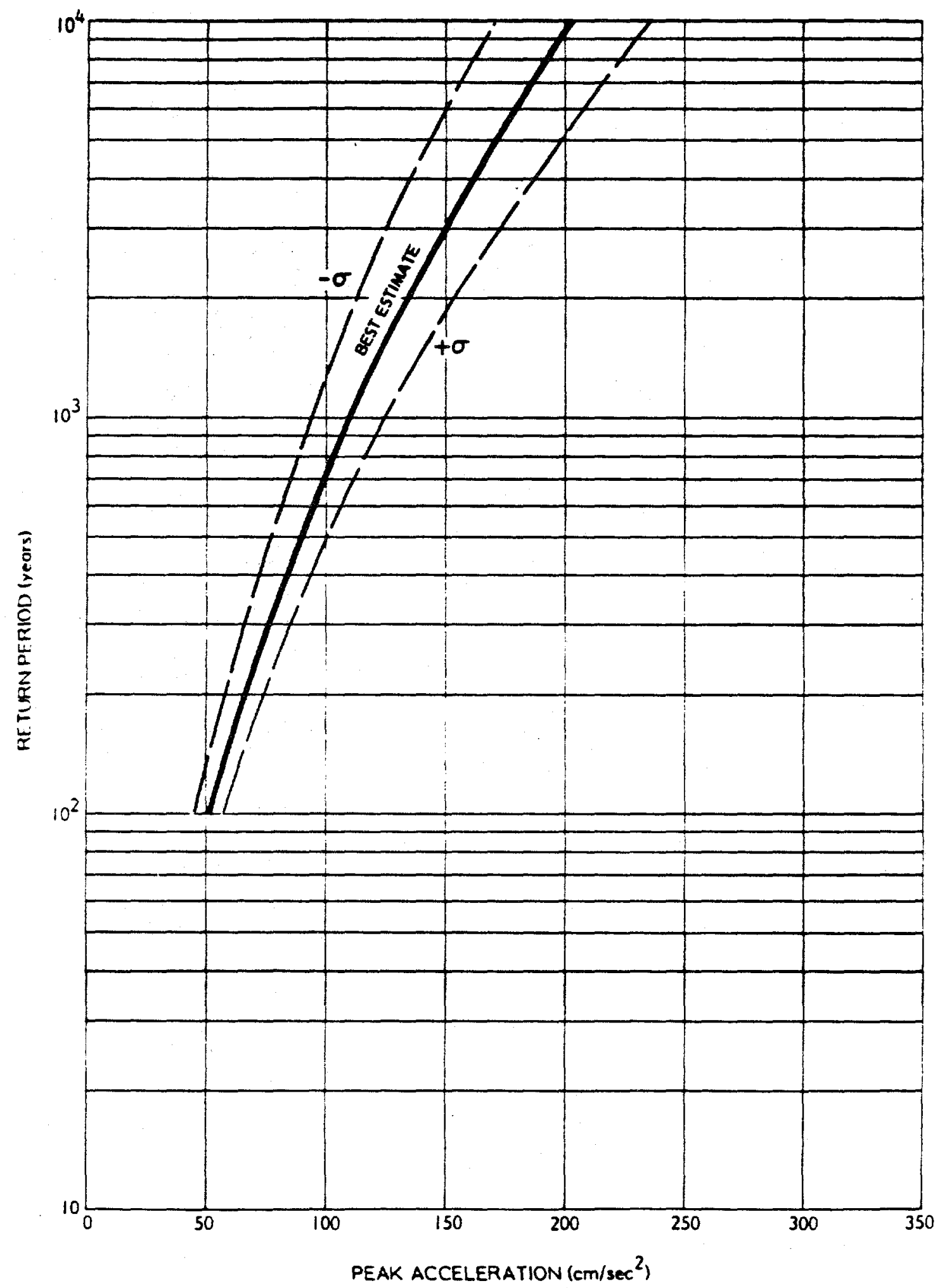

Earthquake Hazard at the Portsmouth Gaseous Diffusion Plant, Ohio 


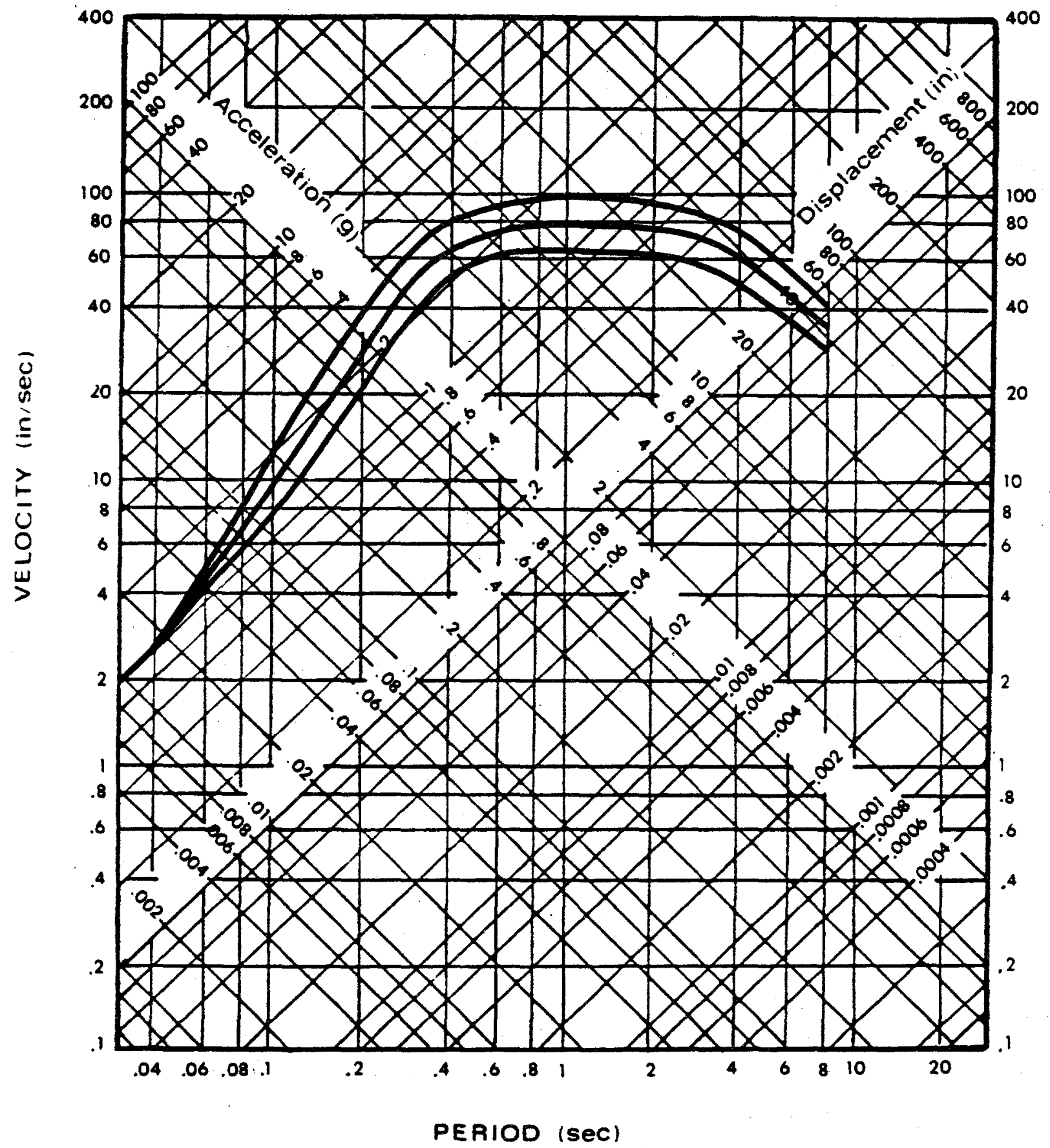

Design Response Spectrum Scaled to $1.0 \mathrm{~g}$

( $2 \%, 5 \%$, and $10 \%$ of Critical Damping)

Portsmouth Gaseous Diffusion Plant, Ohio 


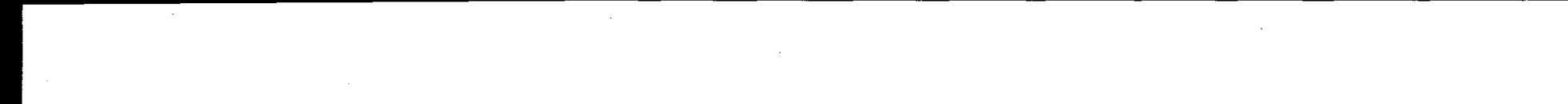


Nevada Field Office Site

Earthquake Hazard Curve and Response Spectrum

$-67-$ 


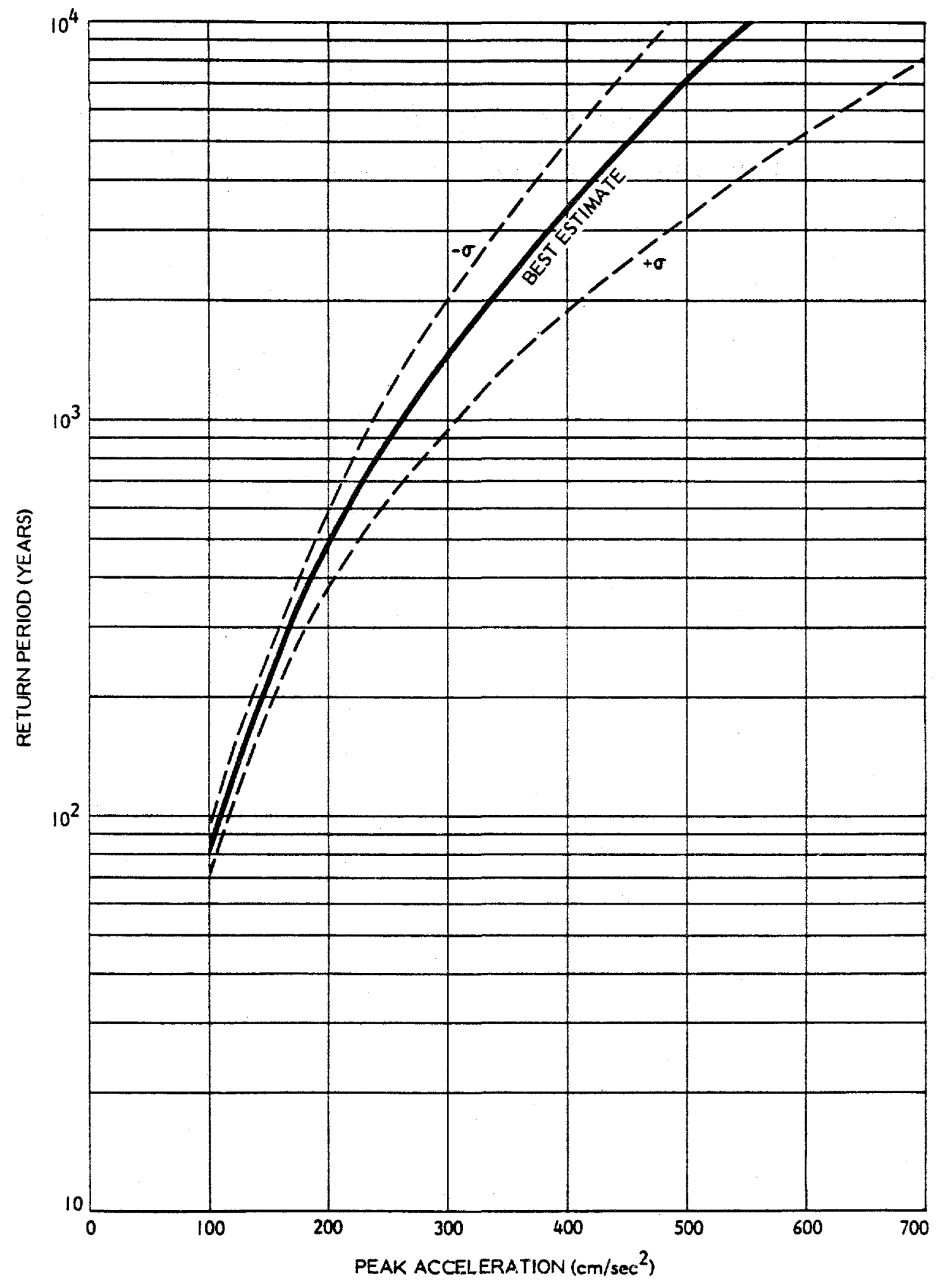

Earthquake Hazard at the Nevada Test Site, Area 410, Nevada 


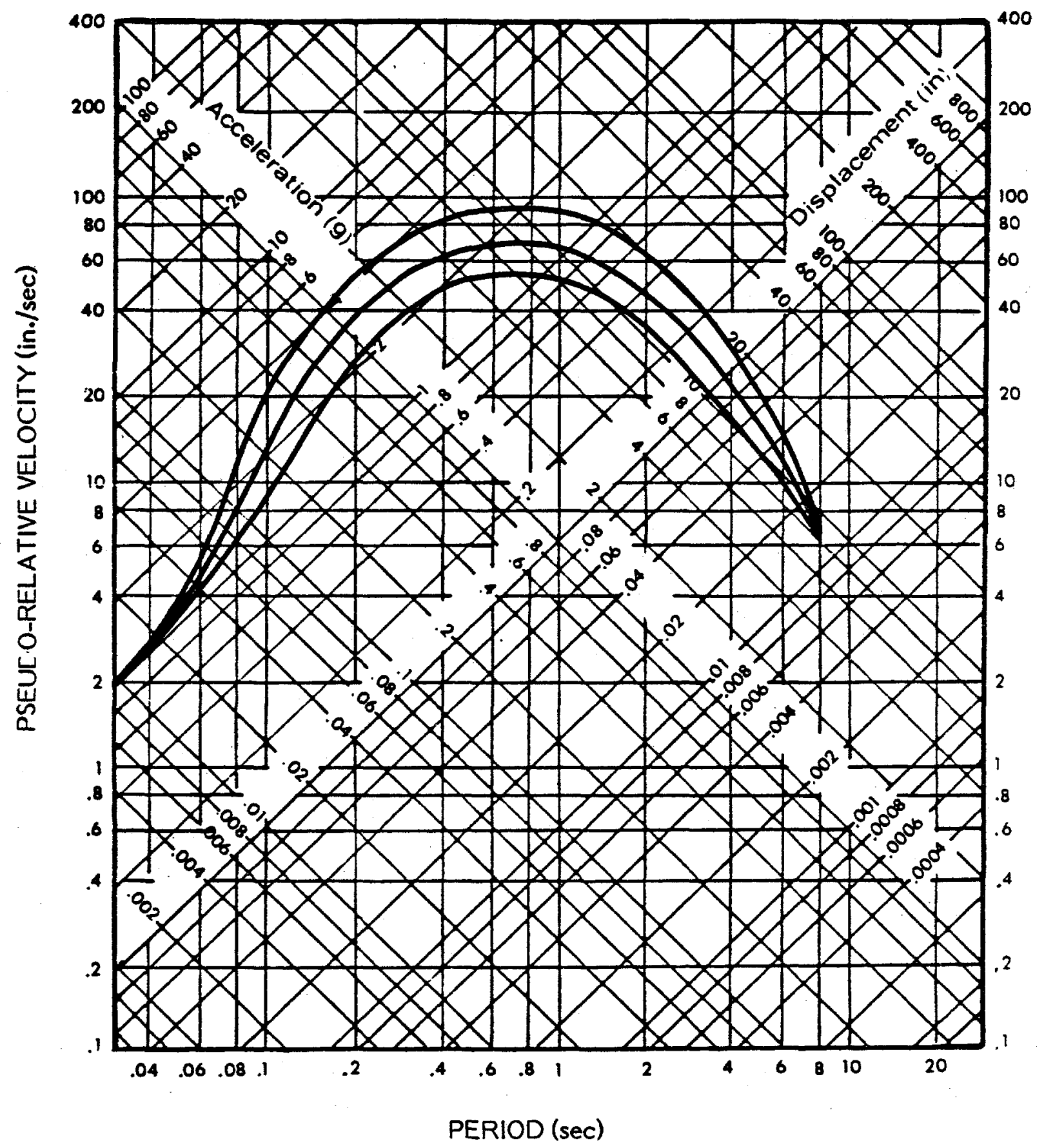

Design Response Spectrum Scaled to $1.0 \mathrm{~g}$

( $2 \%, 5 \%$, and $10 \%$ of Critical Damping)

Nevada Test Site, Area 410, Nevada 

Richland Field office Site

Earthquake Hazard Curve and Response Spectrum 


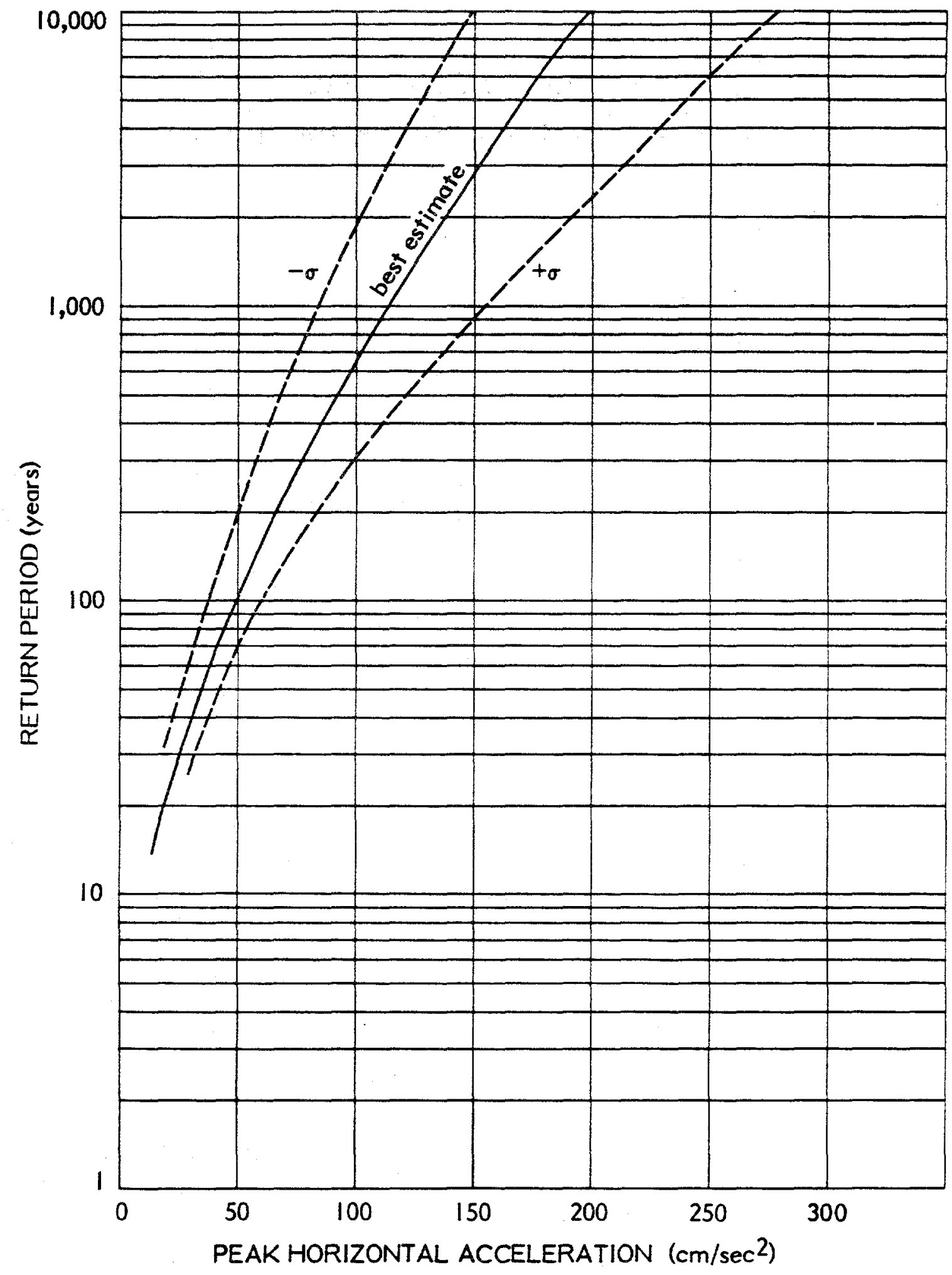

Earthquake Hazard at the Hanford Site, Washington 


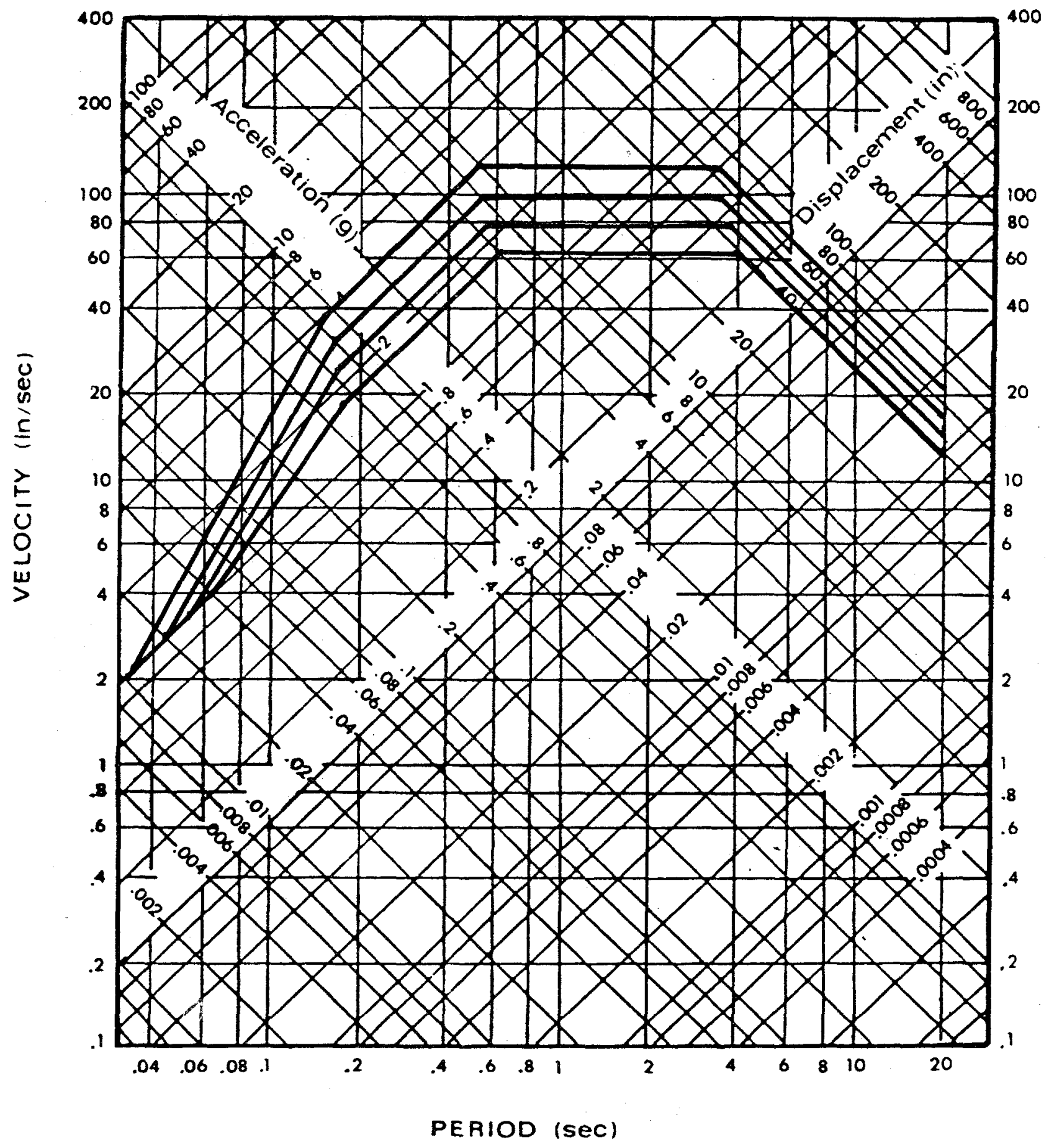

Design Response Spectrum Scaled to $1.0 \mathrm{~g}$

$(0.5 \%, 2 \%, 5 \%$, and $10 \%$ of Critical Damping)

Hanford Site, Washington 

San Francisco Field Office Sites

Earthquake Hazard Curves and Response Spectra 


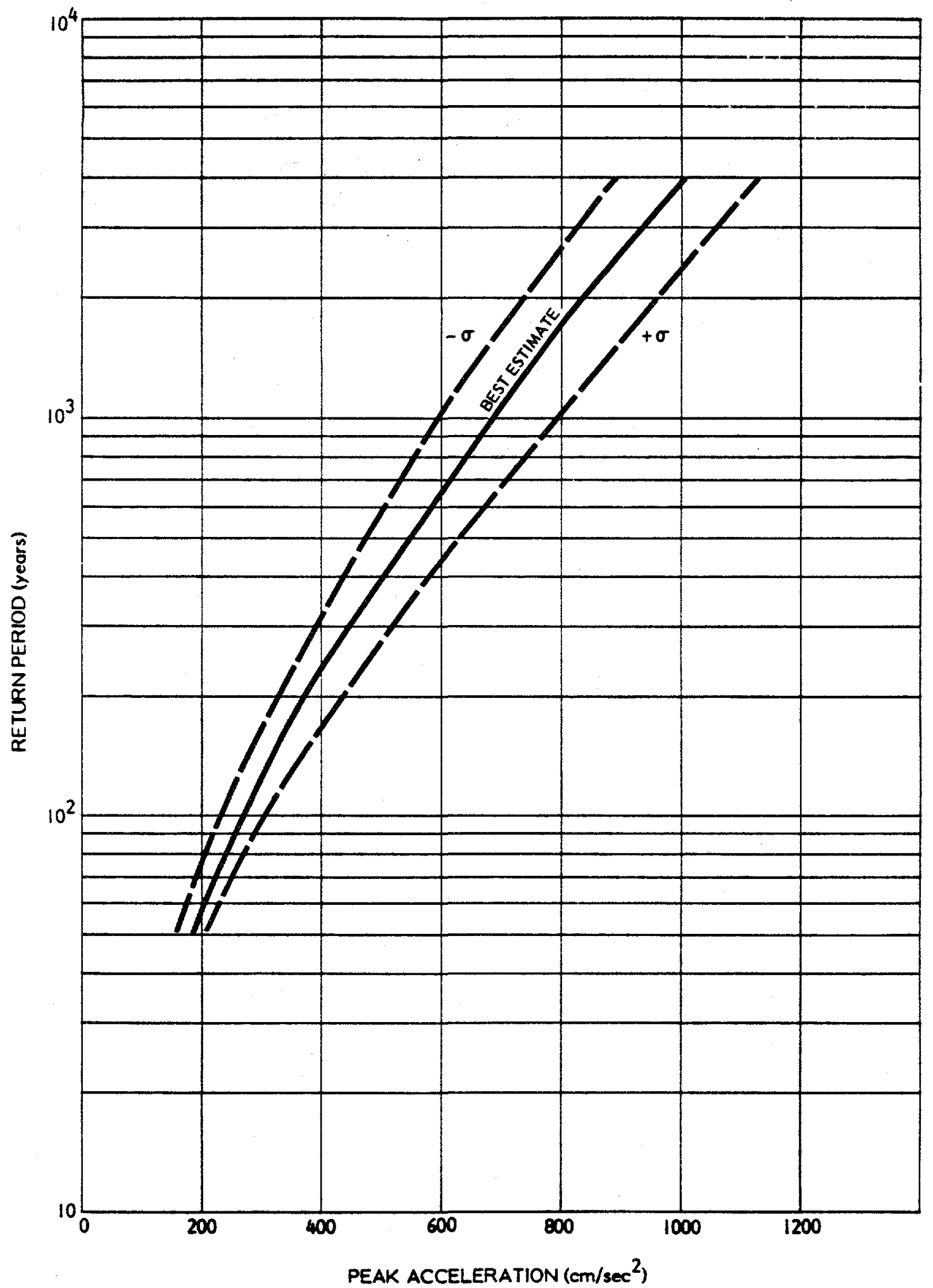

Earthquake Hazard at the Lawrence Berkeley Laboratory, California 


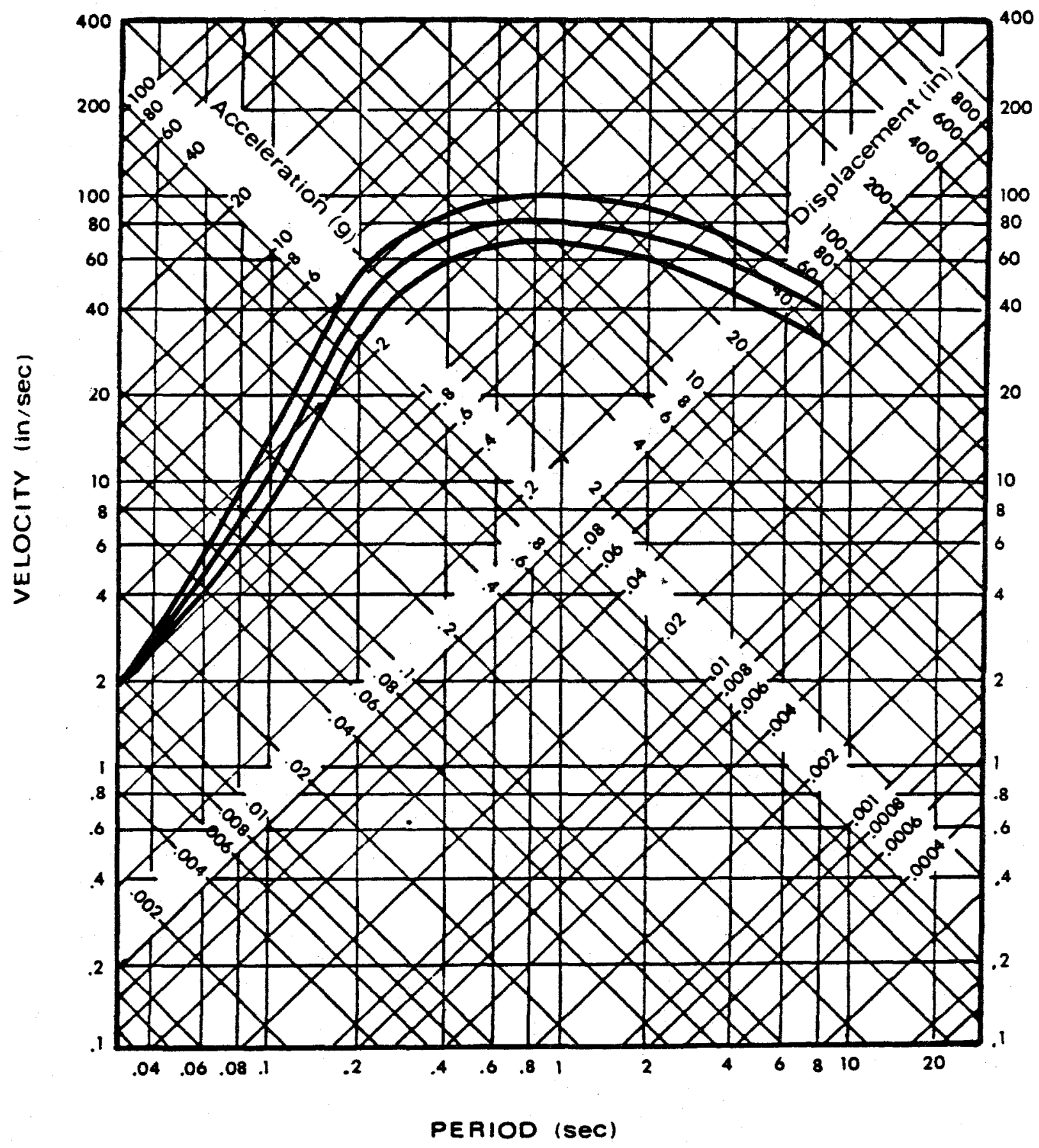

Design Response Spectrum Scaled to $1.0 \mathrm{~g}$

( $2 \%, 5 \%$, and $10 \%$ of Critical Damping)

Lawrence Berkeley Laboratory, California 


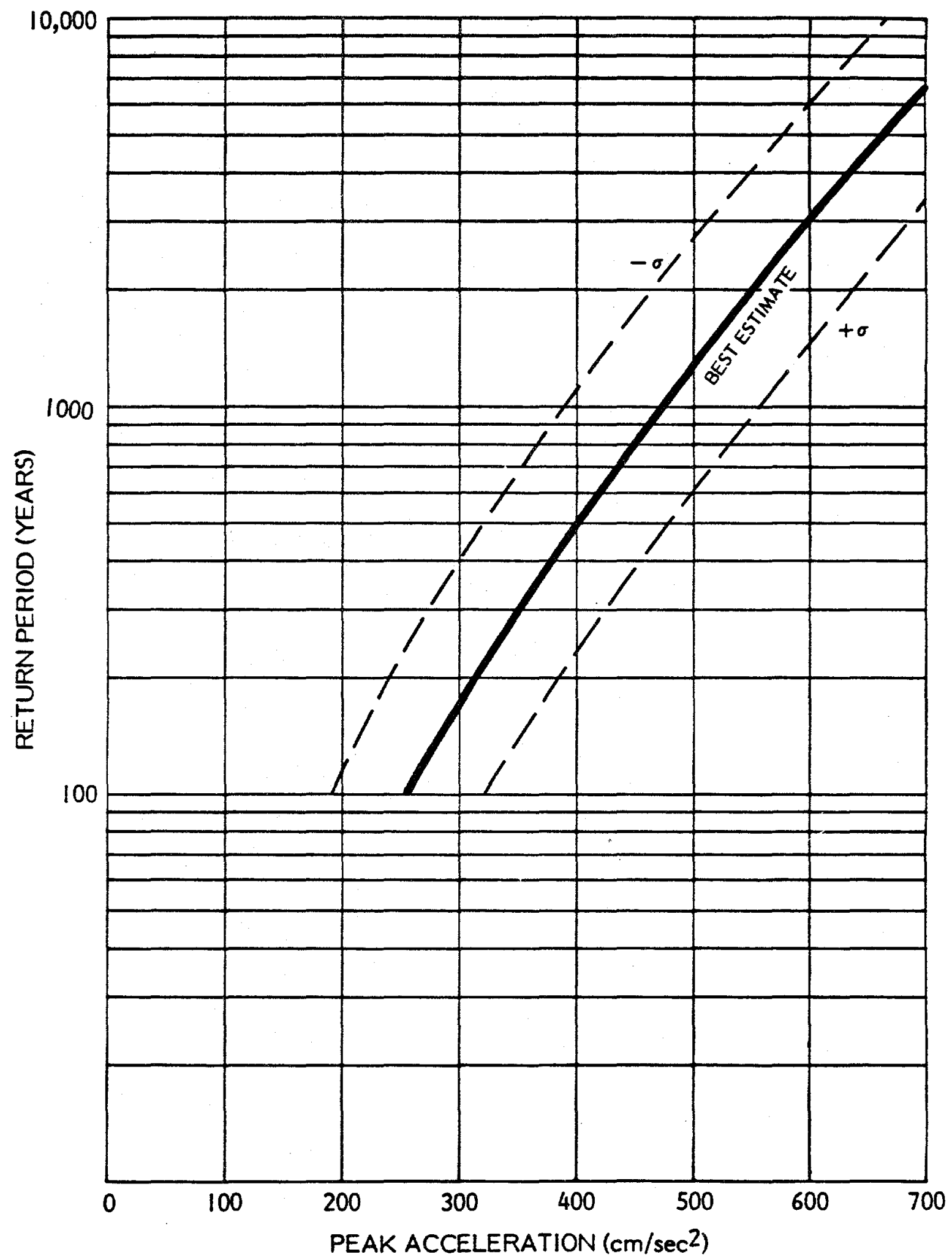

Earthquake Hazard at the Lawrence Livermore National Laboratory, Livermore Site, California 


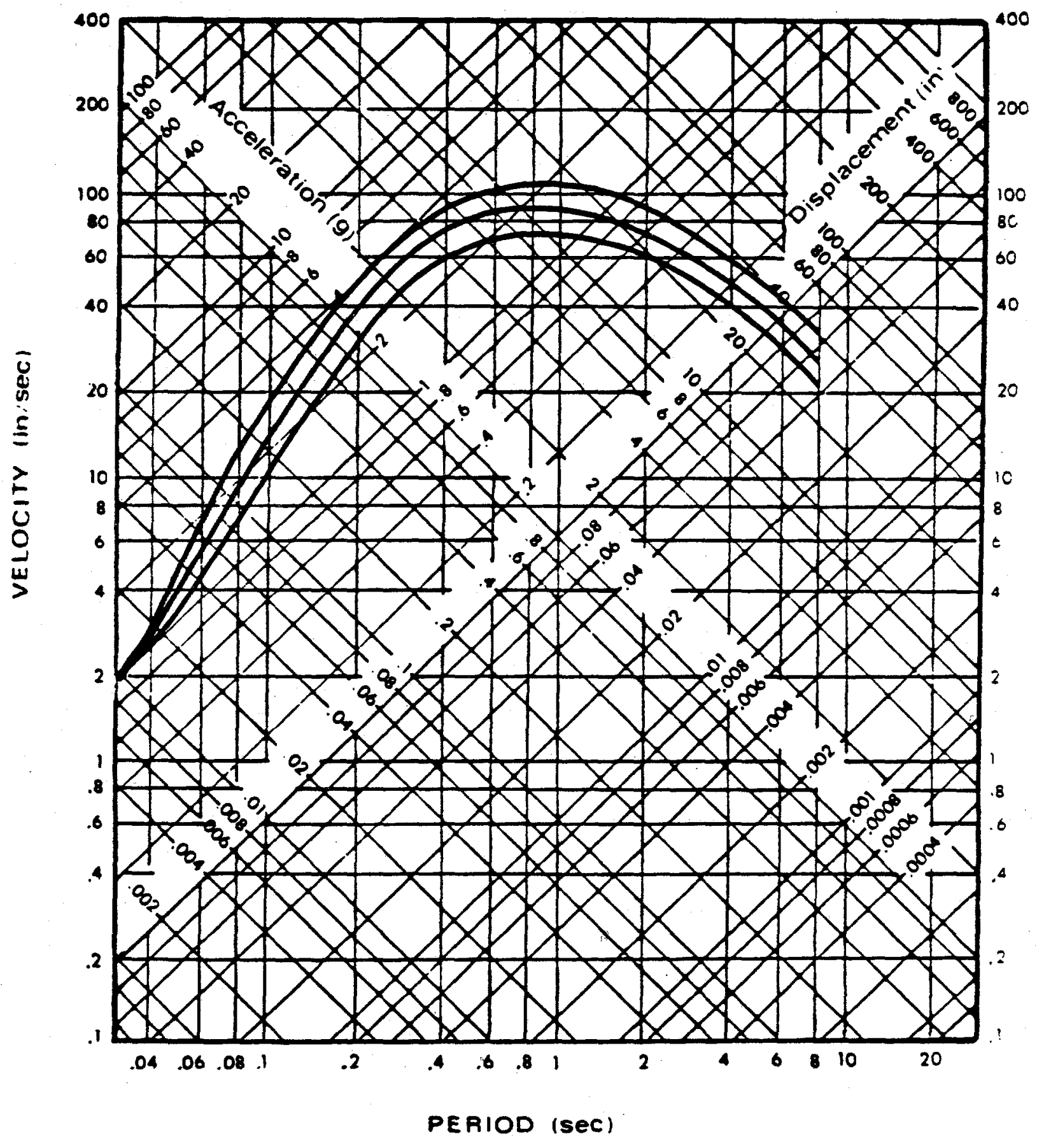

Design Response Spectrum Scaled to $1.0 \mathrm{~g}$ ( $2 \%, 5 \%$, and $10 \%$ of Critical Damping)

Lawrence Livermore National Laboratory, Livermore Site, California 


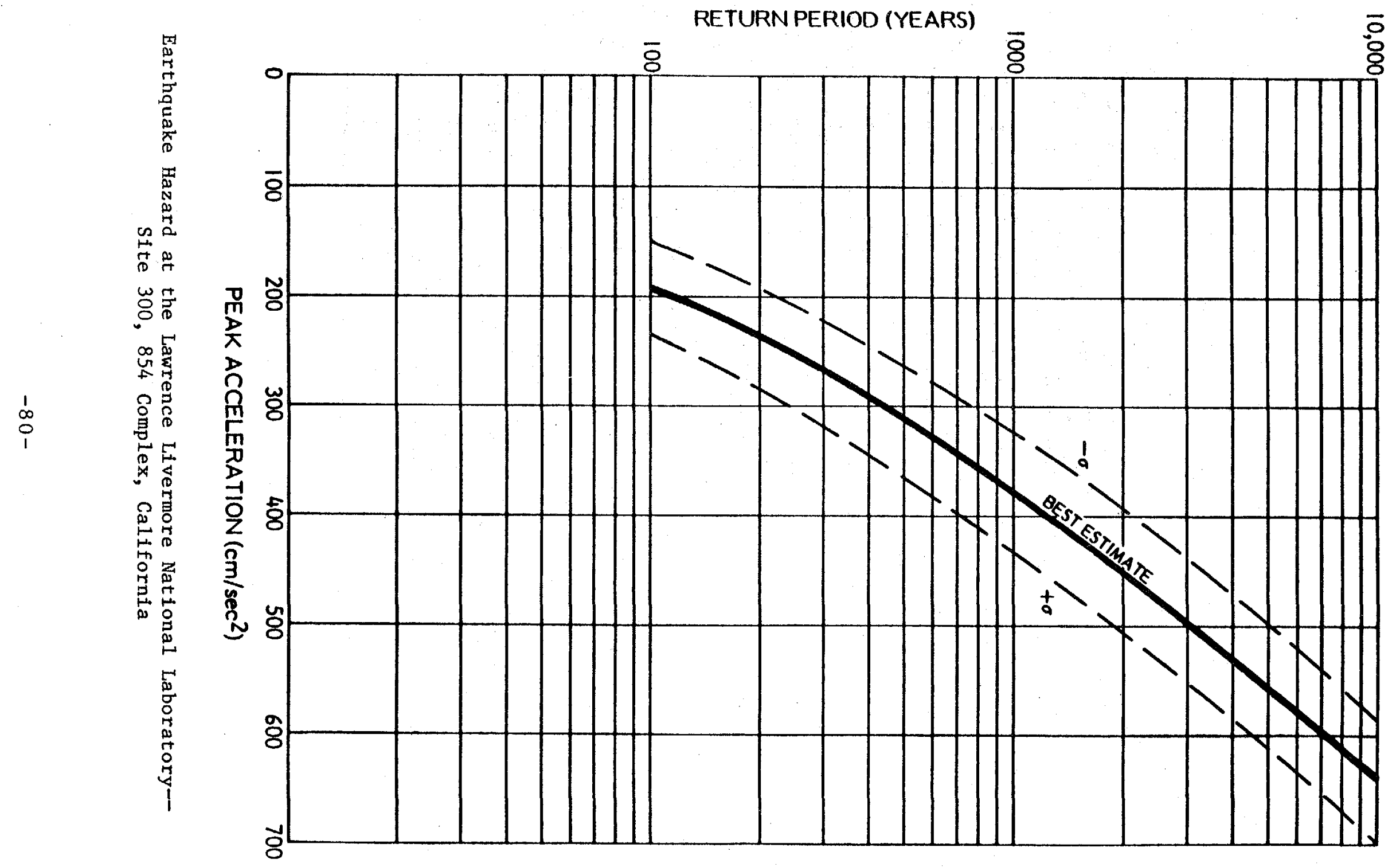




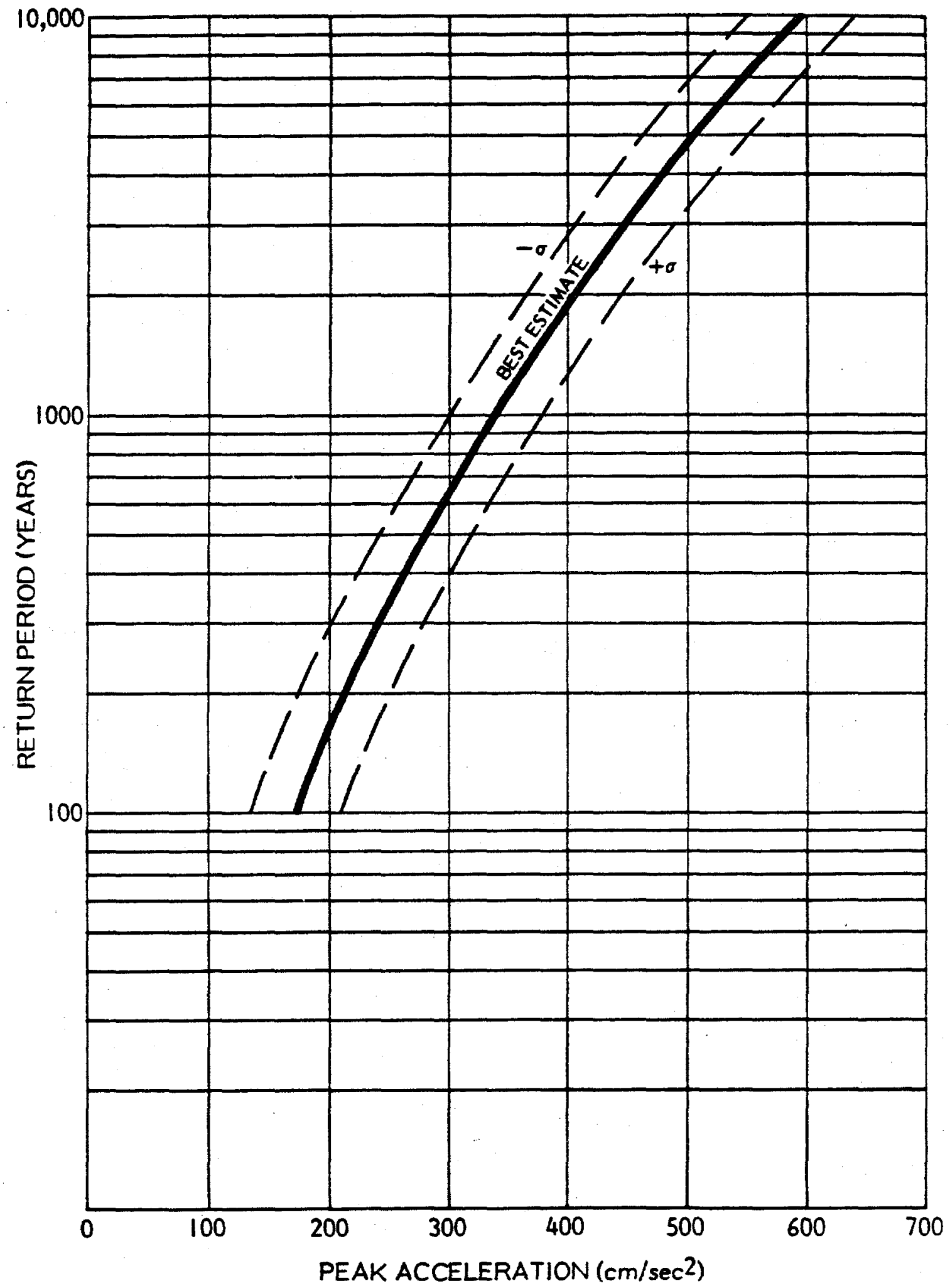

Earthquake Hazard at the Lawrence Livermore National Laboratory-Site 300,834 and 836 Complex, California 


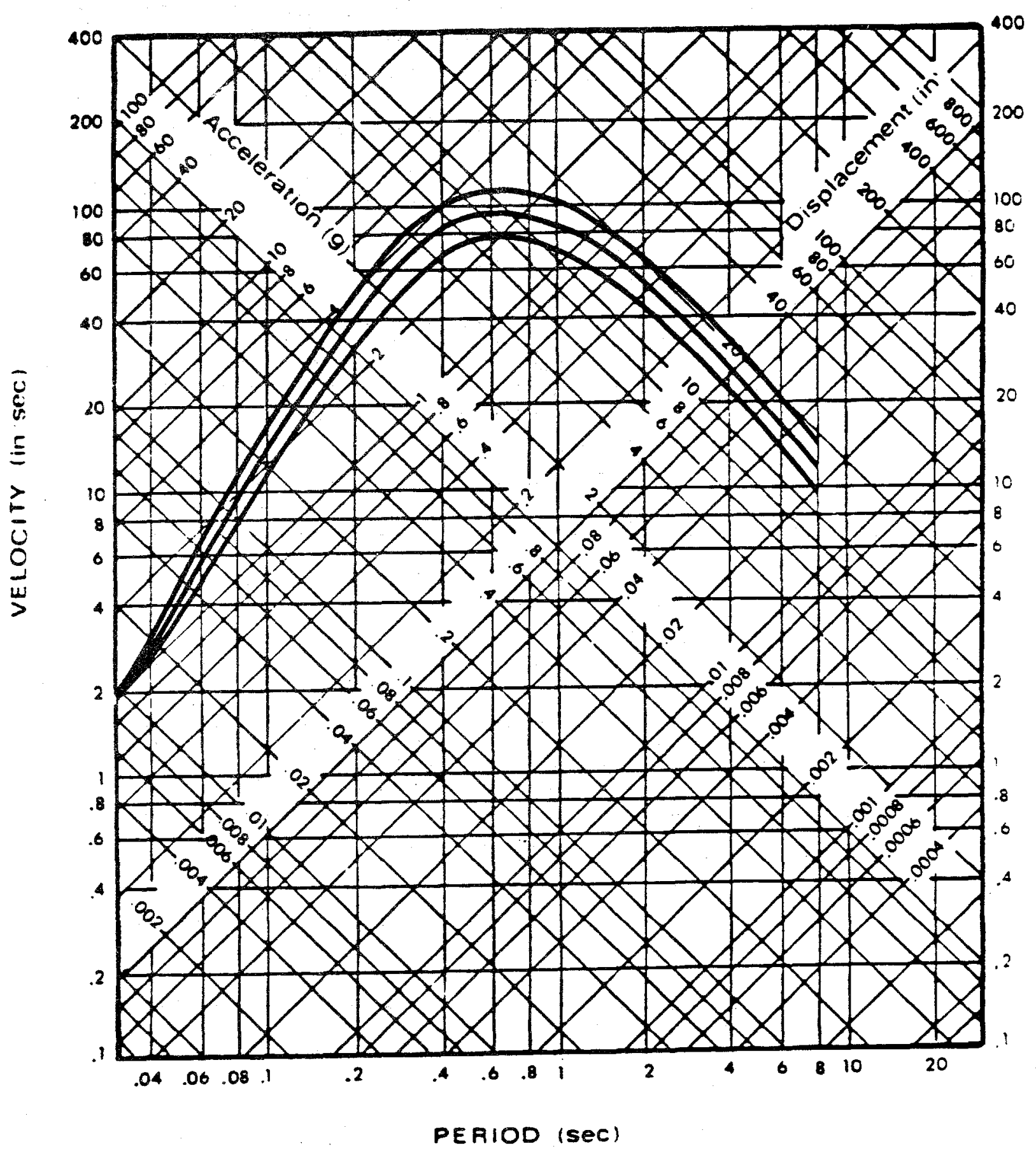

Design Response Spectrum Scaled to $1.0 \mathrm{~g}$

( $2 \%, 5 \%$, and $10 \%$ of Critical Damping)

Lawrence Livermore National Laboratory--Site 300, Entire Site, California 


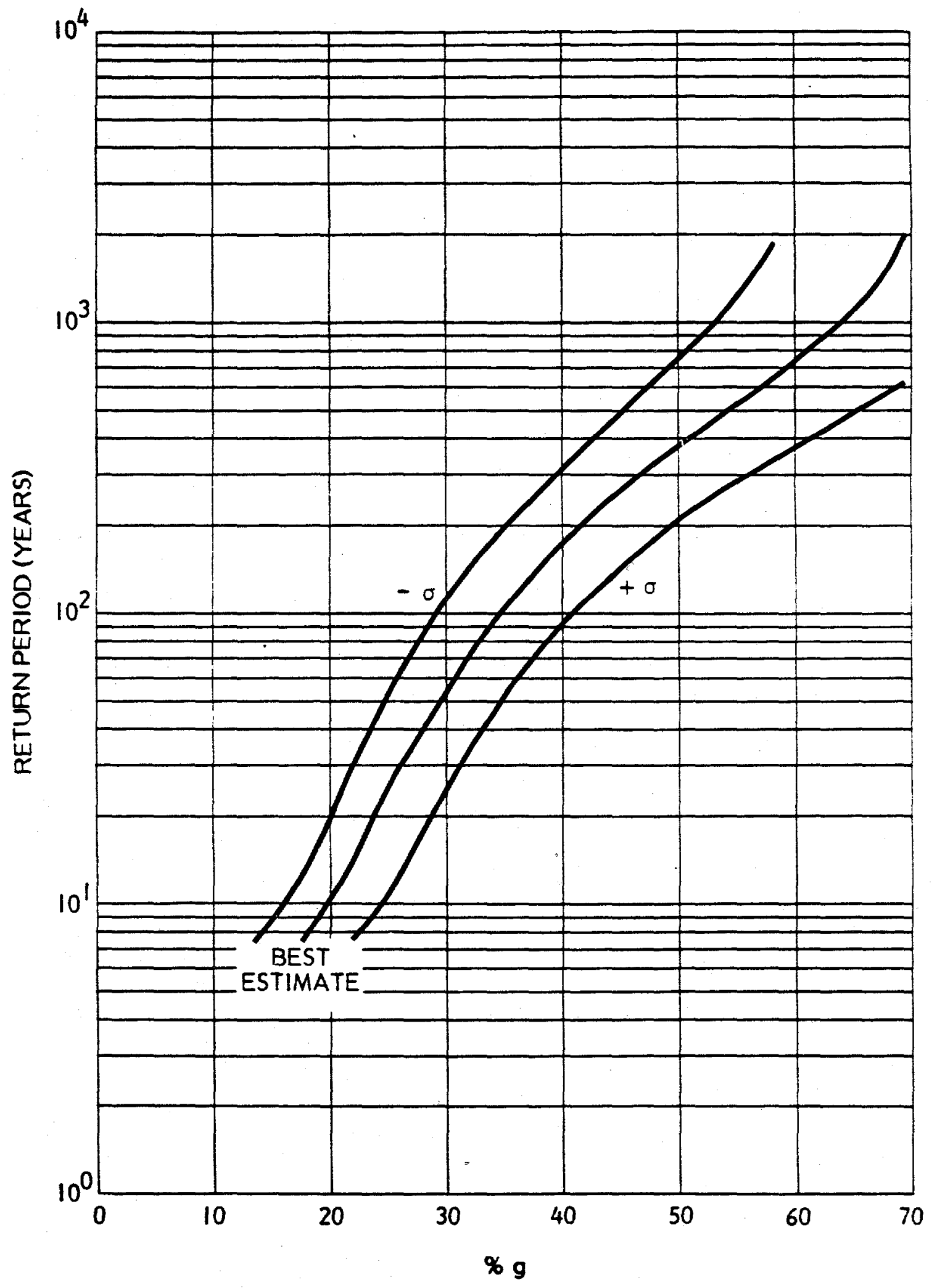

Earthquake Hazard at the Energy Technology and Engineering Center, California 


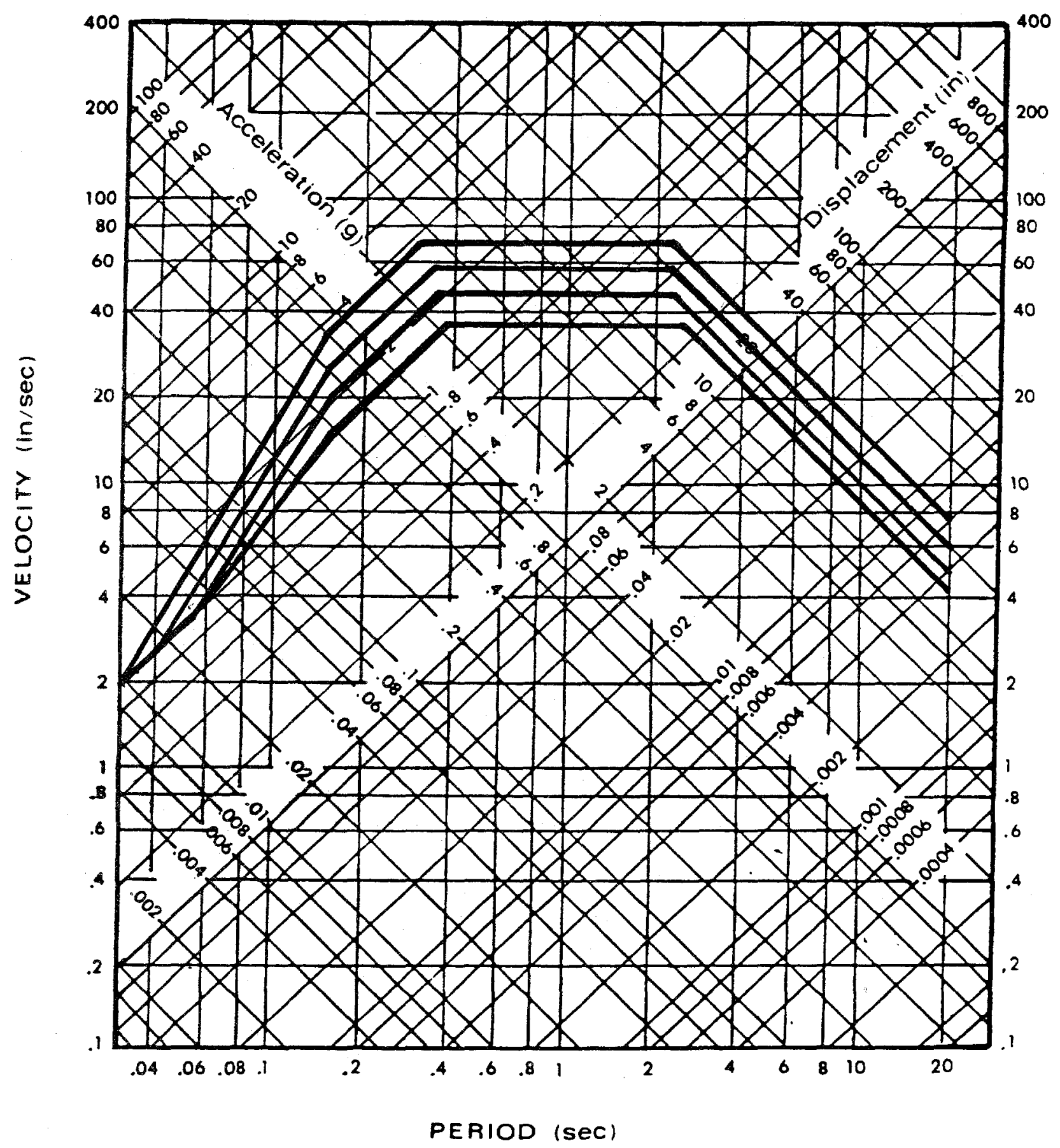

Design Response Spectrum Scaled to $1.0 \mathrm{~g}$

$(0.5 \%, 2 \%, 5 \%$, and $10 \%$ of Critical Damping)

Energy Technology and Engineering Center, California 


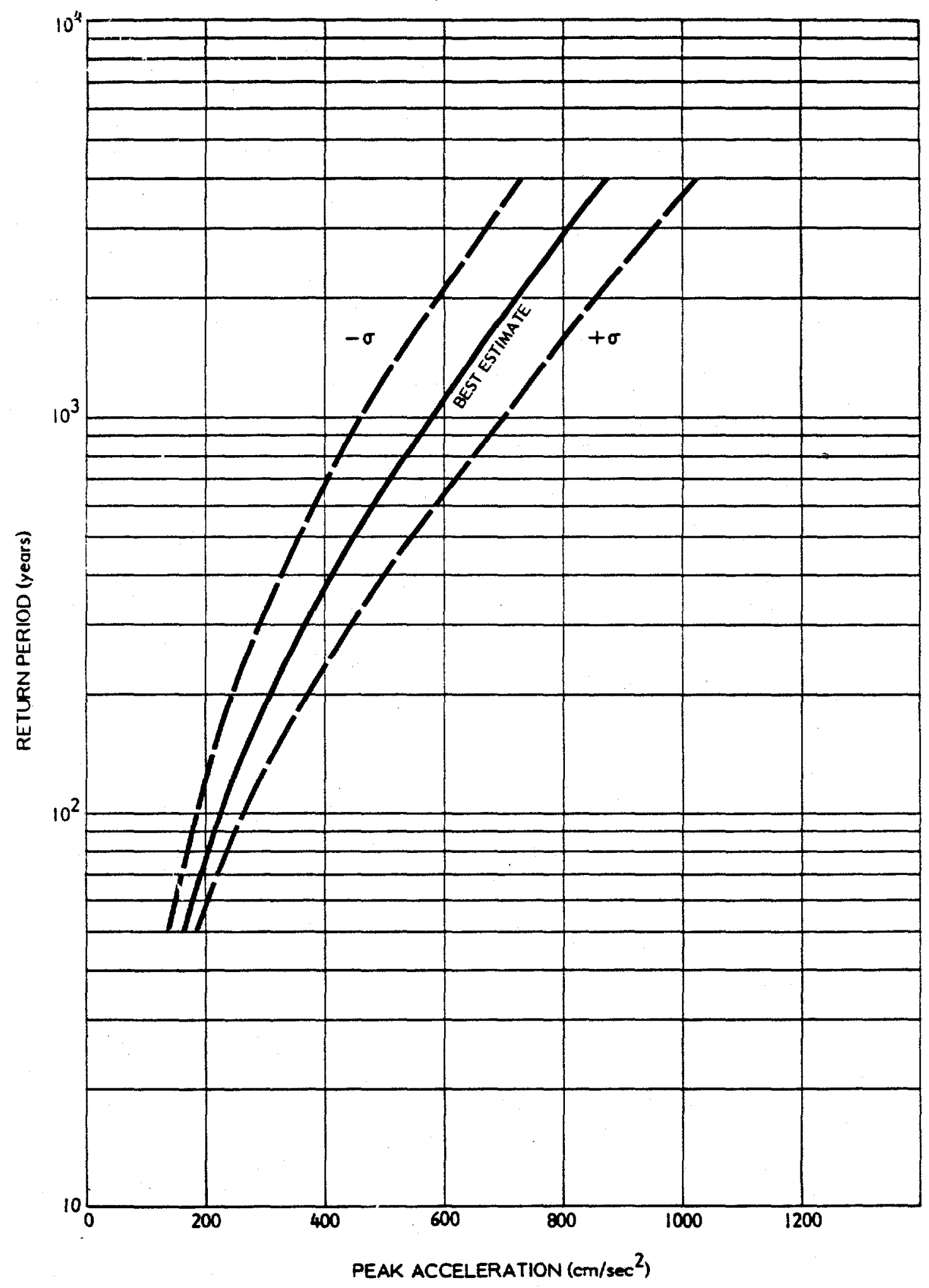

Earthquake Hazard at the Stanford Linear Accelerator Center, California 


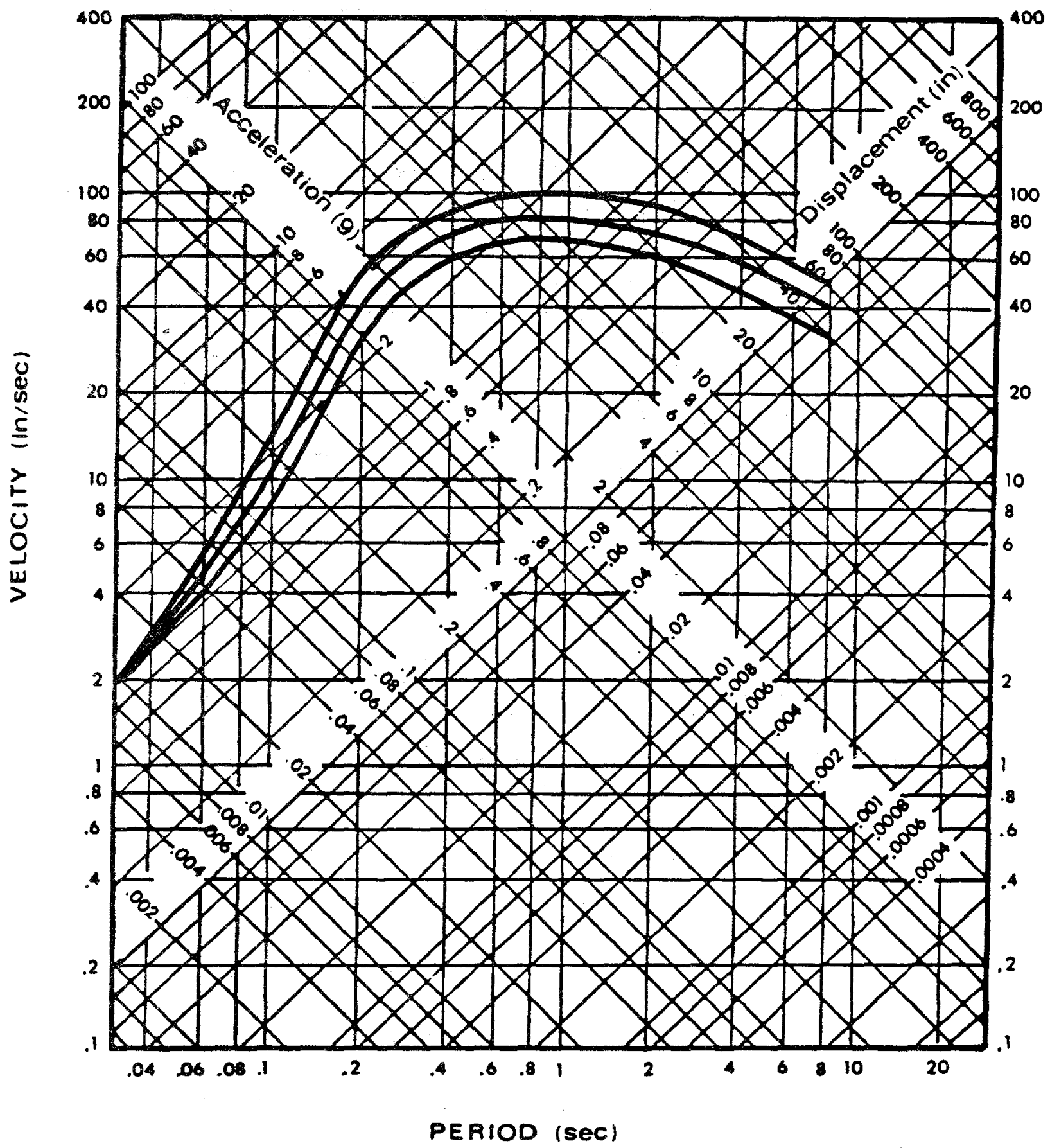

Design Response Spectrum Scaled to $1.0 \mathrm{~g}$

( $2 \%, 5 \%$, and $10 \%$ of Critical Damping)

Stanford Linear Accelerator Center, California 
Savannah River Field office

Earthquake Hazard Curve and Response Spectrum 


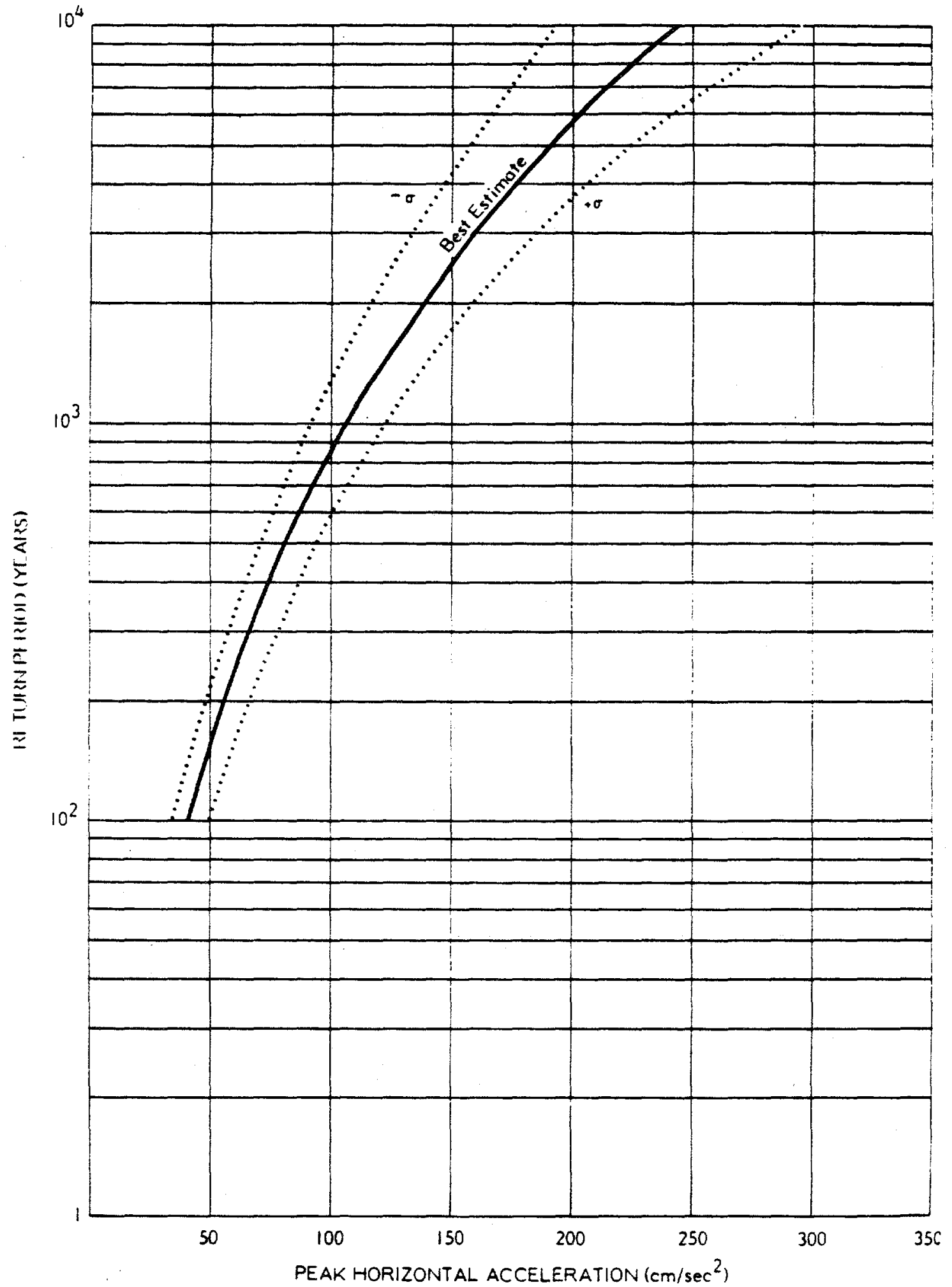

Earthquake Hazard at the Savannah River Plant, South Carolina 


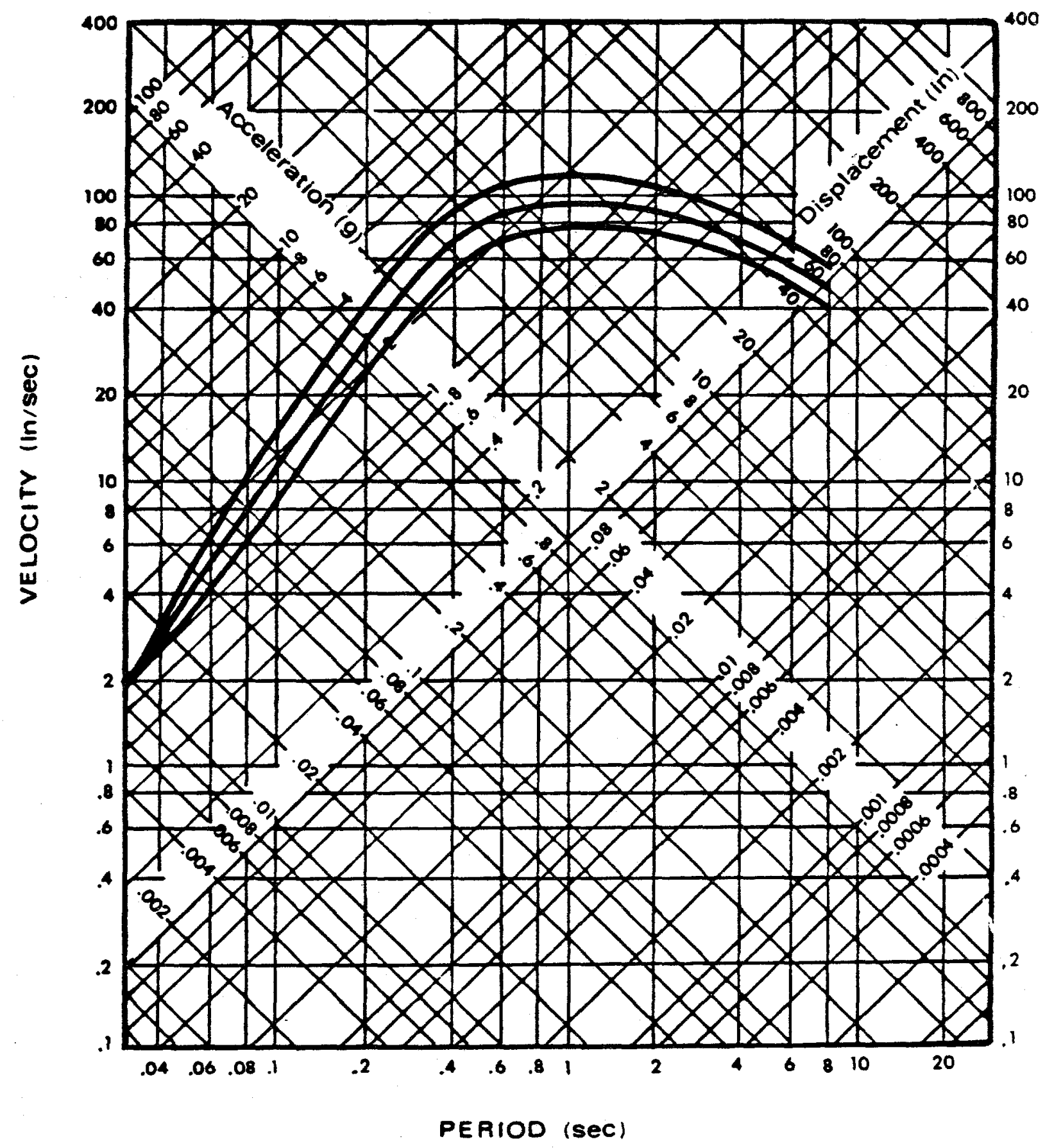

Design Response Spectrum Scaled to $1.0 \mathrm{~g}$

( $2 \%, 5 \%$, and $10 \%$ of Critical Damping)

Savannah River Plant, South Carolina 